\title{
EDIBLE MUSHROOMS OF TANZANIA
}

Härkönen, M., Saarimäki, T. \& Mwasumbi, L.

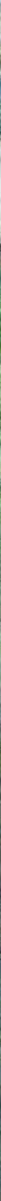

KARSTENIA Vol. 35 suppl. 1995

Ed. S. Stenroos

Helsinki 1995 


\section{KARSTENIA}

\section{Vol. 35 suppl. 1995}

\section{Edible Mushrooms of Tanzania}

Härkönen, M., Saarimäki, T. \& Mwasumbi, L.

Edited by Soili Stenroos

Helsinki 1995 


\section{Foreword}

This book was born of a love for mushrooms and a love for Tanzanians. Marja Härkönen has worked with edible mushrooms and organizing general mushroom advising and training of mushroom advisors in Finland for more than twenty years. Tiina Saarimäki is a trained mushroom adviser. Both have their main work in the Department of Ecology and Systematics in the University of Helsinki. Leonard Mwasumbi knows the people and nature of Tanzania being a Tanzanian himself and from experience as a forestry graduate and later as the keeper of the scientific herbarium of the University of Dar es Salaam.

When the first two authors visited Tanzania for the first time in 1988, they very soon discovered that there are two common things between Tanzania in tropical Africa and Finland in the northern boreal zone: the large woodlands and rich mushroom yields. In both countries people are avid collectors of mushrooms for home consumption. However, when it comes to mushroom guidebooks, the situation in the two countries is very different. There are dozens of mushroom guides available for Finnish collectors, amateurs and professional mycologists, and even specialized books for cookery and for dyeing with mushrooms. The Tanzanians have not even one mushroom guide about the mushrooms growing in their country, and nobody has ever recorded the varied mushroom heritage of the Tanzanian villages.

Although the primeval mushroom heritage is still alive in rural areas of Tanzania, the gradual urbanization is resulting in the loss of some vernacular knowledge. When people move to new areas, they find a different selection of mushrooms that they might misidentify. This unfortunate situation has led even to mushroom poisonings. It is no wonder that many people do not dare to pick mushrooms when they move to a new district.

Obviously, modern Tanzanians need a mushroom guide, and with our experience we are willing to write one. This book will combine the inherited knowledge from Tanzanian villages and the results of modern science, because all popular beliefs about mushrooms are not correct, some even being dangerous. Before we were able to write a mushroom book for Tanzanians, we had to travel around the vast countryside researching what kind of mushrooms are growing there and which species are used for food.

After making four trips of altogether about $20000 \mathrm{~km}$, collecting thousands of mushroom specimens and talking with hundreds of people, we realized that it would take, and probably will, the rest of our lives to discover all the mushroom knowledge in Tanzanian villages. However, we have obtained information enough to prepare a guide at a very practical level.

This guide is directed in the first place to students in vocational schools and colleges of forestry, agriculture and home economics, but we hope it will help anyone interested in mushroom collecting.

At first we deal with the ethnomycological information we collected in Tanzania. After that we give a general introduction of fungi and advise on, how to identify, handle and preserve mushrooms. The main effort is directed to a thorough description of the essential edible and poisonous mushrooms of Tanzania. We introduce the thirty-one commonest and tasting edible mushroom species. The number of species is limited to make it possible to describe them with colour photographs taken in their natural habitat. The species are described so thoroughly that persons who have lost their connections to old traditions can learn to identify these mushrooms reliably. The Latin name of each species is given for unambiguous recognition. From the many vernacular names one is chosen to be adapted as a common Tanzanian name. For mushroom genera and for the introduced species we have created a Swahili name. Each part of the work can be read as an independent unity. At the end of the book there is a list of terminology used in different parts of the work. There is also a condensed list of further reading. 


\section{Contents}

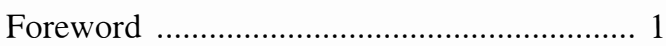

Acknowledgements ..................................... 3

Material and methods .................................... 4

Interviewing ..................................................... 4

Handling of specimens …............................ 6

Results ............................................................. 7

Appearance of mushrooms ......................... 7

Commoness of mushroom use ................. 8

Mushroom heritage .................................... 9

Collecting habits ....................................... 9

Edible species ........................................... 10

Vernacular names ................................... 11

Mushrooms as food ................................ 14

Preserving ............................................... 15

Mushroom trade .......................................... 16

Uses other than for food .......................... 16

Mushroom poisonings ............................. 18

Beliefs ................................................ 20

The Fungi. ................................................... 21

What are the fungi .................................. 21

Where do we meet fungi ........................ 22

The fungal cells ....................................... 22

The classification of the Fungi ................... 23

Lower fungi ........................................... 23

Ascomycetes .......................................... 23

Basidiomycetes ....................................... 23

Deuteromycetes, or Fungi Imperfecti ..... 26

Nourishment of fungi .............................. 26

Saprophytes ............................................ 26

Parasites ................................................... 26

Symbiosis ................................................. 27

Fungi in forest ecology ............................. 28

Edible mushrooms ….................................. 29

Chemical composition of mushrooms ..... 29

Nutrient content of Tanzanian mush-

rooms ................................................. 31

Careful picking ..................................... 31

Careful preserving ................................... 31

Poisonous mushrooms ................................ 33

Frequency of mushroom poisonings ...... 33

Characteristics of poisonous mushrooms 33

Fungal poisons ……................................. 33

Cell damaging poisonings ...................... 34

Psychotropic poisonings ......................... 34

Hemolytic poisonings …........................... 35

Poisonings causing gastro-intestinal symp-

toms
The macroscopic identification of mush-

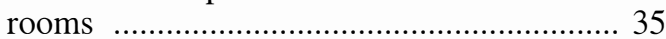

Cap (pileus) ….......................................... 35

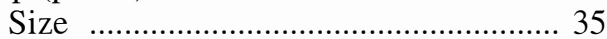

Shape .............................................. 36

Colour .................................................... 36

Surface ............................................... 36

Margin …….......................................... 36

Gills and pores ….................................... 36

Spacing of gills ……............................. 36

Attachment ........................................... 38

Margin of gills ..................................... 38

Colour of gills …................................. 38

Stipe …............................................. 39

Size and shape of the stipe .................. 39

Veils .................................................... 39

Context (flesh, trama) ............................. 39

Latex ................................................. 39

Growth habit ............................................ 39

Sporeprint ................................................ 40

The microscopic identifation ...................... 41

Spores …............................................ 41

Basidia .................................................... 41

Cystidia .................................................... 41

Other features …….................................... 41

Descriptions of the species ........................ 45

Termitomyces, UYOGA-MCHWA ....... 46

Termitomyces aurantiacus, MGUNDA 46

Termitomyces eurrhizus, KIMELO ..... 47

Termitomyces letestui, MKUFU ........... 48

Termitomyces microcarpus, BUSO-

LELE .............................................. 50

Termitomyces singidensis, IMPORA .. 52

Amanita, UYOGA WA INZI ................ 52

Amanita tanzanica, WIGWINGWI ..... 54

Amanita masasiensis, WIGWINGWI ..54

Amanita mafingensis WIGWINGWI ...54

Amanita zambiana, ULELEMA .......... 57

Amanita muscaria, UYOGA MAINZI-

MWEKUNDU ................................... 57

Amanita phalloides, UYOGA MAINZI-

MAUTI

Macrolepiota.

Macrolepiota dolichaula, UNYA-

SENGA

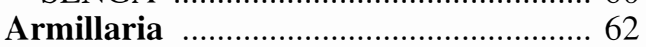

Armillaria mellea s. lat., MANJU- 
LUGO 62

Coprinus Coprinus cinereus, UYOGA TAKAMKONGE 63

Russula, USULULA .............................. 65

Russula cellulata, UHINDA ………..... 65

Russula ciliata, NCHENGA ................ 66

Russula compressa, NITUNDU .......... 68

Russula congoana, NITUNDU ............ 68

Russula hiemisilvae, NITUNDU .......... 70

Lactarius, UYOGA-MAZIWA ............... 70

Lactarius sp. aff. phlebophyllus,

KIKOBA ….......................................... 71

Lactarius kabansus, UMPALALA ...... 72

Lactarius sp. aff. pseudovolemus, MPOFU 73

Lactarius edulis, WISIMBA ................ 74

Cantharellus, WISOGOLO ................... 75

Cantharellus congolensis, WISOGOLO-

MWEUSI 76

Cantharellus isabellinus, WISOGOLO-

MANJANO 77
Cantharellus platyphyllus, WISOGOLO-

MPANA …......................................... 78

Cantharellus symoensii, WISOGOLO WA

RANGI MBILI ……........................... 79

Polyporus .............................................. 80

Polyporus moluccensis, NGAHA ........ 80

Pleurotus ........................................... 81

Pleurotus djamor, MAMAMA ............ 81

Boletes ................................................... 82

Suillus granulatus, USUILISI ............. 83

Auricularia, MASIKIO YA MTI ........... 83

Auricularia delicata, MANGHWEDE 84

Auricularia polytricha, MANGH-

WEDE ............................................... 85

Auricularia fuscosuccinea, MANGH-

WEDE …............................................ 86

Chlorophyllum ....................................... 86

Chlorophyllum molybdites, VIKAO

RANGI-HAFIFU ............................... 86

Glossary ……........................................ 88

Further reading ......................................... 90

\section{Acknowledgements}

Several persons have encouraged and helped us in the course of the work. Prof. Tuomo Niemelä and Mr. Kalevi Härkönen, technician, took part in some of the field trips. Ambassador Kari Karanko, the Finnish Ambassador to Tanzania gave us support and good advice. During the heavy field work we got accomodation and assistance from almost every missionary family of the Finnish Evangelical Lutheran Church in Tanzania. We are also indebted to many Tanzanians, especially Mr. M. Mrecha from the Mazumbai Forest station, for cooperation and quidance in Tanzanian villages. In identification we received help from several experts on certain mushroom groups, for instance Dr. Cornelius Bas, Prof. Bart Buyck, Dr. P. Heinemann, M. Sc., Ms. Tarja
Renvall, M. Sc., Ms. Annemieke Verbeken and Dr. Roy Watling. Researchers in the Department of Asian and African Studies, University of Helsinki and the Institute of Swahili Research, University of Dar es Salaam revised the orthography of the vernacular names and formulated Swahili names from vernacular and Latin ones. Ms. Päivi Karhula is thanked for technical assistance. Prof. Teuvo Ahti and Lic. Phil. Irma Järvinen, a mushroom inspector, are thanked for the critical reading of the manuscript. Ms. Margot Stoutwhiting revised the English of the manuscript. The research was financed by the Finnish International Development Agency of the Ministry for Foreign Affairs (FINNIDA), the Finnish Academy and University of Helsinki. 


\section{Material and methods}

A research project on Tanzanian mushrooms and their uses was carried out in Tanzania in collaboration with the Universities of Helsinki and Dar es Salaam in 1990-1994.

During the project, four collecting trips were made to Tanzania, all during the rainy seasons. The itinerary can be seen in the map underneath. All the promising woodlands along the road were surveyed and sampled. In the villages we contacted the local people, went with them in the field to collect mushrooms, and afterwards watched how mushrooms were prepared for food at their respective homes. When travelling, attention was paid to mushrooms sold along roadsides, markets were visited and mushrooms were purchased for specimens.

After every mushroom foray we went to a nearby village to ask names for the mushrooms collected. Because all the species were not available at a time, we prepared a photo collection with colour pictures of mushroom species collected earlier in Tanzania. It was supplemented during the research and at last included photographs of forty-two species considered important somewhere in Tanzania. We carried this photo collection with us on field expeditions and showed it to people to obtain more vernacular names and people's opinions about the species.

\section{Interviewing}

When interviewing local people, we always asked the same set of questions. This ensures that information collected among different tribes is comparable. Interviews were carried out in Swahili or English, or occasionally even in local languages. Answers were written down and taperecorded. The following items were asked:

Personal details: Name, address, sex, age, tribe, vernacular language, occupation, length of time the family has lived in the area.

Specific questions: Do you eat mushrooms? Do you collect mushrooms yourself or who in your family collets them? Who taught you how to collect them? How many different kinds of mushrooms do you collect for food? Please, list the names of the mushrooms now on hand or tell us what species you can recognize. Which species tastes the best? Is everyone here allowed to collect mushrooms everywhere? When and how often are the mushrooms collected? How do people prepare mushrooms for food? Who in your family prepares mushrooms for food? How highly do you value mushrooms as food if compared to other foodstuffs such as meat, fish or vegetables? Do you preserve mushrooms? How? Which species? Are mushrooms sold in the market places in this region? Do you use mushrooms for other purposes than for food, for instance as medicine? Is there a traditional healer in your village who uses mushrooms? How? Are there poisonous mushrooms in this region? Have misidentifications occurred, leading to mushroom poisonings? How do you recognize a poisonous mushroom? Do you know any beliefs, stories or fairytales about mushrooms?

We ourselves also collected such mushrooms that are widely known and used for food elsewhere in the world, for instance Agaricus species and boletes. We showed them to experienced pickers, asking if they recognize them. So we found out if there were big differences in the selection of mushrooms accepted for food in Tanzania and elsewhere.

We collected information from people of the following thirty-five tribes: Arusha, Bena, Bondei, Chagga, Gogo, Haya, Hehe, kizu, Kaguru, Kinga, Kwere, Luguru, Makonde, Makua, Maasai, Meru, Mwera, Ndendeuli, Ngindo, Ngoni, Ngulu, Nyakyusa, Nyamwezi, Nyiha, Pangwa, Pare, Safwa, Sambaa, Sangu, Sukuma, Sumbwa, Turu, Yao, Zaramo, Zinza. Full interviews were made with a hundred people, all of whom showed interest in mushrooms. The album with mushroom photos was shown to eighty-seven people. 


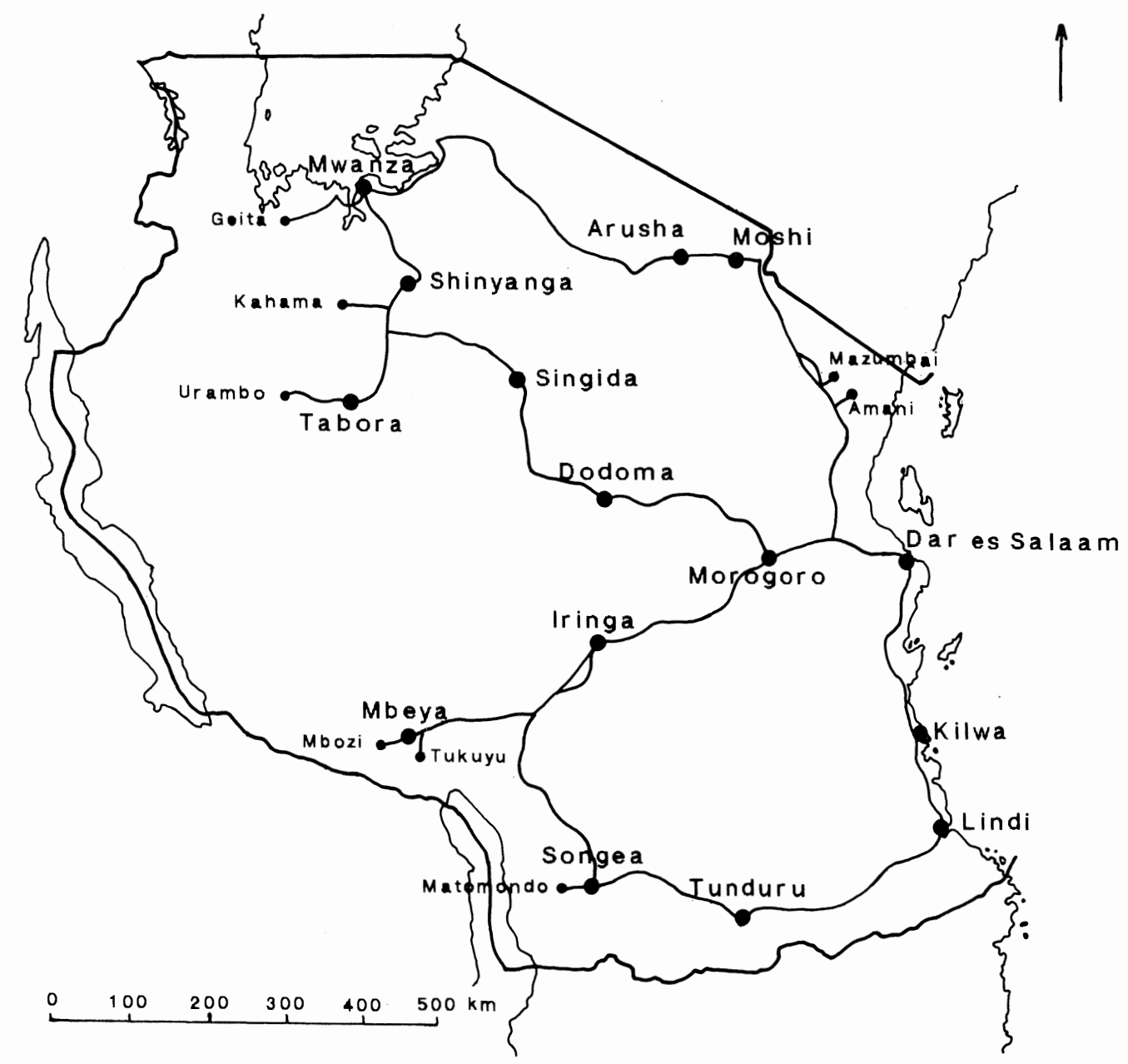

Fig. 1. A map of Tanzania showing the itinerary of the four collecting trips.

In the villages people at first were astonished by our interest in mushrooms. They might even gather together and have a good laugh at us. They had believed that white people never eat wild mushrooms, and, indeed, the many missionaries we met in Tanzania had never received any dish of mushrooms from the people of their parish, although they often visit them and are invited to have a meal at their homes. Maybe this results from the fact that Tanzania was earlier a British colony and British people prefer cultivated champignons. After some conversation, most of the village people were very friendly and willing to help us and were quite proud of their knowledge. In many places the village secretary or teacher organized children to pick mushrooms for us. Our best advisers, however, were the housewives or such men who pick mushrooms commercially to be sold at market places. The full interviews were made with ordinary peas- 


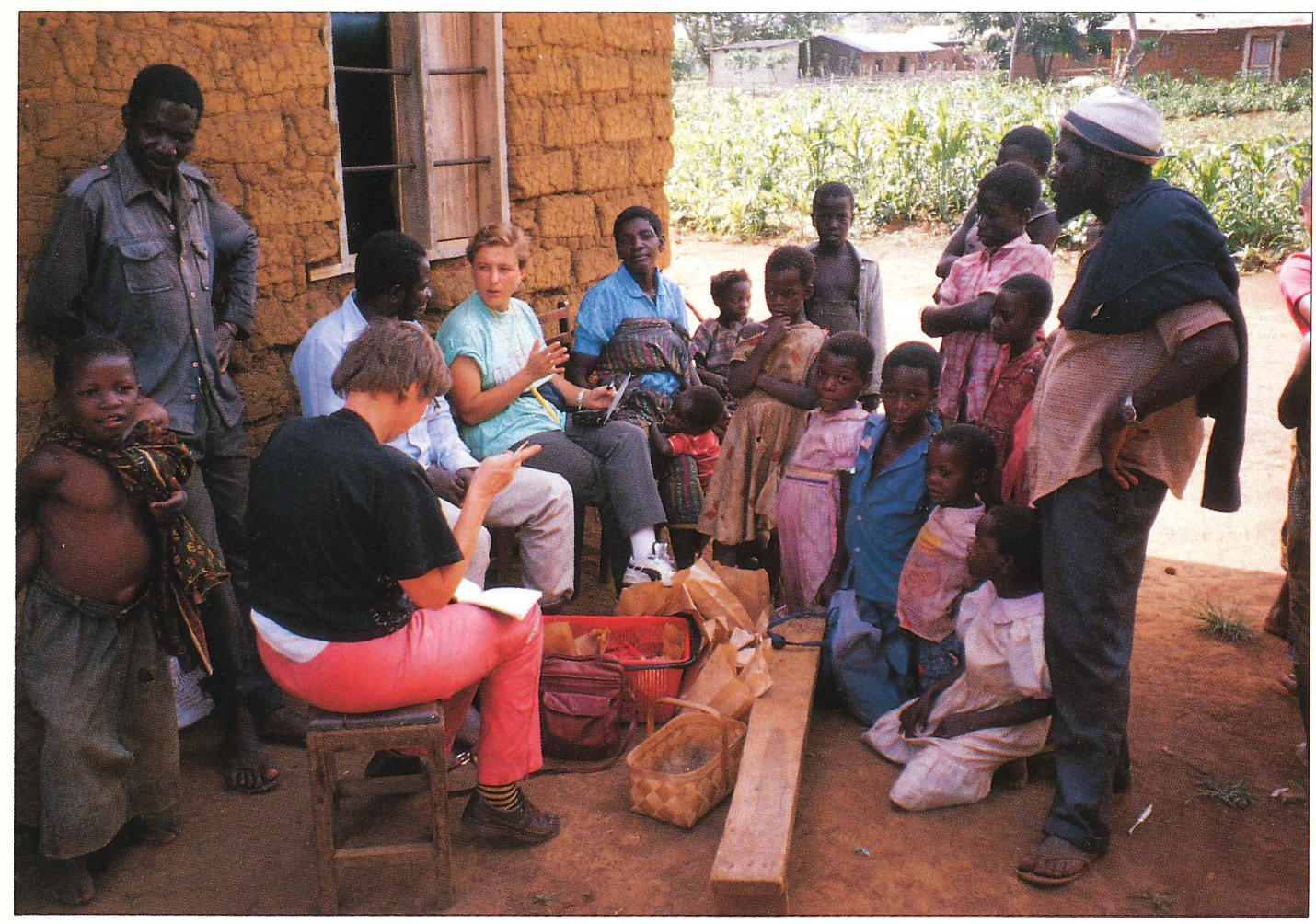

Fig. 2. In Geita, Mwanza district Mama Luziga gives Nyamwezi names for mushrooms we have collected from the nearby miombo.

ants, who had spent all their lives in the same region. Only they knew where the mushrooms grow and how to use them. The educated people had forgotten almost everything that they had learned about mushrooms in their home villages. However, for most of them, mushroom hunting was a happy memory from childhood.

\section{Handling of specimens}

Every evening the fresh characteristics of the fungi collected were recorded. Specimens were tasted when raw, and whenever possible, also cooked. Representative fruit bodies were photographed. All specimens were dried with a field dryer heated with kerosene lamps. The speci- mens were identified at the University of Helsinki, Finland. Representative specimens of species widely used or species suspected to be poisonous were chemically analyzed in the Technical Research Center in Espoo, Finland. 


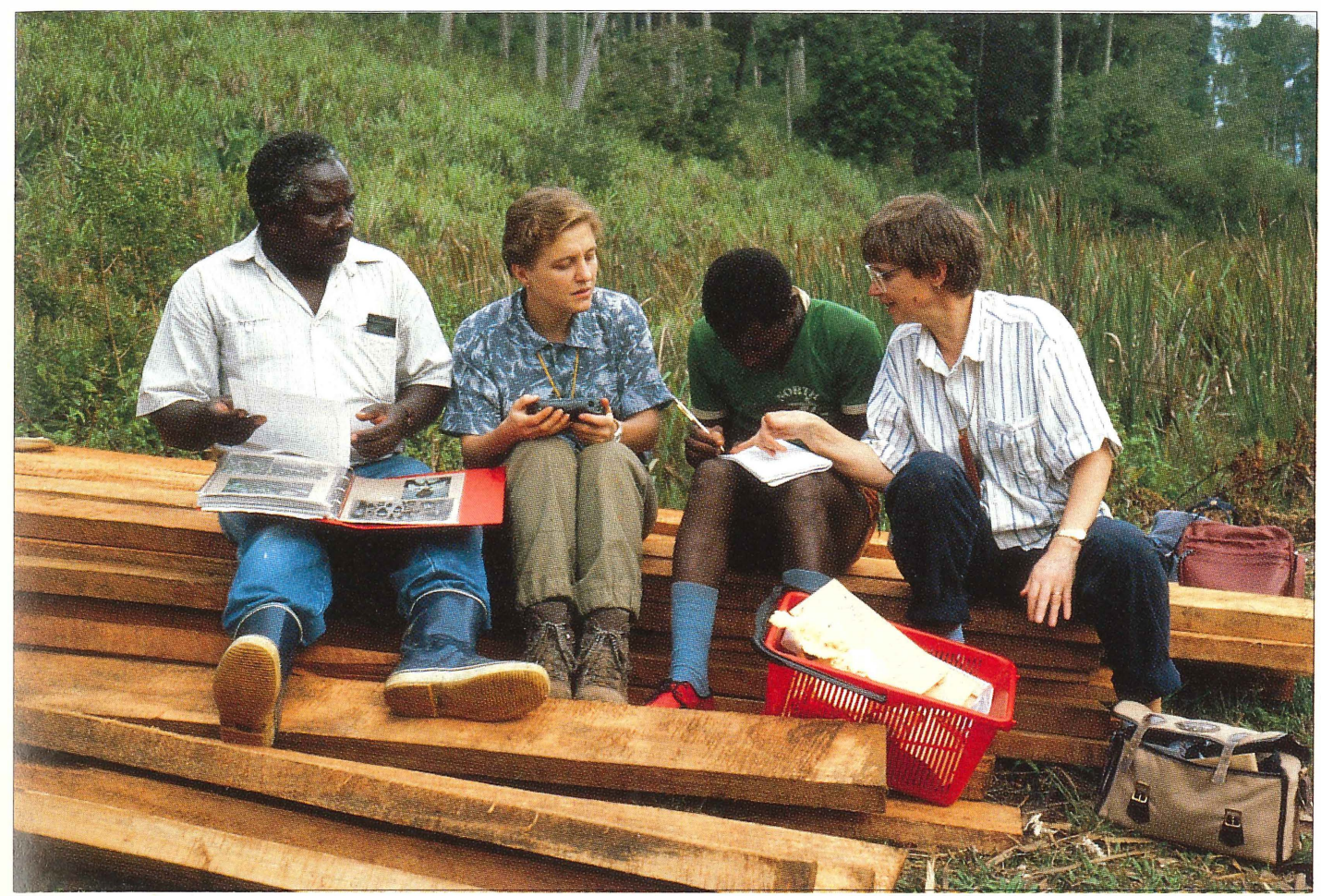

Fig. 3. An interview near Amani in the East Usambara Mountains. Superintendent Leonard Mwasumbi has the photo album of Tanzanian mushrooms in his lap. Researcher Tiina Saarimäki taperecords the interview. The interviewee, Julius Uzieli, writes vernacular names in the Sambaa language. Docent Marja Härkönen on the right.

\section{Results}

\section{Appearance of mushrooms}

Because of the variable topography and climate of Tanzania there is a wide variation in the vegetation from rain forests to semideserts and mountain vegetation. The biggest area of the country, in the western and southern parts, is covered by wooded savanna, miombo woodland.

In the lowland rain forests and forested mountains many types of wood decaying fungi exist. Many of them e.g. some species of Auricularia, Armillaria, Pleurotus and even Schizophyllum and some polypores are harvested for food. These fungi are rarer in miombo woodland and usually rejected.

Specimens of Termitomyces, growing from the decaying matter that termites have brought into their nests, can be found all over the country during the early rains, and are highly appreciated everywhere.

The best mushroom yields occur in miombo woodlands, where most of the miombo trees, e.g. Brachystegia, Combretum, Julbernardia, and Uapaca have mycorrhizal fungi in their root systems. At the beginning of the rainy season a rich variety of fungal fruit bodies appear. The species are mostly indigenous but often belong to widely distributed genera, such as Cantharellus, Amanita, Russula, Lactarius and Boletus s.l. All these, except the boletes, are commonly used for food.

Shifting cultivation is a common practise in miombo woodland. Hardly any untouched miombo can be found. They have been used for 


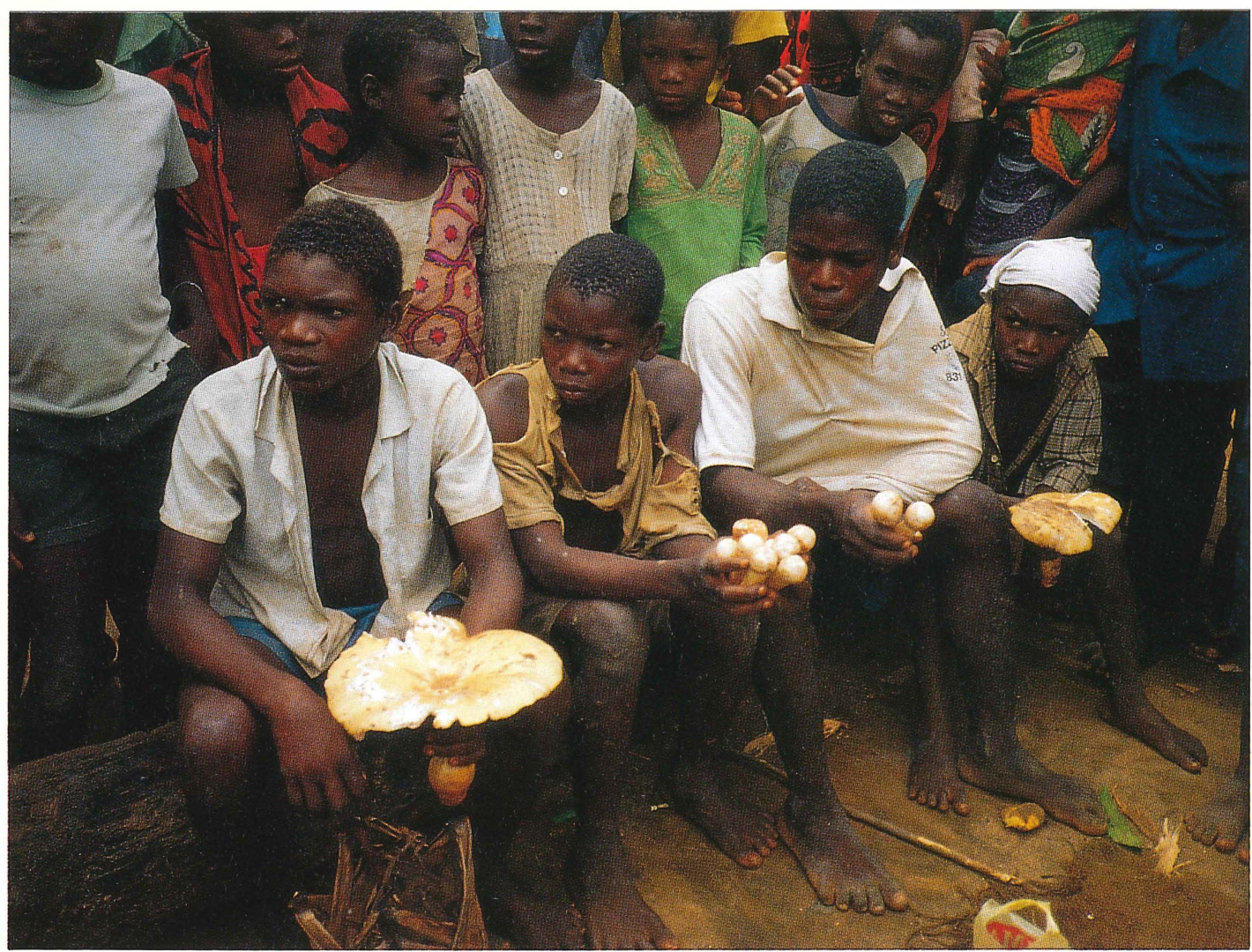

Fig. 4. Young boys have collected mushrooms for our research group in Lindi district in Mbanja village.

agricultural purposes from time immemorial. This trend continues today and trees are periodically cut and burned for agricultural purposes. After some years of cultivation, when the fields are abandoned, tree stumps recover and sprout, most probably with the aid of their fungal companions. Soon miserable looking stunted trees produce a rich yield of mushrooms.

Since colonial times the woodlands have also become an object of more irreversible management. Large areas have been taken over by plantations of exotic trees, for instance Pinus and Eucalyptus. These tree plantations are useless to local people. The indigenous mushrooms can not grow in symbiosis with the introduced trees. The plantations do not yield wild vegetables, fruit or herbs either, as miombo woodland does. The ground in these plantations is covered with a thick layer of litter and no grass or herbs are growing for cattle to graze on. Not only the yields of local mushrooms have been destroyed, but some exotic mycorrhizal fungi have unintentionally been introduced. More information about two such species, Amanita muscaria and Suillus granulatus, is given later (see page 83).

\section{Commonness of mushroom use}

Most people in Tanzania include mushrooms in their diet and collect them. There are, however, tribes such as the Chagga, Arusha, Meru and Maasai who do not eat mushrooms. In the rainy season most families eat mushrooms two or three times a week, but some people in the Bena, Hehe, Makua, Nyamwezi, Nyiha and Sambaa tribes told us that they have a mushroom meal every day. 


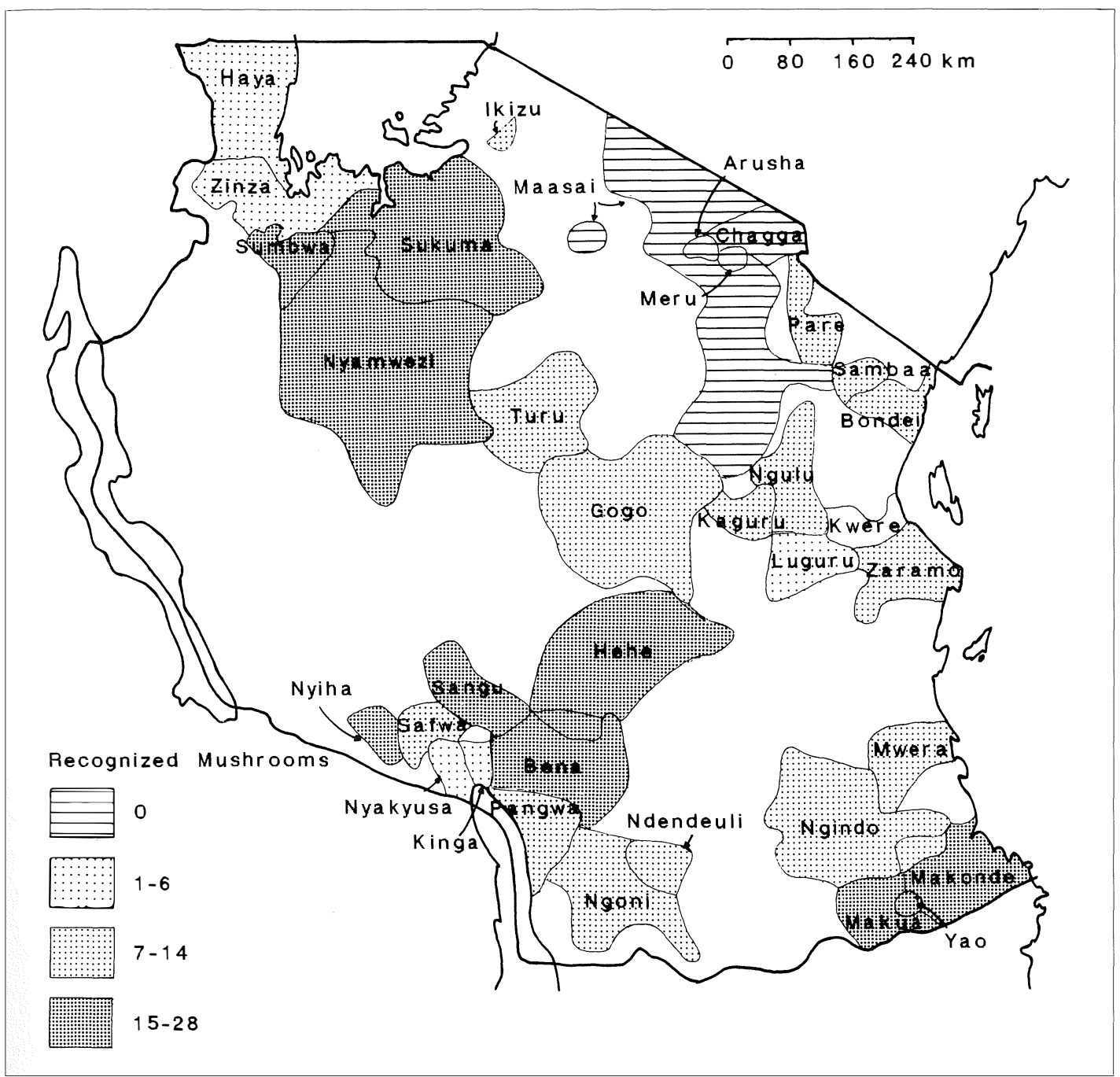

Fig. 5. A map showing the living areas of tribes visited during the four collecting trips. From the map you can also see how many mushroom species an expert from every tribe could list.

\section{Mushroom heritage}

Practically all the people we asked had learned their mushroom knowledge from their family, and the manners of mushroom use are similar within certain tribes. Mushrooms are not taught at school and there are no mushroom books. This means that we have been documenting oral traditions of different tribal groups.

\section{Collecting habits}

It seems to be a common rule that everyone is free to collect mushrooms anywhere. However, in some villages it is not acceptable to pick fungi from other people's fields. Some mushrooms, e.g. the species of Termitomyces, are so desirable that one has to go to look for them at dawn to be the first one to find the newborn fruit bodies. 
Fig. 6. Mama Upendo in Kidugala, Njombe district, has collected her basket full of Russula, USULULA.

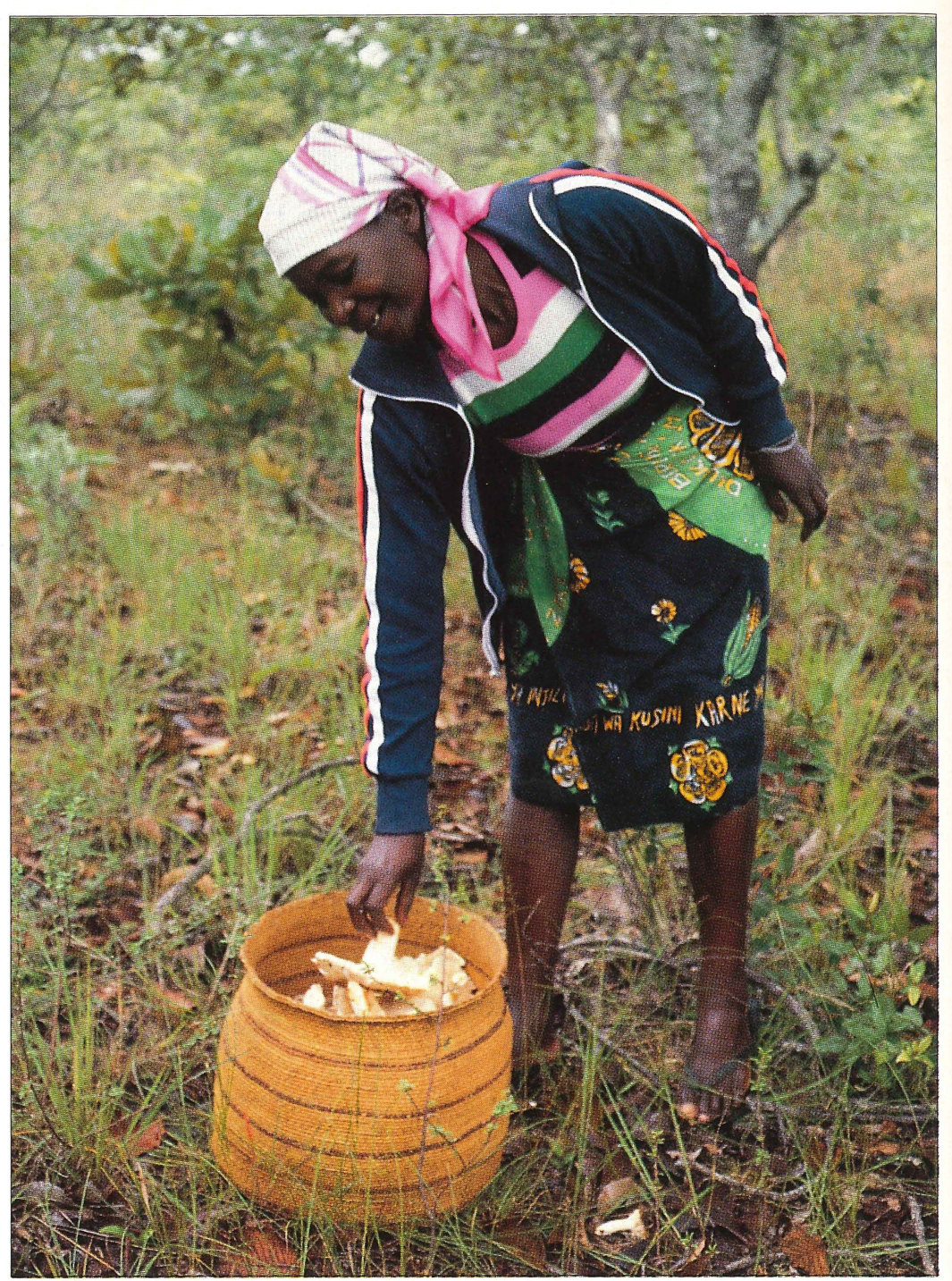

In most tribes all family members collect mushrooms. Men mostly pick them only when they see them by chance, but women and children go purposely mushroom hunting. That's why the best mushroom specialists in villages are usually women.

\section{Edible species}

Most people whom we have interviewed were able to recognize from three to seven mushroom species. The selection of mushrooms used for food is small in mountain areas and large in miombo woodlands on the high plateau (see Fig. 5). The largest diversity of edible mushrooms exists in the southern and western parts of the country. The longest lists of edible species (20-28 species) we got from the Bena, Hehe, Makonde, Nyamwezi, Sumbwa, Sukuma and Yao people. 


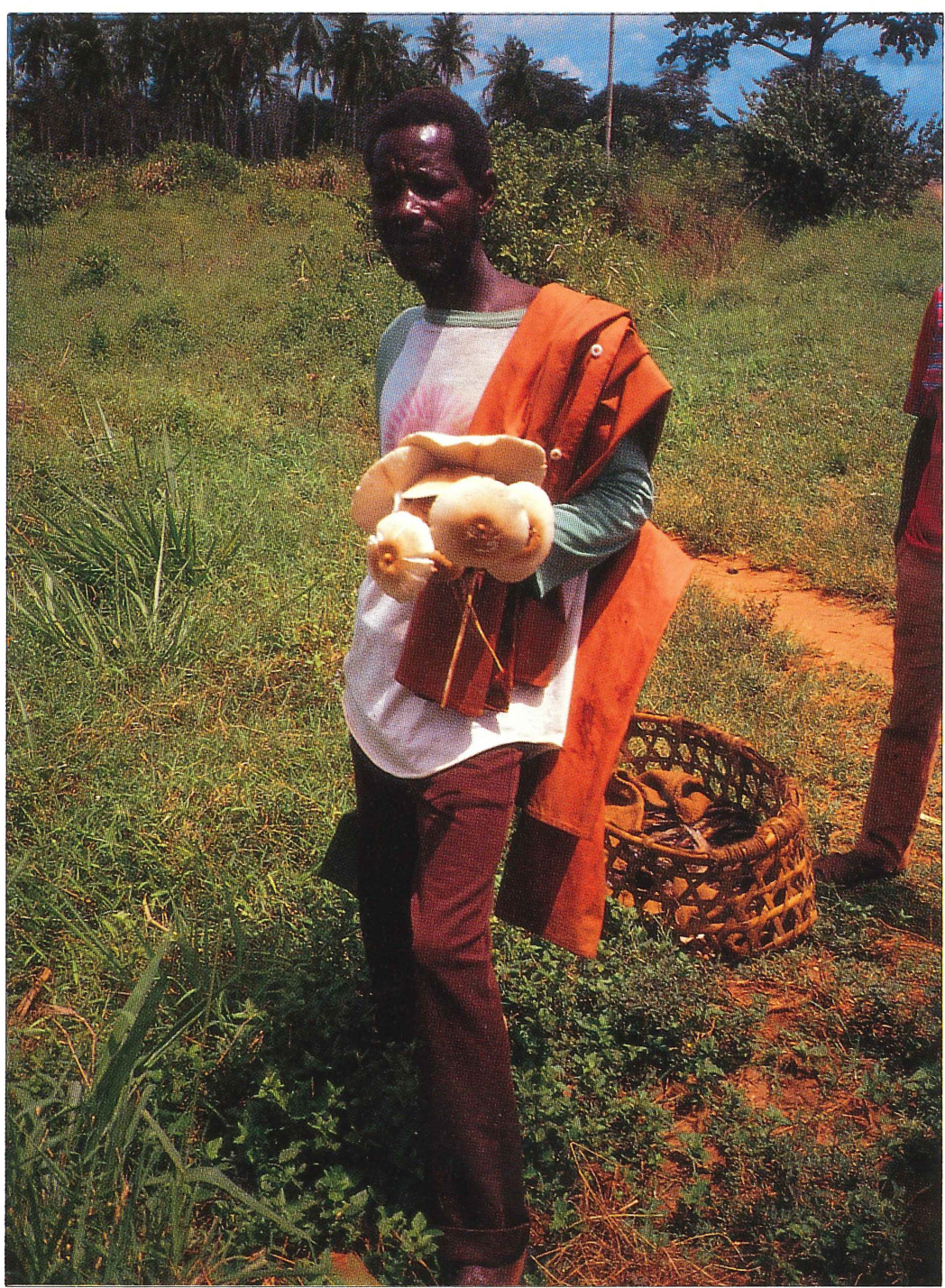

Fig. 7. A farmer on his way home in Mkumbi village near Tanga has found Termitomyces letestui, MKUFU.

iroom ed for rge in l (see mushparts e speBena, ikuma

\section{Vernacular names}

We have collected hundreds of vernacular names for mushrooms, but it is very difficult to put them in any logical order. The species concept is quite variable. As for the genus Cantharellus, Tanzanians seem to have a good systematic eye. Most tribes have a collective name for all chanterelles, including yellow, red or grey, and even two coloured species. On the other hand, some tribes give two names for a single species at different stages. For instance the popular Termitomyces eurrhizus is in the Kinga language called USUMBA when it is young and spindle-shaped but LUTUTELU when it is old and umbrellashaped.

Sometimes a special characteristic is a reason to unite different species. For instance in the Nyiha language the name UNANZYOGOLI referring to a millipede, is a common name for all Amanita species with a striate pileal margin, in 


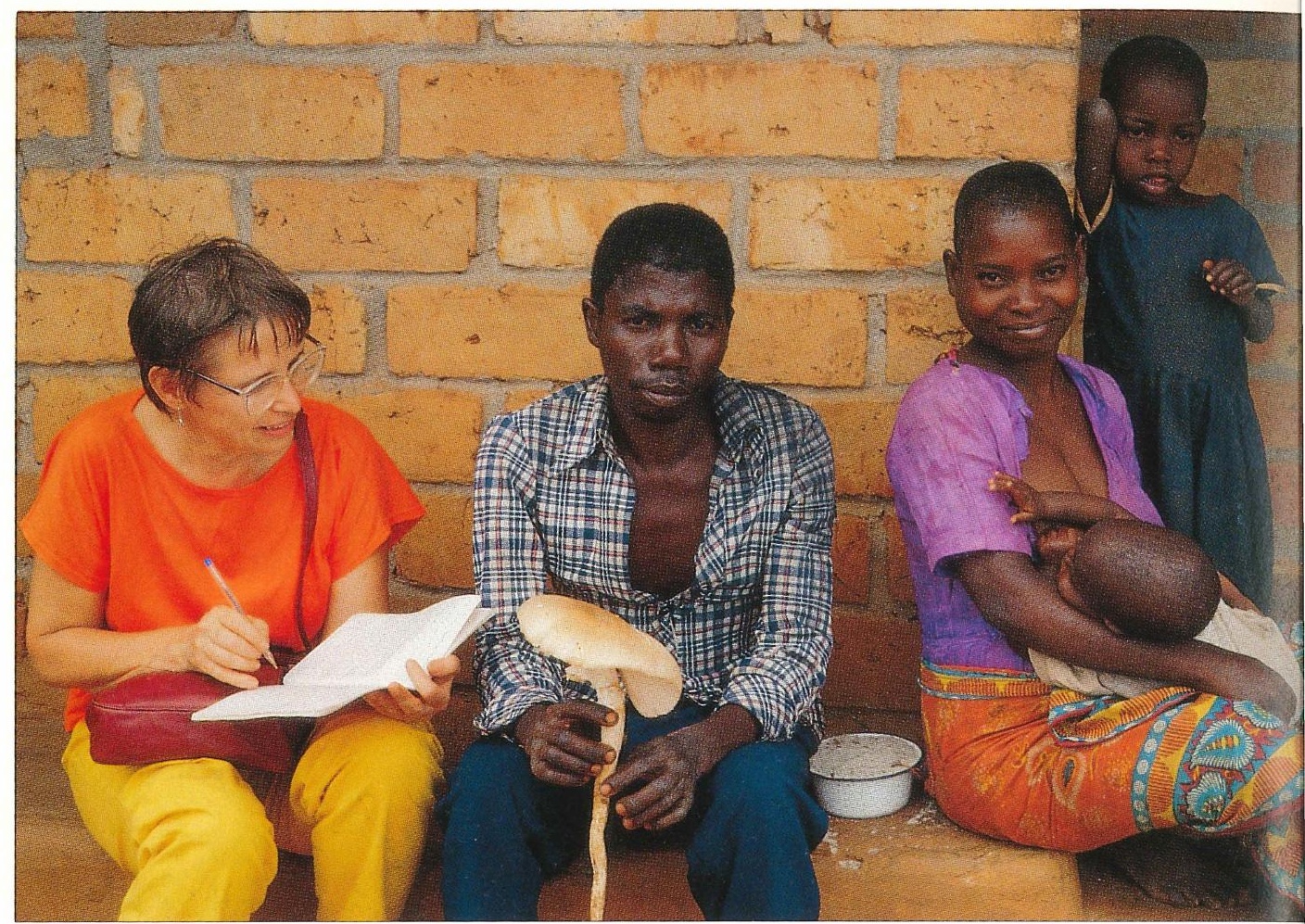

Fig. 8. Lukas Ngosongo from Mlilayoyo village near Songea can recognize nine edible and two poisonous mushrooms. He has Termitomyces letestui, MKUFU in Ngoni language, in his hand. In this book MKUFU has also been adopted as the Swahili name

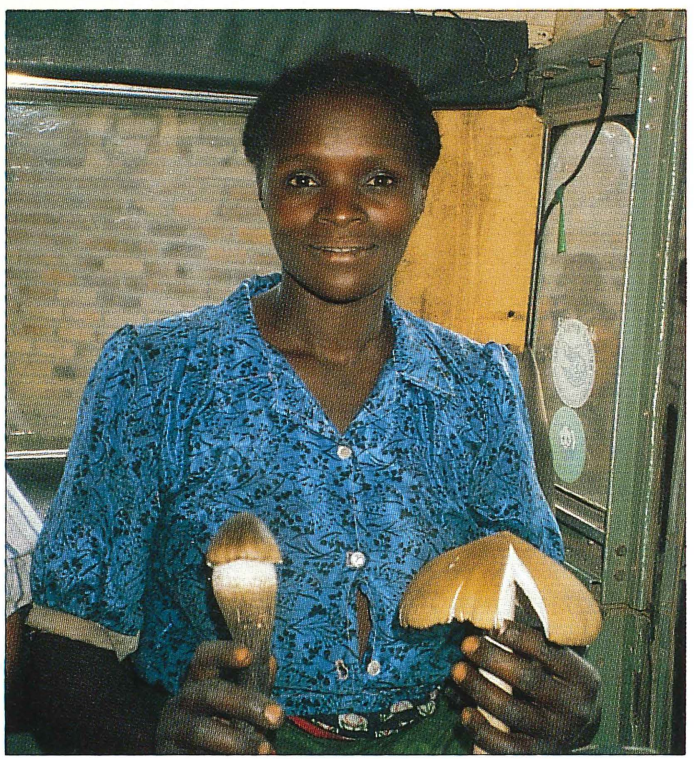

Fig. 9. Mushrooms may have different names during different stages. Mama Lusiana Sanga in Mufindi shows two specimens of the same Termitomyces species, the young one is called USUMBA and the old one LUTUTELU. spite of the fact that some have a ring and som do not, and some have white gills, others yellow

People of several tribes have noted the navel like umbo of some Termitomyces and given then a corresponding name like MKUFU (Ngoni lan guage), NYAMUKUNDI (Haya), LUNYASW LWA MATUMBO (Nyakyusa). Other name deriving from the appearance of mushrooms ar for instance: for Ramaria KILEZU CHAMW GUKU (Nyamwesi) and KADEVU (Gogo meaning old man's beard. Like in several Indo European languages, some Africans have name some Lactarius species according to their mil latex, e.g. UNYAMAZIWA in Bena languag means a mushroom that gives milk.

Many names refer just to the colour of mushroom and so have no value in distinguishin the same coloured mushrooms of unrelate genera.

In some cases mushrooms may be namer after their habitat, for instance a name o Lactarius sp. aff. pseudovolemus in Bena lan 


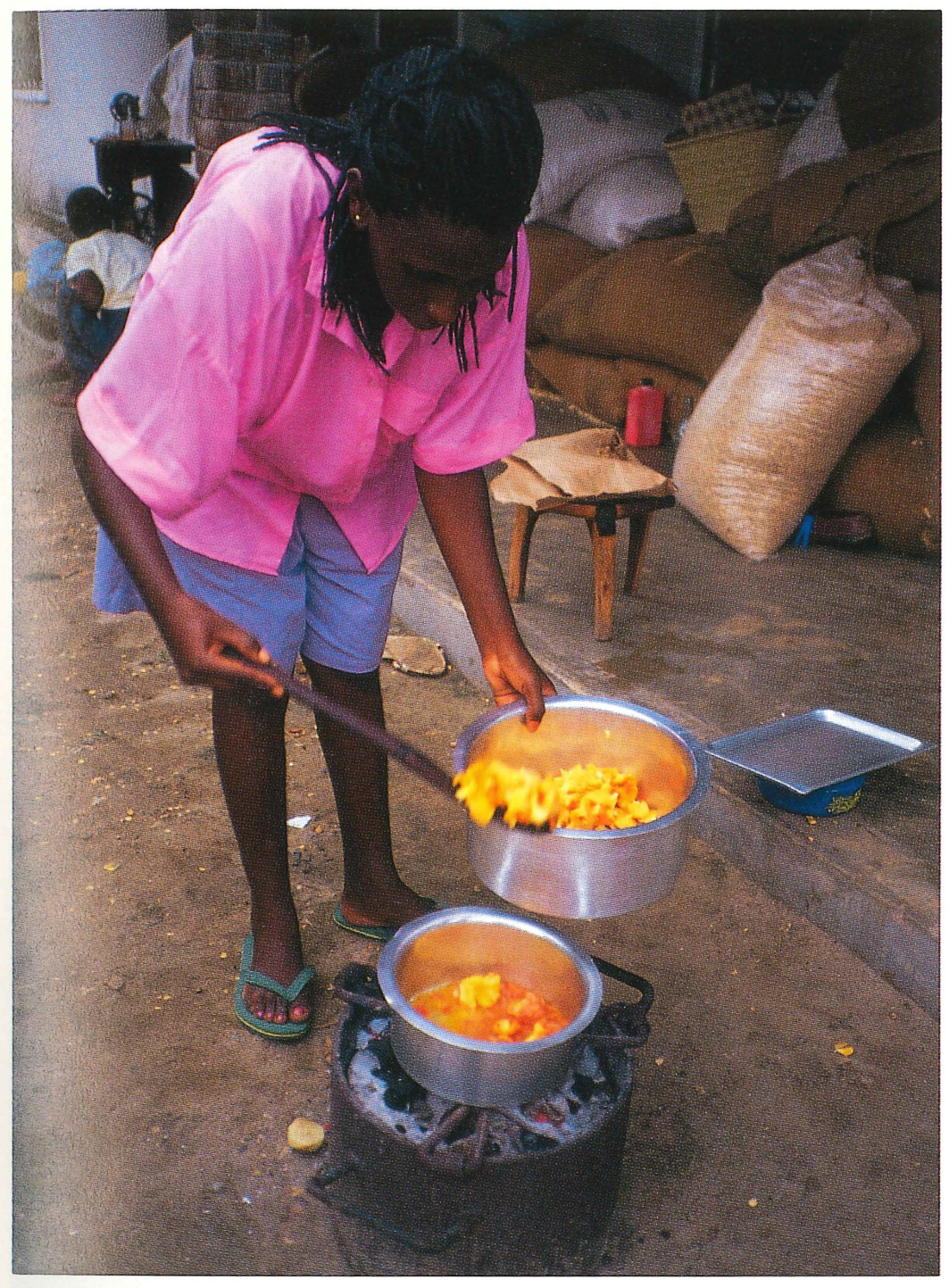

Fig. 10. Although mushroom species differ in different parts of Tanzania, the mushroom stew is made in the same way. Here Ms. Summa Mwasumbi is cooking "mboga" of Cantharellus symoensii, WISOGOLO WA RANGI MBILI, bought in the Dar es Salaam market place. guage is WUNYAMAGULU meaning that it grows under a Uapaca tree. In Mazumbai, in the West Usambara Mountains, two different edible species growing on banana litter have a common name, UYOGA NTINDI. Some people have noticed the connection between Termitomyces species and termites and given a corresponding name, e.g. UNYANSKU in Nyiha language.

Some common names refer to the mushrooms value as food. For instance MAMAMA, a Pleurotus in Sambaa refers to meat. Likewise the fleshy Termitomyces eurrhizus, is in Pare lan- guage called KICHOGA CHA NG'OMBE, cattle mushroom.

In most languages there is a general word for mushroom. Often it is related to the Swahili word UYOGA, but for instance the Sukuma and Nyamwezi call a mushroom BWOBA, and the Haya EBITUZI.

Many tribes have a collective name for inedible or poisonous mushrooms. MANUAKUVEMBA means deadly poisonous in Hehe. MAKOKO is a term used by the Ngoni and MAKOHO by the Bena and they refer to anything which is not 
edible. A Ngulu name for inedible mushrooms, UYOGA WA MUNGU, means God's mushroom and a Makua word VIDULU means something wild. In Pare inedible mushrooms are called NKUNGURU, which refers to a blackand-white bird. In Ngoni language one poisonous species is called MAKETANJUELE. The name means that a haircut has to be made, which is a sign of mourning in a house of death.

As the present book has been written for all Tanzanians, the Tanzanian names should be logical and only one name should be adopted for every mushroom. That is why we have chosen only one vernacular name for every species to be adopted as common name. It has been selected according to the commonness of the name and to the popularity as an edible mushroom. For exotic species as for Amanita muscaria we have created a Swahili name as a translation from Latin name. For such genera which include several edible species we have also created a generic Swahili name.

\section{Mushrooms as food}

Although the selection of edible mushroom species varies a lot, mushrooms are prepared for eating in almost the same way in different parts of the vast country. First mushrooms are washed, then they are cut into pieces, then cooked in a kettle over an open fire. Different kinds of oil or oily seeds are used for cooking. Onions and tomatoes or some other vegetables are added, but seldom any spices other than salt. Some mushrooms, particularly Lactarius species, are first parboiled, and the boiling water is thrown away. The mushrooms are eaten as a stew with ugali, rice or cooking-bananas.

In African society it is always the mother who makes the food. If other members of the family have picked the mushrooms, the mother checks their identification before accepting them.

Most people value mushrooms as food very highly. Especially in the beginning of the season

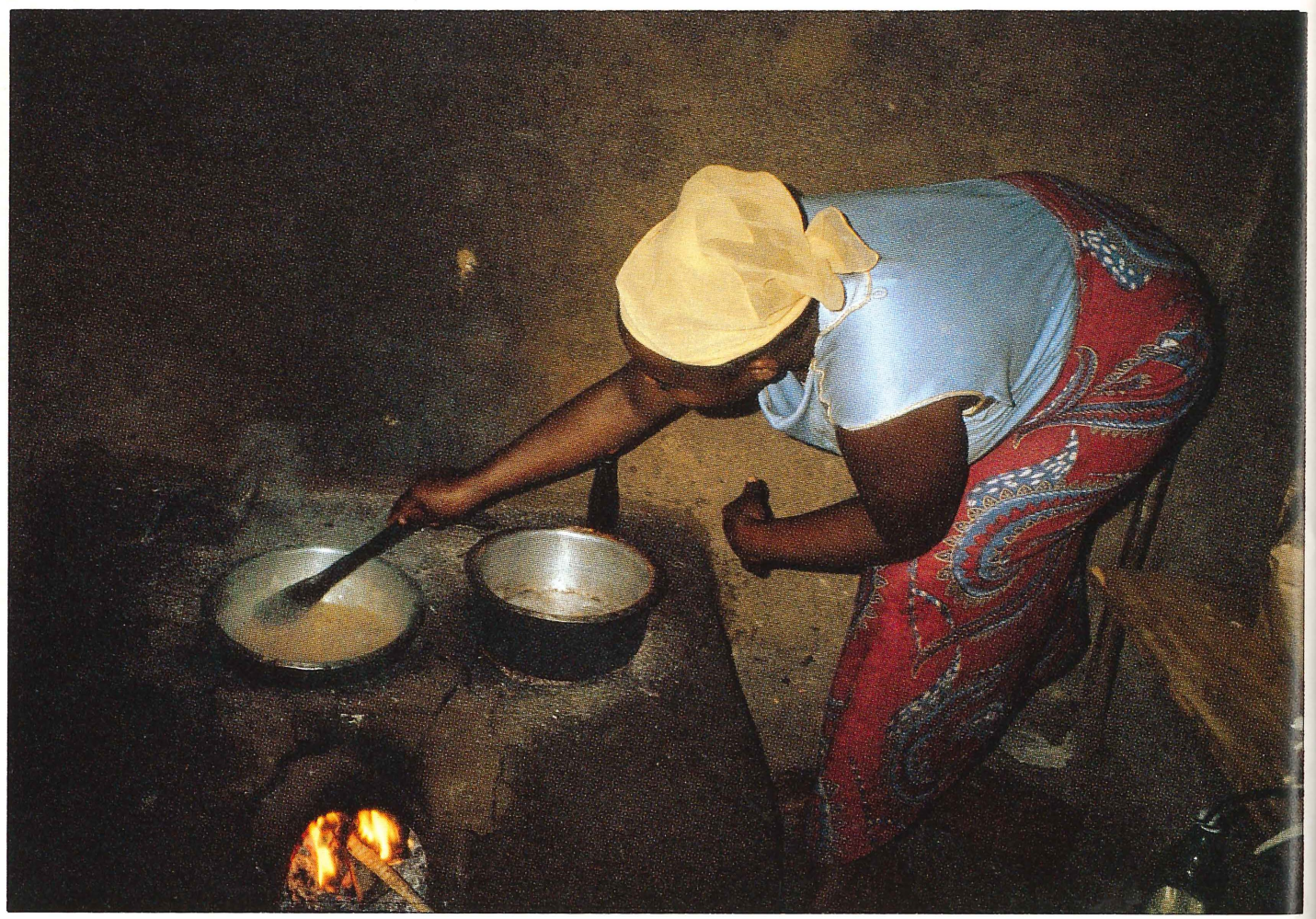

Fig. 11. In Mbaga Manka, Pare Mts., Mrs. Maria Msuya prepares a stew of KIMELO, Termitomyces eurrhizus, KICHOGA CHA NG'OMBE in Pare language. 
they are preferred to any other kind of food. When we asked people to compare mushrooms to other foodstuff like meat, fish and vegetables, most people considered mushrooms similar to meat, most of all chicken.

When we asked people which of the edible mushrooms is the best, the big early-season mushroom, Termitomyces letestui, got the most votes. Also other Termitomyces species like $T$. eurrhizus and T. microcarpus are very popular. Chanterelles are also highly valued. The most used mushrooms in Europe and Asia, Agaricus species (the champignons) are not eaten by most Africans, even though they are common in fields and pastures. People of some tribes consider their dark spore dust as poisonous. In southeastern Tanzania among the Ngindo and Makua species of Agaricus are, however, highly valued. Boletes are mostly rejected, though a potential edible bolete Suillus granulatus seems to be common in cultivated Pinus forests and is represented in this book. Russula and Lactarius species are eaten in miombo woodlands, but not in the mountain forests that we visited.

\section{Preserving}

Some tribes preserve mushrooms regularly, some not at all. Drying is the only method of preservation we have received information about. Mushrooms are cut into pieces and spread on a mat or iron sheet in the sunshine. Some Lactarius species are boiled before drying, and some tribes boil all the species. In mountain areas rains are more continuous, so mushrooms cannot be dried in the sun. Some people dry smaller amounts in the smoke over the fireplace.

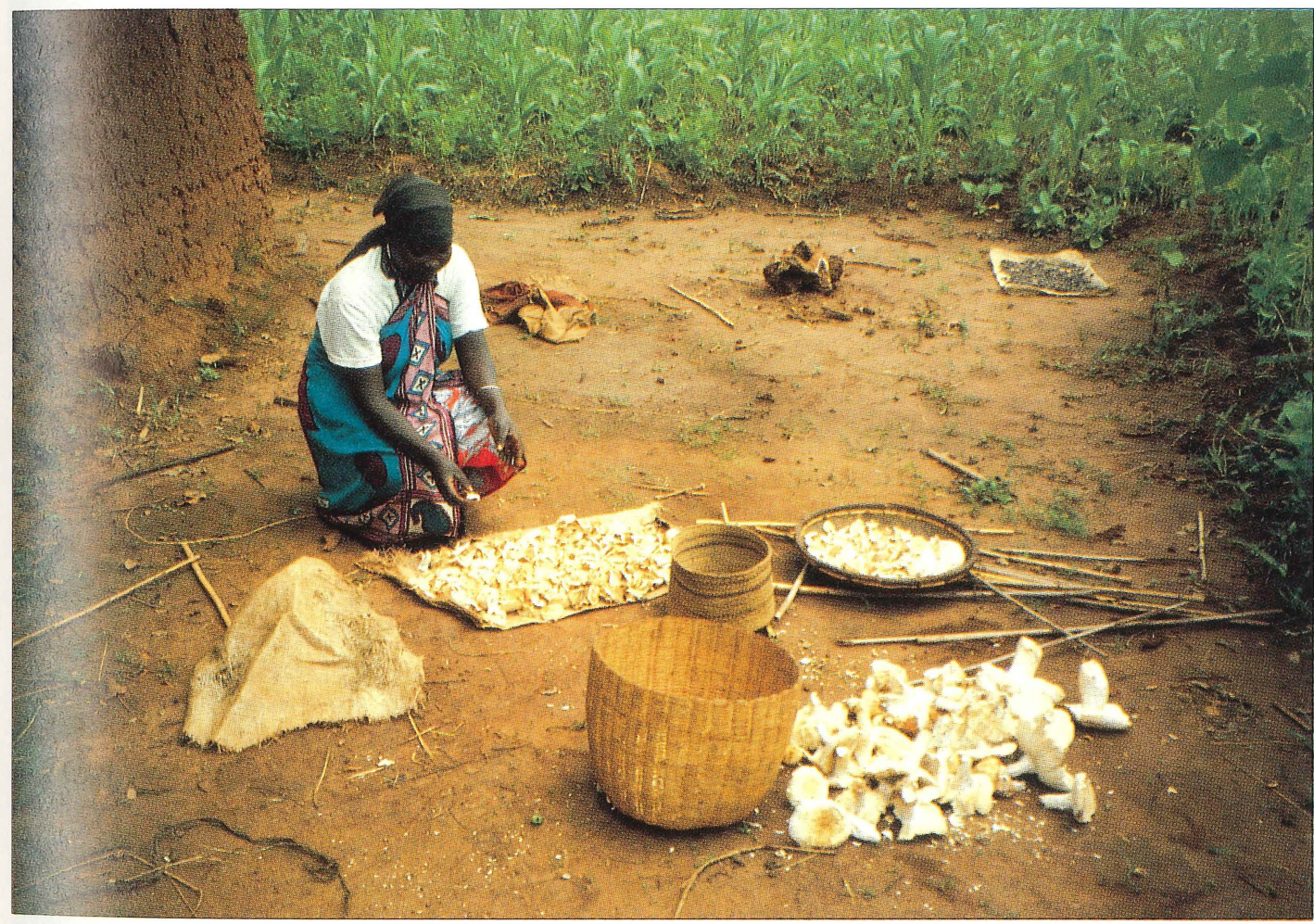

Fig. 12. Mushrooms (Russula, USULULA, and Lactarius, UYOGA-MAZIWA, are cut into pieces for drying. The photo was taken in a farm yard in Masaulwa, Njombe district. 


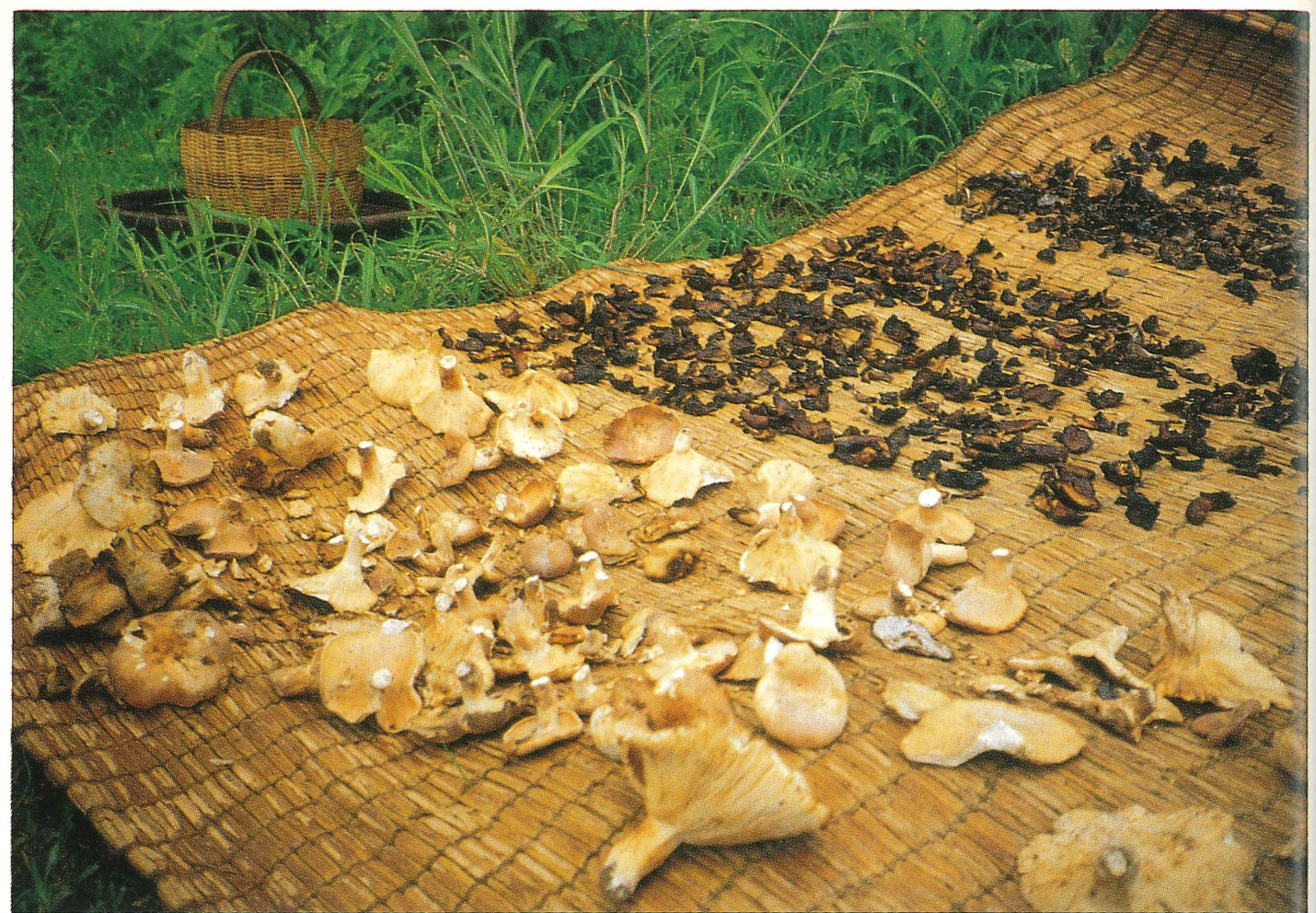

Fig. 13. Mushrooms drying in the sun. The pale pieces are fresh Russula, USULULA, and the dark ones parboiled Lactarius, UYOGA-MAZIWA.

\section{Mushroom trade}

Mushrooms are sold at market places and along roadsides mostly as fresh, but also as dried. We have interviewed some commercial mushroom pickers who regularly collect mushrooms for certain dealers in market places. In some remote mountainous areas mushrooms are collected only for domestic consumption.

\section{Uses other than for food}

There are famous ethnomycological studies on the ritual uses of hallucinogenic fungi among the herbalists of the Mesoamerican Indian tribes and the shamanistic and narcotic uses of the red fly agaric among the North Siberian cultures. Although we made inquiries everywhere in Tanzania, we could collect only a little information about medicinal uses of fungi, and none at all about usage as hallucinogens or drugs.

In several villages in Tanzania mushrooms are given to mothers after child birth to promote recovering. Some mushrooms are used as medicine for stomach and heart. In the Tabora district especially a soft mushroom species ULELEMA (Amanita zambiana), is considered to be good for stomach-problems.

In Eastern province we were told that in precolonial times KUVU (Zaramo language meaning Termitomyces letestui) was used to cure bilharzia. In Morogoro district we met a young man who used to seek the long root-like pseudorrhizas of NEMBO (Luguru language meaning Termitomyces letestui) and sell them to the local healer. He, however, did not know for what purpose the mushroom was used.

Luguru people in Morogoro district have used Auricularia for ear-sicknesses. The mushroom is warmed by a fire, and then its jelly-like 


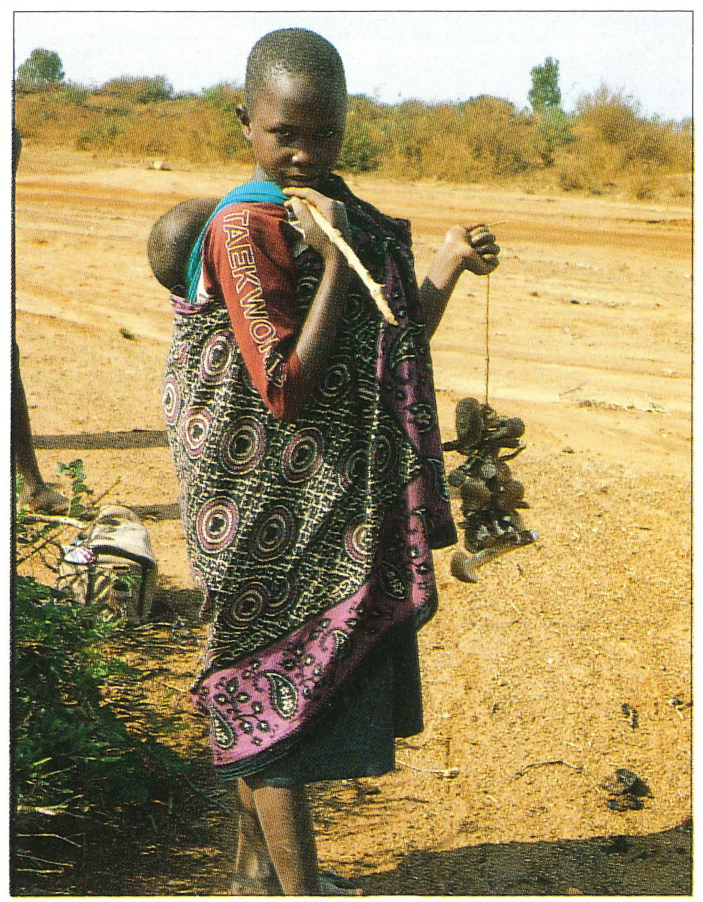

Fig. 15. This Turu girl near Singida collects mushrooms to be sold in the market place.

also use pieces of this mushroom mixed with milk for curing stomachache.

\section{Mushroom poisonings}

Mushroom poisonings, including fatal ones, seem to happen at times. Poisonings are rather rare in the mountain areas where only two to three mushroom species are used for food, but much commoner in the miombo woodlands where tens of mushroom species are used and the identification of edible mushrooms is thus much more difficult.

African families just pick the traditional edible mushrooms and reject all the others. They pay no attention to the identification of inedible fungi. Some people, however, described to us presumed characteristics of poisonous mushrooms, such as a slimy surface, bitter taste, bad smell, the presence of a ring, or brown spore dust. Some people pick only those mushrooms which they see monkeys eating, or which are infected by maggots, supposing that they are also safe for humans. All these beliefs are wrong. Some dangerous poisonous mushrooms taste mild. The digestive organs of some animals are different from that of humans. Animals probably can secrete such enzymes that decompose the poisonous substances.

We also met people who said that poisonous mushrooms have no common character, and one can avoid them only by identifying carefully the edible ones. That is true, but we think that a double checking would add to the safety and people should also know what the most dangerous poisonous mushrooms look like.

There are three types of incidents that commonly lead to mushroom poisonings. One involves children, who usually go to pick mushrooms for their mother. The mother always checks the mushrooms before preparing them for food. While the parents work, and the children stay alone at home, they may find mushrooms and, after poor identification and preparation, eat them.

The other time of danger is during famine. When nothing else is available, people may eat species of mushrooms which are usually rejected.

The third case of danger is caused by the introduced poisonous mushrooms, which are totally unknown to the Tanzanian tradition. Miombo woodland is rich in plant species. Every miombo tree is associated with certain mushroom species living in the soil in close contact with tree roots. When the trees are killed, also the mushrooms disappear. Indigenous mushrooms are incapable of living in symbiosis with exotic trees. In tree plantations usually only one kind of tree is grown in rows. The ground is covered with a thick layer of dead plant litter, which without fungi decays very slowly. When foreign trees are planted, the seedlings may accidentally bear spores and hyphae of some mushroom. Now the situation is favourable to that mushroom: lots of its host trees are around and there is no competition with other mushrooms. It can now produce masses of fruit bodies. Something like this must have happened in Mafinga and Mufindi in the Iringa Region.

When in February 1993 we were driving through some monoculture pine plantations in Mufindi and Mafinga, we could see even from a distance that the needle cover on the ground was full of red spots. A closer observation revealed 
safe for ne dandd. The ifferent can sepoisonsonous ind one dlly the that a ty and langer-

it comOne inmushalways lem for hildren arooms on, eat

amine. lay eat lly re-

by the are todition. Every mushontact lso the rooms exotic and of d with ithout es are bear w the lots of mpetioduce must in the riving ons in rom a d was realed

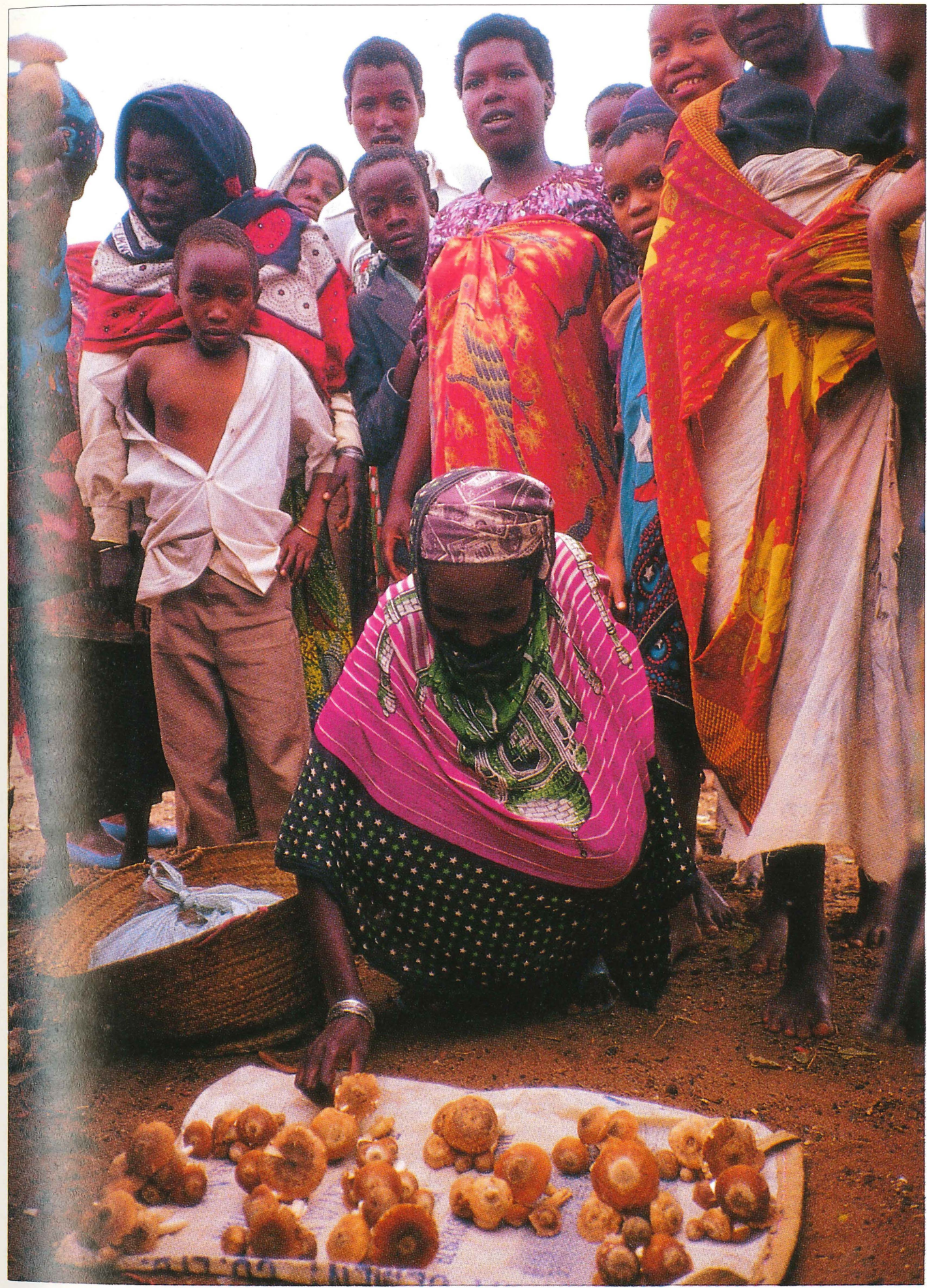

Fig. 16. Termitomyces singidensis, IMPORA, offered for sale at market in Singida. 
them to be the poisonous Red Fly Agaric (Amanita muscaria), common in Europe and Asia, but not indigenous to tropical Africa.

By interviewing people we found out that several poisonings, some even fatal ones, had been caused by mushrooms in this region. In hospital we visited two victims of mushroom poisoning. They told us that they had believed they were preparing a tasty edible mushroom (Amanita tanzanica, WIGWINGWI in Hehe language). The food had a good mild taste. After a couple of hours the women began to feel sick, but did not vomit. Very soon they lost consciousness and began to hallucinate. One of them had a vision of her dead relatives and could talk with them. The other imagined that she went to a church, which was crowded with people, all women, and she felt herself very uncomfortable. Later she was left alone in the church with all the doors locked and she was very much afraid.

When we showed some Red Fly Agarics that we had collected from a nearby pine plantation, the women at once realized that this was the mushroom they had mistaken for WIGWINGWI. After recovering one of the women took us to the miombo woodland of her usual mushroom area, where she presented us many species of edible mushrooms, also the red WIGWINGWI. There was only one exotic tree around, a planted Pinus patula along the road - and under it there were several fruit bodies of Amanita muscaria. This convinced us how well this poisonous species has established itself in Tanzania and how essential it is to teach every mushroom picker how to distinguish it from the indigenous red Amanita species.

Later we heard many other stories about mushroom poisonings, all concerning mushrooms found in tree plantations and collected as WIGWINGWI. Sometimes people had vomited - and that probably saved them, but some people did not vomit spontaneously e.g. the women we met in hospital. To our dismay, one of them died the following night. This proved us that it is important to cause vomiting to remove as much poison as possible from the stomach. In the latter part of this book we will give practical advice how to avoid mushroom poisoning and how to behave in poisoning cases.

\section{Beliefs}

We have collected some interesting stories and beliefs and even songs about mushrooms. Some are just funny fairytales, but some have an ecological approach and show how people have made conclusions about their environment.

For instance, an old Nyiha woman sang a song dancing with her arms lifted up and waving beautifully. The words were something like this: "The leaves fall from the trees. The mushrooms come up from the fallen leaves. Nowadays there are less mushrooms, because the trees have decreased."

The Chagga people, who live on Mt. Kilimanjaro never eat mushrooms. They believe that mushrooms are bad, because they grow from dirty decomposing matter and have the same kind of poison as the snakes have.

UVUMBU (Termitomyces letestui) is appreciated among the Nyiha. Some people do not collect it, because they believe it can change into a human being. Some people collect it eagerly, but they must not say anything about it. They pretend to look for something else, otherwise they do not find it. There is a song about this mushroom, to which people dance and repeat the words many times. The words tell that UVUMBU changed into a human being and sang: "People die forever but we mushrooms, we come and go, come and go." (We have taperecorded this song).

Also the Hehe appreciate Termitomyces letestui, which they call WIKULWE. They have a belief that if you find a WIKULWE, you should rub your forehead with its navel to be able to find it easily next time.

Many stories about mushrooms are connected to the tall species of Termitomyces. The very large specimens of Termitomyces are called NTEMBO (elephant mushroom) among several tribes, and it may refer to different species in that genus. Some Bondei believe that NTEMBO brings bad luck and they are afraid to pick it. The Ikizu people believe that it should be struck with a stick to frighten away the snake which might be coiled around its stipe. According to the Bena other animals, for instance, a small antelope DIGIDIGI, may hide under such a mushroom 
and even eat pieces of it. One Bena told us that a name of a big Termitomyces USIKULWIKE literally means "to escape a danger". The name originated from a story where several animals were gathered together and one animal put this mushroom on its head and frightened all the others.

From a Makonde man we heard another story about an animal involved in a mushroom's name. It is about Auricularia, MAKUTU MBONGO in its vernacular name. The story goes: Once upon a time there was an animal called Mbongo, which had very big ears. Men killed the animal. They did not like to take the ears home, because the women would have been afraid of them. They cut the ears off and threw them away. Next time when the men went to that forest, they found the ears growing on a log and become bigger. Ever since that mushroom has been called MAKUTU MBONGO, "the ears of Mbongo".

There are also some beliefs about mushrooms. From the Nyamwezi and Nyiha people we heard the same story: If someone during a safari steps on a puffball so that smoke comes out, he will get lost and cannot find the way home.

The Nyaturu believe that if there is a mushroom growing on somebody's grave, that means the person in the grave was very powerful.
A Pare woman told us that if you dream about picking a lot of UYOGA WA NG'OMBE (Termitomyces eurrhizus), some misfortune may follow. She herself once had such a dream, but nothing happened.

In the West Usambara Mountains there is a ritual concerning a certain mushroom species and almost everyone told that he also follows it: When a person finds a group of UYOGA NTEMBO, he hits at one fruit body with a stick and sings:"Ntembo, Ntembo, You mushroom, I want that tomorrow there will grow another mushroom!" One mushroom is beaten into pieces and the others are picked. If you do not act like this, no more mushrooms will grow. (We have tape-recorded this song.)

In Mbeya District in Mbozi we heard from a Nyiha how a fungus can be used as an amulet. INSIVILISI (a big club-shaped Xylaria) is just dried and carried in a pocket. When you meet a cruel person, who might want to beat you, you just take some of the mushroom into your mouth and chew it and rub your hair with it. That man becomes very polite. Also if you have committed a crime yourself and are brought to court, this mushroom can help you. You just put this mushroom onto your head and the one who accuses you forgets all the bad you have done.

\section{The fungi}

Fungi are an important element of nature; they are organisms present almost everywhere. They exist in the soil, water and air, and they are associated closely both with plants and animals, humans included. Mostly they have tiny dimensions, and we are usually unaware of the abundance and diversity of fungi in our environment. On the other hand, edible larger fungi are important in our daily diet. Parasitic species cause severe losses in forestry and agriculture, and so their negative effects are also well known.

\section{What are the fungi}

Living things have traditionally been classified into two kingdoms, plant and animal, and fungi included in the plant kingdom. Fungi, however, lack many essential characteristics of plants, for instance, ability to photosynthesize their organic components with the aid of sunlight. Their nutrition can better be compared with that of animals. Both are heterotrophic: they get energy by decomposing molecules which were originally built up by plants. Fungi, however, do not indulge pieces of food like animals. Instead, they excrete digestive enzymes into their surroundings and afterwards absorb dissolved organic molecules into their cells. Typical fungal cells have cell walls like those of plant cells. Animal cells never have a wall, but an outer, flexible cell membrane only. So fungi are neither plants nor animals and they are nowadays classified as a kingdom of their own, the Fungi.

Demarcation between these three kingdoms is gradual. Some primitive fungi resemble very 

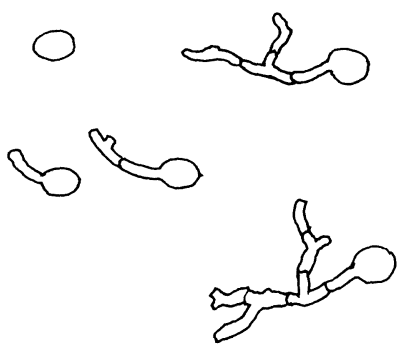

germinating spores
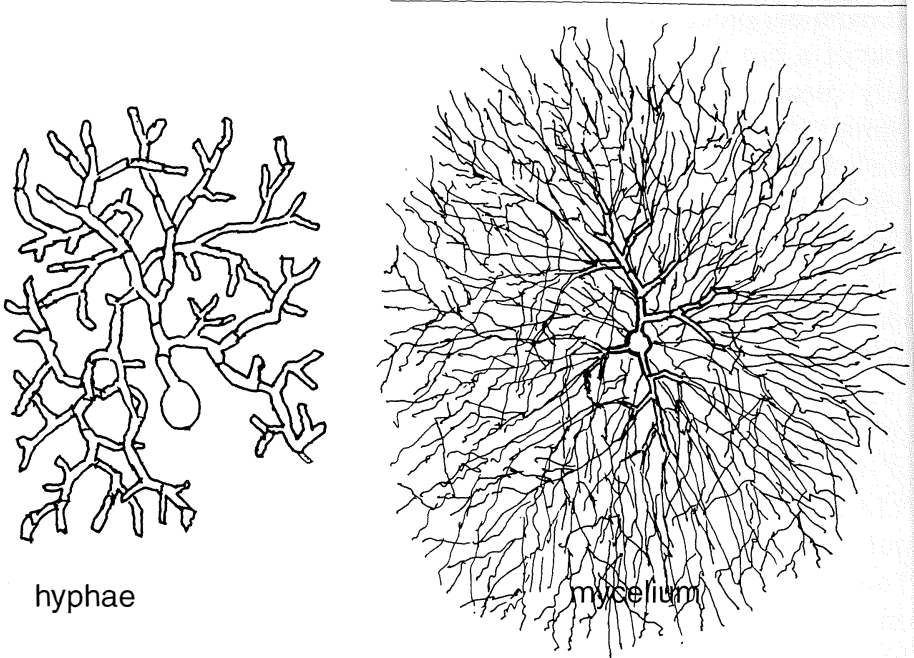

Fig. 17. Fungi reproduce themselves by spores.

much algae in the Plant kingdom. Maybe they have developed from algae that have lost their chloroplasts. The actively moving plasmodia of the slime moulds relates to the Animal kingdom and so they are sometimes considered as primitive animals, the Mycetozoa, sometimes as Fungi, the Myxomycetes.

Because of the scarcity of fossils, we have no clear picture about the evolution of fungi. The earliest fossil records of primitive fungi date back to the Cambrian and Devonian periods, some 570 to 390 million years ago. Different main groups of fungi seem to have developed from different ancestors. So we could define fungi as a heterogeneous group of organisms having a heterotrophic way of living. Common features in fungi are:

- Eukaryotic cell having a cell wall of chitin or cellulose and a cell vacuole, but no chloroplasts.

- Simple structure: vegetative phase is made up of single cells or most often of simple filaments of cells, called hyphae.

- Fungi reproduce themselves by spores. These can be sexual or non-sexual and are usually enclosed by a rigid wall. Spores are microscopic in size, and unlike seeds of higher plants, contain no embryo.

\section{Where do we meet fungi}

During the rainy season we can see fungi al around. Big and small caps emerge from the ground, fallen logs and termite mounds. Some look like umbrellas, some like clubs or cups and some even like ears or hooves. They all represent the visible part of fungal individuals, the socalled fruit bodies, existing to take care of the reproduction of fungi. The fungi, however, exist all the year around. Even if we do not see them we see their work.

Fallen leaves disintegrate, wooden constructions decay, fruit juice begins to ferment. In the air there are always floating large amounts of invisible spores of fungi. Winds carry them around and later, most of all with rain, they fall down. If the place is suitable, the spores germinate and develop into filaments of fungal cells, the hyphae.

\section{The fungal cells}

Cell walls of fungi are usually fairly thin if compared to those of plant cells. The major constituent of the wall is chitin, a nitrogencontaining polysaccharide. 
In animals and plants cells make up a threedimensional entity or network. In fungi cells are arranged in long chains or hyphae separated by a transverse wall, the septa. A mass of hyphae is called mycelium.

The hyphae are arranged in different ways in different parts of a fungus. Nutrient-absorbing mycelium in the soil or host plant is usually loosely dispersed, penetrating into a wide area. In fruit bodies the hyphae are arranged compactly, running parallell or in an interwoven fashion. Sometimes spaces between the hyphae are filled with excreted substances, which may make the fungus jelly-like or hard.

Even if most fungi have hyphae, some grow as single cells, which means that the cells of the mycelium become separated and continue their living as individuals. Single-celled fungi are called yeasts; the best known yeasts are those used in baking and the making of alcoholic beverages.

\section{The classification of the fungi}

The amount of known fungal species is about 100000 and it is estimated that an equal amount still await findings and describing. To master this huge knowledge the fungi have to be classified somehow. Modern taxonomy of living organisms is based on kinship which can be judged from structural and other similarities. The nearer the relatives, the more they look alike. The system starts from the most primitive forms and ends with the most advanced ones.

The vegetative phase of fungi, the mycelium, very seldom has details clear enough for classification or identification. Most good details are found in the fertile phase, the structures that produce or support sexual cells, the spores.

In a simplified manner the fungi can be divided into two main groups: lower fungi and higher fungi. The most important groups in higher fungi are Ascomycetes, Basidiomycetes, and Fungi Imperfecti.

\section{Lower fungi}

The most primitive fungi live in water, or at least their sexual reproduction depends on free water. They give rise to different types of zoospores, which are mobile cells with one or two flagella to swim with. Such primitive fungi are small and unicellular or they have aseptate, tube-like hyphae. More developed lower fungi have septate hyphae and nonmobile spores. The structure of a fungal hypha is very simple and fairly similar in different groups. Lower fungi make up the most diverse and heterogenous of all main groups of fungi.

\section{Ascomycetes}

The class Ascomycetes have been named according to the sexual spores (ascospores) which develop inside a sac-like cell, ascus. The asci develop in or on a fruit body as terminal cells of the hyphae. Often the asci develop side by side, forming a sporebearing layer, the hymenium. The asci have mechanisms to discharge the spores. If you touch a fresh ascomycete you can sometimes even see the spores discharging into air like smoke from the surface of the fruit body.

There are about 33000 species of Ascomycetes, 18000 of which are lichens. You can find Ascomycetes during all seasons of the year and in many kinds of environments. Some are plant pathogens, some decay dead wood, plant debris or animal excrement. Some are difficult to find, because they grow under ground (truffles) or are very small.

\section{Basidiomycetes}

The class Basidiomycetes includes about 30000 species. The best-known macrofungi like polypores, boletes, mushrooms and toadstools belong here. The rust fungi (order Uredinales) and the smut fungi (order Ustilaginales) which cause serious plant diseases are Basidiomycetes 


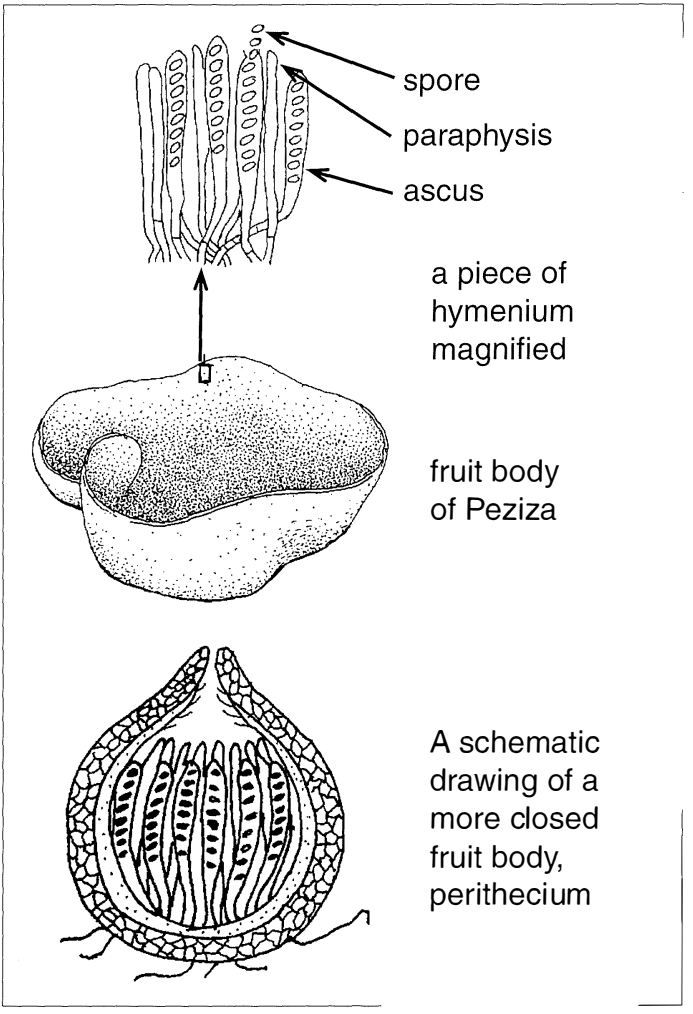

Fig. 18. Fruit bodies of some Ascomycetes. as well. They cause different kinds of spots and flecks on their host plants and because of their small size are called microfungi. According to the size of fruit body, fungi are often assigned to two informal groups: microfungi and macrofungi.

Within Basidiomycetes the sexual spores are born exogenously on the terminal cell of hypha called basidium. Most often the basidia develop on fruit bodies, basidiocarps.

The basidiomycetous macrofungi are classified according to the hyphal structure and developmental history of the fruit bodies. The most important groups are as follows:

Phragmobasidiomycetidae. This suborder differs from all the following microscopically by their basidia, which are longitudinally or tranversely septate. It includes fungi of very diverse external forms, most being so called microfungi. Of the edible fungi, the so called jelly-fungi, eg. Auricularia belong here.

Aphyllophorales. The development of the fruit body is open. That means that new hymenium develops when the fruit body grows and the fruit bodies are relatively long-lived. The basidia are developed on the smooth or wrinkled surface of the fruit body or on special structures of the fruit body like gills, spines, or tubes.

Agaricales. The development of fruit bodies is partially closed (see Fig. 21). That means that the hymenium is determined already in the primordia
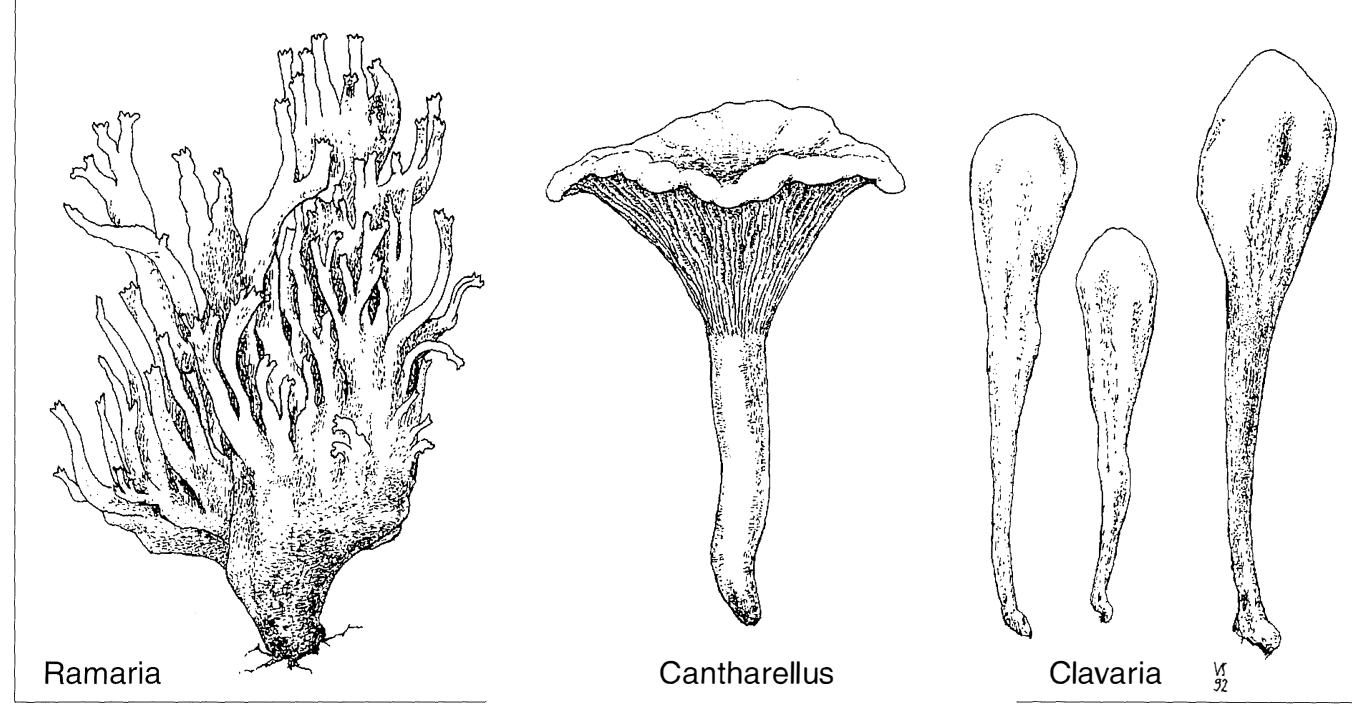

Fig. 19. Fruit bodies of Basidiomycetes belonging to the order Aphyllophorales. 
ots and ir small size of nformal res are hypha elop on assified opmenportant

aborder ally by 1ly or diverse ngi. Of gi, eg. he fruit nenium he fruit dia are of the it body

dies is hat the nordia

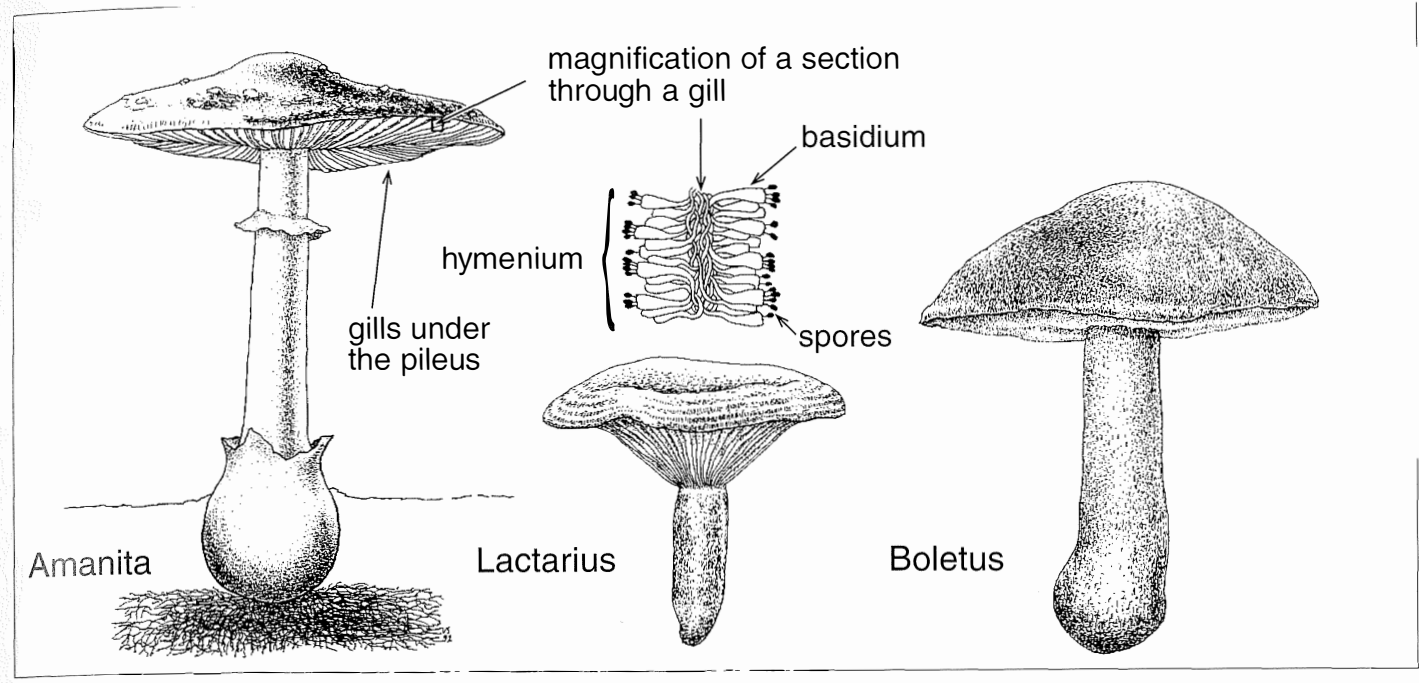

Fig. 20. Fruit bodies of Basidiomycetes belonging to the order Agaricales.

of the fruit bodies. Afterwards the fruit bodies grow to their full size, but no new hymenium will develop. The fruit bodies are relatively shortlived. The basidia are borne on gills or tubes (Boletaceae) on the lower surface of the fruit body.

Gasteromycetes. The development of fruit bodies is closed. A membrane, called peridium surrounds the fruit body. The basidia and spores are born inside the fruit body. In different groups of Gasteromycetes different patterns have developed to release the mature spores.

a cross section of a young

fruit body
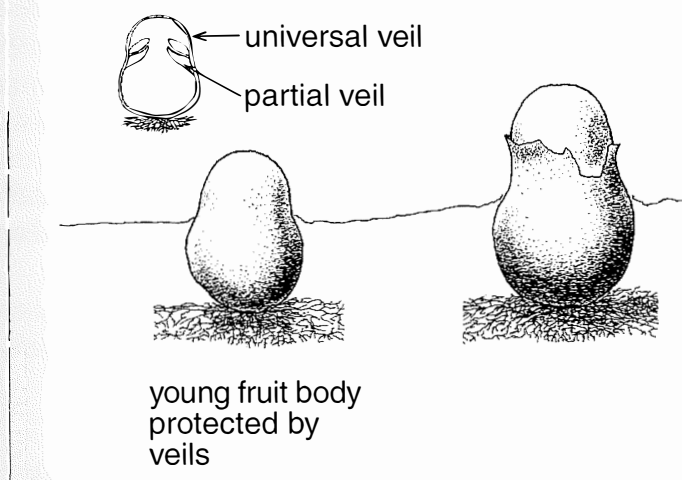

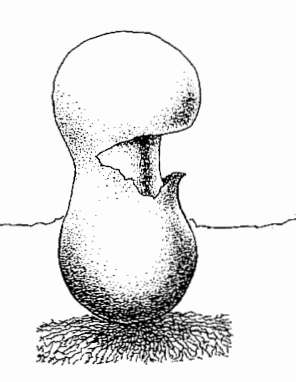

universal veil breaks

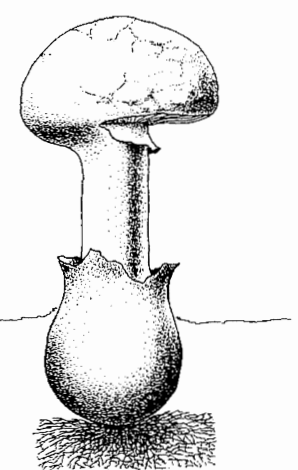

partial veil breaks

Fig. 21. Partially closed development of an Amanita. 


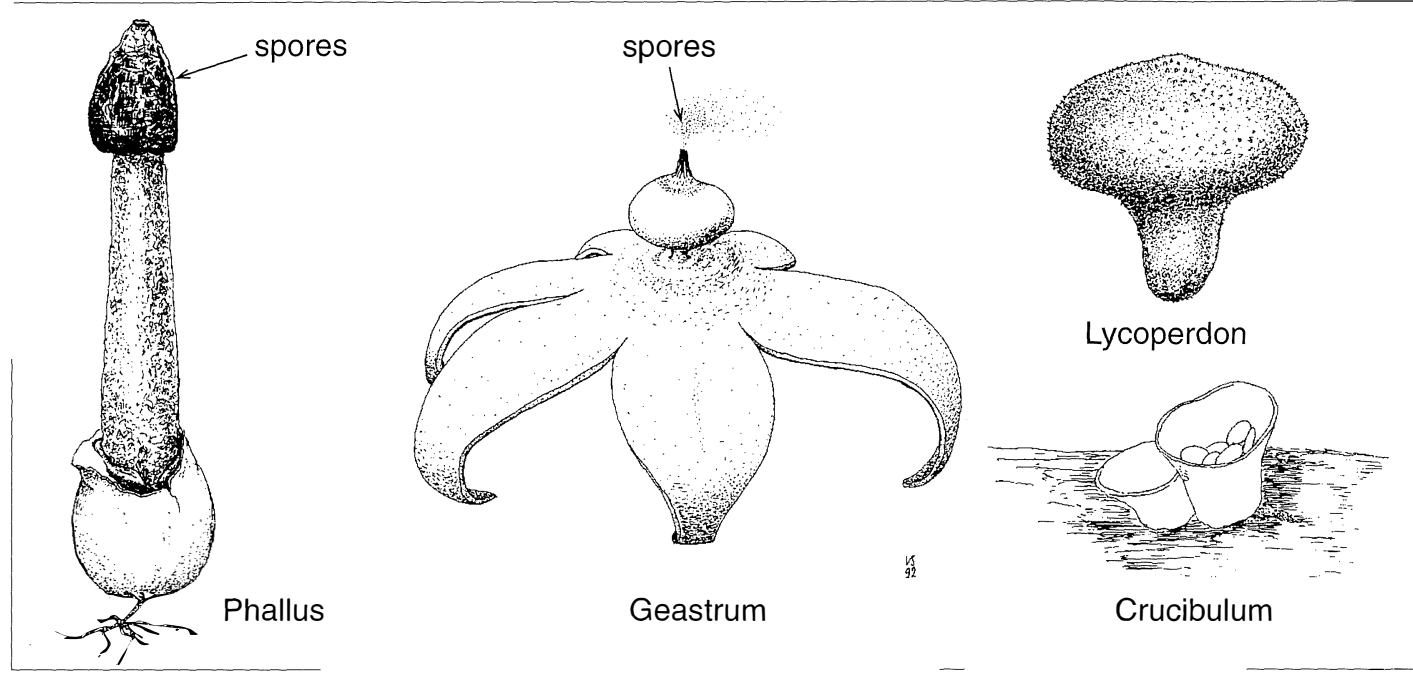

Fig. 22. Fruit bodies of Basidiomycetes belonging to the order Gasteromycetes.

\section{Deuteromycetes, or Fungi Imperfecti}

It is often difficult to decide in which group a certain fungus belongs. The decision is most difficult with such fungi which are found as mycelia only or which only seldom fruit.

For practical reasons the mycologists created a special form group, Deuteromycetes, for those fungal species which never seem to produce sexual stages. Most of them are capable of propagation by non-sexual spores. Many microscopic fungi in the soil, for instance, belong to this group.
As they evidently lack the ability of sexual reproduction, they are often called imperfect fungi (Fungi Imperfecti). Most of these fungi live as moulds on soil, spoiling foodstuffs etc., and there are also many plant and animal parasites.

Many Deuteromycetes spoil foodstuffs by their toxic substances. If groundnuts are stored in a moist place, a thin mycelium of Aspergillus flavus may grow on them. The fungus produces aflatoxin, one of the most potent poisonous substances known in nature. Continuous consumption of aflatoxin will cause liver cancer.

\section{Nourishment of fungi}

\section{Saprophytes}

As the fungi are not capable of photosyntesis, they get their energy by decomposing organic material. Such material can be, for instance, a dead tree, a pile of straw, a wall of a house, or a piece of bread forgotten on the table. When the fungi get their nourishment from wood, their enzymes split the long cellulose molecules shorter and so wood becomes fragile. The presence of fungi on bread can be seen from the white mould and the special smell and taste caused by the metabolism of the fungus.

\section{Parasites}

Some fungi do not rely on dead material, but take their nourishment from living organisms. Such fungi are parasites. Armillaria mellea, for in- 


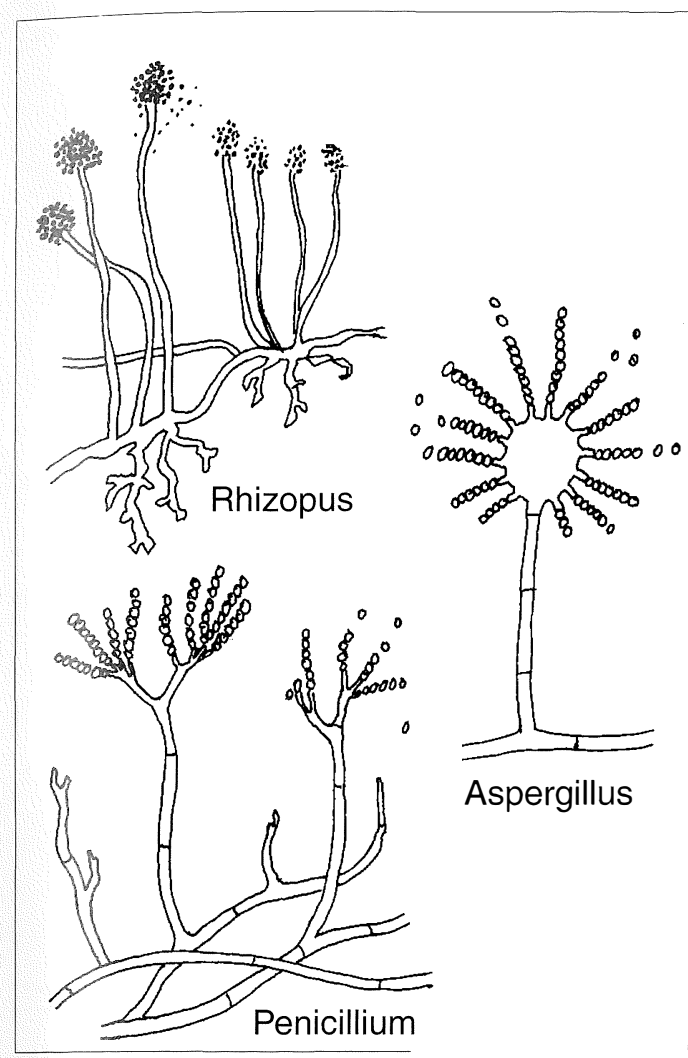

Fig. 23. A microscopic drawing of some moulds which spoil foodstuffs. Rhizopus belongs to the so-called lower fungi and Aspergillus and Penicillium to the imperfect fungi.

stance, is a worldwide pathogen causing diseases of forest-, park-, and fruit-trees and even of vegetable crops. The fruit bodies of Armillaria mellea can be seen during the rainy season to grow as dense bundles on tree-trunks and stumps. Some parasitic fungi specialize on certain plant species. Hemileia vastatrix is a pathogen causing the rust diseases on coffee. It has no such mushroom-like fruit bodies as Armillaria mellea. Its spores develop in tiny spots on the leaves of coffee.

Plant diseases caused by fungi are quite common. Some fungi can cause diseases also on animals and humans. The commonest type of fungus-originating diseases or mycoses in humans is an inflammation on the skin, called dermatosis. In that case the fungus utilises the keratin of the skin, hair and nails as the source of energy. Fungal dermatosis can be identified from circular peeling and a tickling, hairless area on the skin. The identification can be confirmed by taking a sample from the skin and looking at it under a microscope. The fungus can be seen as long hyphae.

\section{Symbiosis}

Some fungi live in symbiosis, which is a mutually useful relationship, with another organism from which the fungi get their nourishment. For instance mycorrhiza is a symbiotic relationship between a fungus and the root of a plant. Most of the common miombo trees have such mycorrhizas. In this case the fungi penetrate into the roots and receive carbohydrates from there as nourishment. The fungal hyphae for their part collect water and minerals from the soil to the benefit of the tree. Many common mushrooms, for instance species of Cantharellus, Lactarius and Boletus are mycorrhizal fungi. If we eat such a mushroom, we eat food synthesized by the tree.

Fungi can also live in a symbiotic relationship also with animals. The most remarkable example of this in Tanzania are the termites. The so-called higher termites, which make up about $75 \%$ of the termite species cannot live without fungi. Termites are best known as destroyers of wood. But if they are fed with plain wood, without the opportunity of using fungi, they will die of undernourishment. They grow mycelia of fungi in their mounds in underground compost heaps under skilfully controlled conditions. They chew the plant material and use the cellulose enzyme of fungi to decompose it. These fungi called Termitomyces serve as a diet for the termites. Species of Termitomyces also make fruit bodies. Such good edible mushrooms are produced early in the rainy season, but only after the colony has abandoned its nest. If the termites still inhabit the mound, they eat the fruit bodies of Termitomyces already as primordia. 


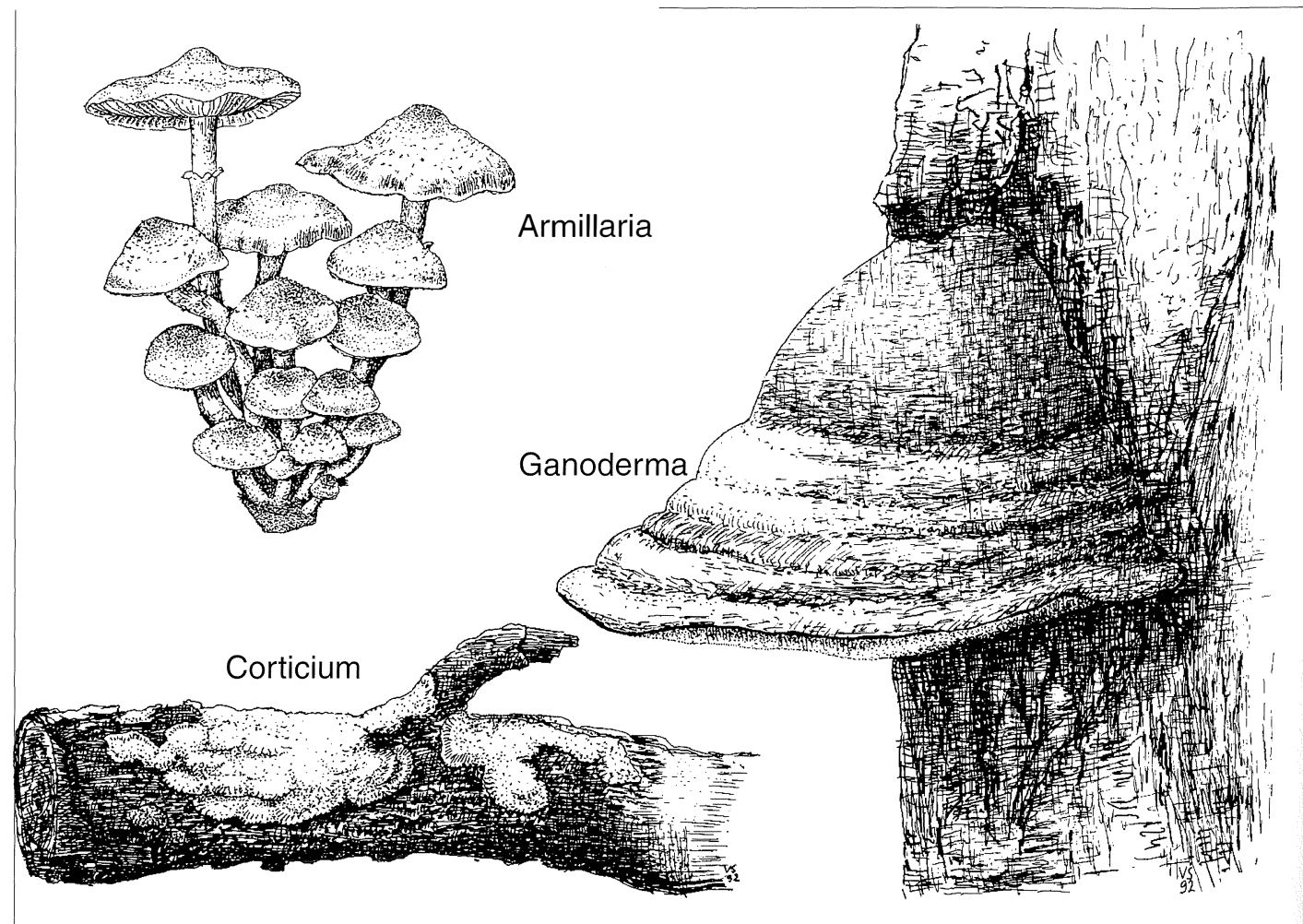

Fig. 24. Some wood decomposing fungi. Corticium decomposes only dead wood, but Armillaria and Ganoderma may attack also living trees.

\section{Fungi in forest ecology}

Fungi make up a very important element in the ecology of the forest. In fact, forest trees would not survive without fungi. With other soil microorganisms, the fungi make forest litter decompose. This process causes fallen leaves, branches and trunks to disintegrate; fungi enzymatically split large plant molecules (cellulose, lignin etc.) into smaller and soluble components, and so the nutrients which have accumulated in the structures of the plants become available for new growth. We call this process of decomposition 'decay' or 'rotting', and so decaying is primarily a positive phenomenon in forest ecology. Without it the forest floor would become covered with thick layer of branches, leaves and tree trunks and new tree seedlings would die for lack of nutrients and space.

Fungi are important for the trees also as mycorrhizal partners, which take care of effective water and mineral uptake. This character is essential especially in forests growing on poor laterite soils. When trees are felled, the fungi stay alive in the roots and when new sprouts grow up from the stump, the fungi help its recovering by collecting minerals from the surroundings. Complete destruction of forest results in the death of these symbiotic fungi, and it is very difficult to initiate new tree growth in such cleared areas. 


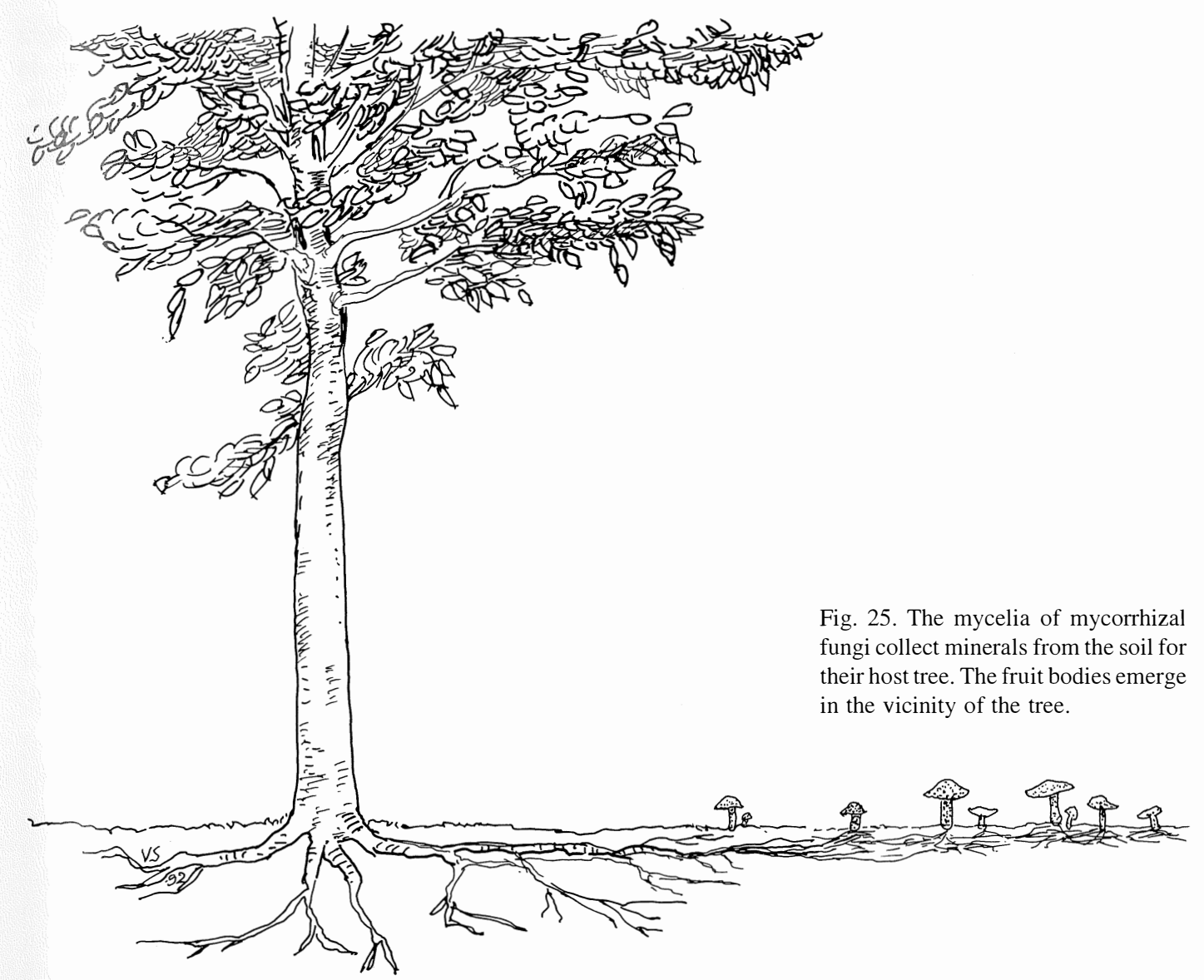

trunks ack of Edible mushrooms

lso as effecacter is n poor gistay row up ing by Comeath of cult to reas.

\section{Chemical composition of mush- rooms}

There are big differences in the chemical composition of different species of mushrooms. There are differences also within one species depending on the substratum and the stage of development.

The biggest share of the content is water, about $85-95 \%$ of the fresh weight. The water percentage varies a lot according to weather and 


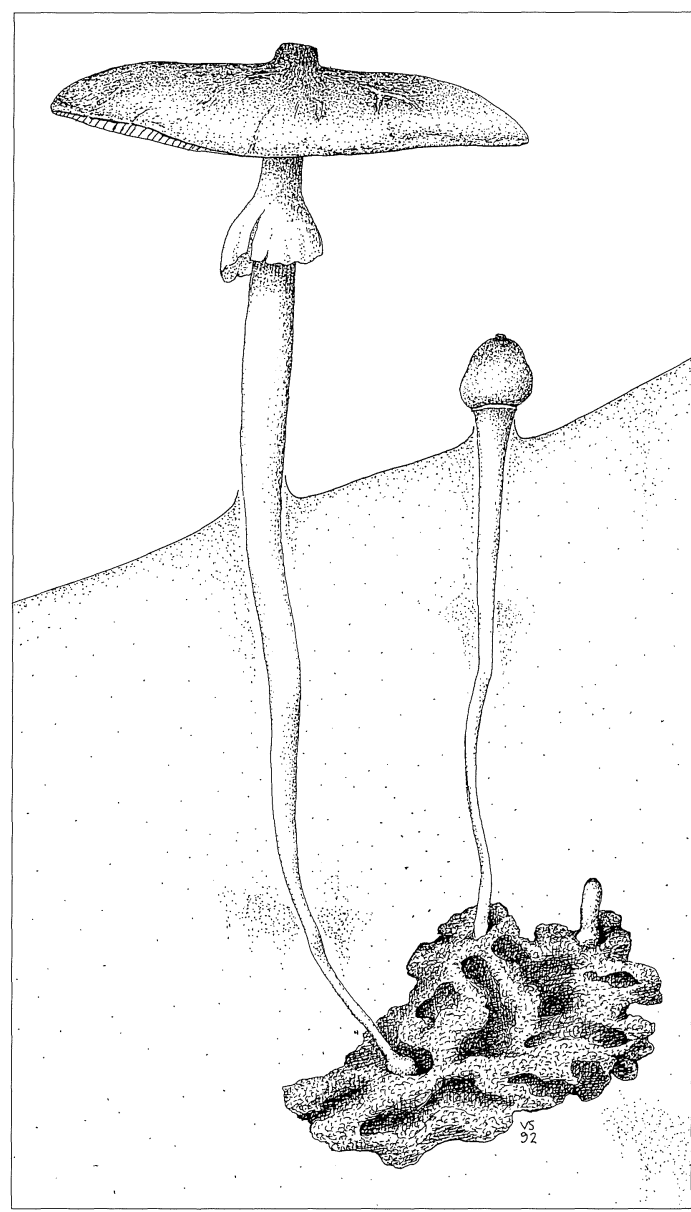

Fig. 26. A Termitomyces, UYOGA-MCHWA, pushing up from underground chambers in a termite nest where termites cultivate mycelia of fungi in chewed plant material.

the age of the specimen. That is why the composition and nutritional value are usually announced according to dry weight.

About 50-70\% of the dry weight are carbohydrates. Part of these are different sugars, most common of these being glucose $(3-43 \%$ of dry weight). That is why some mushrooms have a sweet taste. In mushrooms a special fungal sugar, trehalose is common. It is a disaccharide and does not have a sweet taste. In the digestive process an enzyme, trehalase splits trehalose molecules into two glucose molecules. Some people do not have this enzyme and they might get stomach pains after a mushroom meal. In similar way some people do not tolerate milk. They lack the enzyme lactase, which splits the molecules of milk-sugar, lactose. Trehalose and lactose molecules are so big that they cannot be absorbed from the small intestine without splitting into monosaccharides. So they continue to the large intestine and there serve as a substratum for bacteria, which then generate a lot of gas.

About $15-50 \%$ of dry weight are proteins and other nitrogenous substances like chitin. The aminoacid contents of the proteins differ in different species of mushrooms but in general they are close to those of animal proteins. The proteins serve as valuable nourishment, but chitin cannot be digested in the human digestive system. For ruminant animals chitin is good nutritive substance.

Mushrooms contain only small amounts of fats, about $1-15 \%$ of the dry weight, but their quality is good, most of them consisting of unsaturated fatty acids.

The rich and many-sided mineral content is the most valuble part of mushrooms as food. The selection of minerals varies a lot according to the mushroom species and especially according to the soil where the mushroom is growing. Potassium, phosphorus, copper, cobalt, aluminium and zinc are often present in high quantities, but mushrooms tend to collect any minerals from their surroundings so poisonous heavy metals such as lead, cadmium and mercury are present in polluted areas.

Fungi have a good ability to compose many kinds of chemical substances such as aromatic agents. That is why different mushroom species have their special smell and taste. Not all the mushrooms have a pleasant aroma. Some may have a bitter or even a burning taste. That is why qualified mushroom pickers use also smell and taste when identifying mushroom specimens. The taste is an addition to the identification of mushrooms, but mild taste does not guarantee the edibility of a mushroom. Some mushroom species compose poisonous substances, and these do not always have a bad taste. On the other hand some edible species of Lactarius (UYOGAMAZIWA) have a milk latex with a sharp taste. This can be made milder by boiling the mushrooms and throwing the water away. 
y might neal. In te milk. plits the ose and nnot be ut splittinue to stratum $f$ gas.

eins and in. The in difral they oroteins cannot em. For ve sub-

unts of ut their of un-

ntent is od. The $\mathrm{g}$ to the ding to Potasninium ies, but $\mathrm{s}$ from metals esent in

\section{Nutrient content of Tanzanian mushrooms}

In Fig. 27 you can see nutritional values of some Tanzanian specimens of mushrooms analyzed in the State's Technical Research Center in Finland. Because proteins are considered as the most valuable nutrients of mushrooms, the species are arranged according to their amounts of proteins.

The corresponding values of cultivated champignon are added for comparison. You can see that the species Termitomyces have the highest protein contents. Apparently mushrooms with good nutritive value also taste good. When we asked Tanzanians which species of mushrooms they consider best, species of Termitomyces were most often mentioned. Other genera among which some people found their favourite mushroom are: Amanita, Cantharellus, Lactarius and Russula.

Fungi contain many kinds of enzymes, which they need for decomposing organic matter of their environment and for composing new chemical substances. In mushrooms picked from the field these enzymes are still active and may begin to decompose the tissues of the mushroom itself. This may change the taste and colour during the preservation as long as the mushrooms are still alive. Boiling or frying stops the enzyme activity.

Mushrooms are good substratum for many kinds of microorganisms such as bacteria and moulds, which spoil them. If picked mushrooms are left in a moist and warm place these microorganisms multiply very fast. The situation is the same with maggots. They might be quite small and unnoticeable when the mushrooms are picked, but increase and grow fast in warm weather. That is why mushrooms are a rapidly deteriorating foodstuff. In that respect they are comparable to meat and should be used soon after picking or preserved with care.

\section{Carefull picking}

When you go to collect mushrooms, always have a basket and a knife with you. When picking a mushroom from the ground, first cut off the sandy base of the stipe. If you put sandy mushrooms into your basket, the sand will drop be- tween the gills of the other mushrooms in your basket, and you will have a lot of washing to do at home. Also split every mushroom into two halves to see that there are no maggots inside. It is waste of time to carry home mushrooms in poor condition and then throw them away.

Always take into your basket only such mushrooms that are good and edible. If there are mushrooms that you do not know yourself but would like to ask somebody about later, keep them separate, away from the other ones.

\section{Careful preserving}

There are several methods of preserving mushrooms, but in Tanzanian households only drying in the sun and smoking are used. The tropical sun makes a very effective dryer.

The drying does not kill the microorganisms on mushrooms, but it makes the substratum so dry that they do not find enough water for their needs and they enter a dormant phase. Some people cook the mushrooms before drying and that kills the microorganisms and makes the product more hygienic. With this method the mushrooms become very hard and are not pleasant to use. Also part of the valuable food and mineral contents are thrown away with the cooking water.

The mushrooms grow best in rainy weather, but for drying purposes they should be picked in the morning of a sunny day. Only mushrooms of the best quality should be dried, the others can be cooked for food on the same day.

Before drying, the mushrooms should be cut into slices about half a centimeter thick and spread loosely on to a mat or iron sheet. Mushrooms are dry enough if they make a snapping noise when you break them. If they are flexible, it means that there is still moisture inside them, and you must continue the drying.

Dried mushrooms should be preserved in a container with a cover to be protected from moisture. They may absorb moisture from moist air and then the dormant microorganisms recover and begin to spoil the mushrooms. Well dried and preserved mushroom will last until the next mushroom season and can be used after soaking in a small amount of clean water. Some nutritive elements dissolve in the soaking water, so do not throw it away, but use it when preparing the food. 


\begin{tabular}{|c|c|c|c|c|c|c|c|}
\hline & $\begin{array}{l}\text { Proteins } \\
\mathrm{g} / 100 \mathrm{~g}\end{array}$ & $\begin{array}{l}\text { Lipids } \\
\mathrm{g} / 100 \mathrm{~g}\end{array}$ & $\begin{array}{l}\text { Ash } \\
\mathrm{g} / 100 \mathrm{~g}\end{array}$ & $\begin{array}{l}\text { Carbo- } \\
\text { hydrates } \\
\mathrm{g} / 100 \mathrm{~g} \\
\end{array}$ & $\begin{array}{l}\text { Energy } \\
\text { value } \\
\mathrm{kJ} / 100 \mathrm{~g}\end{array}$ & $\begin{array}{l}\text { Potassium } \\
\mathrm{g} / 100 \mathrm{~g}\end{array}$ & $\begin{array}{l}\text { Magnesium } \\
\mathrm{g} / 100 \mathrm{~g}\end{array}$ \\
\hline $\begin{array}{l}\text { Termitomyces } \\
\text { microcarpus } \\
720\end{array}$ & 49,0 & 10,5 & 10,9 & 29,5 & 1740 & 3,5 & 0,17 \\
\hline $\begin{array}{l}\text { Termitomyces } \\
\text { sp. } \\
669 \mathrm{~b}\end{array}$ & 41,5 & 5,6 & 6,2 & 46,4 & 1710 & 1,9 & 0,13 \\
\hline $\begin{array}{l}\text { Termitomyces } \\
\text { sp. } \\
994\end{array}$ & 39,2 & 8,35 & 14,1 & 38,5 & 1640 & 2,6 & 0,17 \\
\hline $\begin{array}{l}\text { Termitomyces } \\
\text { microcarpus } \\
996\end{array}$ & 34,8 & 5,8 & 22,6 & 36,8 & 1440 & 1,6 & 0,16 \\
\hline $\begin{array}{l}\text { Termitomyces } \\
\text { eurrhizus } \\
556\end{array}$ & 33,5 & 2,9 & 5,6 & 57,6 & 1660 & 2 & 0,11 \\
\hline $\begin{array}{l}\text { Lactarius sp. } \\
\text { aff. } \\
\text { phlebophyllus } \\
1116\end{array}$ & 30,2 & 8,9 & 9,4 & 51,5 & 1730 & 2,9 & 0,86 \\
\hline $\begin{array}{l}\text { Termitomyces } \\
\text { letestui } \\
666\end{array}$ & 30,1 & 3,6 & 7,8 & 58,5 & 1640 & 3,3 & 0,11 \\
\hline $\begin{array}{l}\text { Termitomyces } \\
\text { letestui } \\
601\end{array}$ & 28,5 & 3,2 & 6,9 & 61,4 & 1650 & 2,9 & 0,90 \\
\hline $\begin{array}{l}\text { Amanita } \\
\text { zambiana } \\
1085\end{array}$ & 27,3 & 15,7 & 10,7 & 46,2 & 1850 & 3,9 & 0,11 \\
\hline $\begin{array}{l}\text { cultivated } \\
\text { Agaricus } \\
\text { bisporus }\end{array}$ & 27,0 & 8,0 & 8,0 & 57,0 & 1460 & 3,2 & 0,12 \\
\hline $\begin{array}{l}\text { Cantharellus } \\
\text { sp. } 682 *\end{array}$ & 25,3 & 6,0 & 19,2 & 49,4 & 1450 & 2,4 & 0,07 \\
\hline $\begin{array}{l}\text { Lactarius sp. } \\
\text { aff. pseudo- } \\
\text { volemus } 705\end{array}$ & 24,9 & 8,6 & 9,1 & 57,5 & 1730 & 4,6 & 0,09 \\
\hline $\begin{array}{l}\text { Cantharellus } \\
\text { sp. } 828^{*}\end{array}$ & 24,6 & 6,7 & 13,3 & 55,4 & 1610 & 5,0 & 0,15 \\
\hline $\begin{array}{l}\text { Cantharellus } \\
\text { sp. } 1104\end{array}$ & 22,8 & 15,3 & 10,4 & 51,4 & 1840 & 4,4 & 0,13 \\
\hline $\begin{array}{l}\text { Ramarioid } \\
\text { fungus } \\
703\end{array}$ & 21,1 & 7,4 & 18,7 & 52,9 & 1540 & 4,6 & 0,16 \\
\hline $\begin{array}{l}\text { Polyporus } \\
\text { moluccensis } \\
944\end{array}$ & 20,2 & 3,0 & 2,2 & 74,5 & 1730 & 0,8 & 0,06 \\
\hline
\end{tabular}


If the weather is not sunny, small amount of mushrooms can be smoked on a net over a fire place. Otherwise they are handled like the mushrooms dried in the sun.

\section{Poisonous mushrooms}

\section{Frequency of mushroom poisonings}

There are no statistics about the mushroom poisonings in Tanzania but in the mass media there are often stories about whole families who have been killed by mushroom poisoning. During our research journeys we got the impression that mushroom poisonings are rare in mountain areas where people use only two or three species of mushrooms. In miombo areas tens of mushroom species are used, which makes the identification much more difficult and poisonings caused by misidentification more common. On the other hand it is often difficult to tell if a mushroom poisoning has really happened or if the stomach problems are caused by usual food poisoning. In the beginning of the rainy season all foodstuffs including mushrooms have been stored for a long time and the warm and rainy weather may promote microbial growth on them. Some moulds and bacteria are toxic and may cause the food poisoning.

\section{Characteristics of poisonous mush- rooms}

Many Tanzanians believe that there are general characteristics by which one can identify a poisonous mushroom. These characteristics have been reported to us: slimy appearance, brown sporedust, habit of growth on decaying wood, presence of a ring, bad smell and taste, absence of maggots, forming of foam when boiled. All these are wrong arguments. Many maggots have enzymes to decompose the poisonous compounds. So the mushrooms which are safe for animals may be poisonous to humans. Some poisonous mushrooms have a bad taste, but the most dangerous ones are mild - this is the fact that makes them so dangerous, because one would not eat a bad tasting mushroom by accident. The most dangerous poisonous mushrooms do have a ring, but there are also edible mushrooms with a ring and some poisonous species without a ring. So, the only reliable way to avoid mushroom poisoning is to eat familiar edible mushrooms and not to experiment with unfamiliar mushrooms. In addition, it is best to know the most dangerous poisonous mushrooms.

\section{Fungal poisons}

Some fungi compose toxic metabolites. The toxity depends on the fungal species, but to some extent also on the environment and the age and even the part of the fungus. Some analyses show that the most poisonous part of the highly toxic Amanita phalloides is the volva. (Is it only by chance that Tanzanians cut off the volva of the edible Amanita tanzanica before cooking?) People are also different, some individuals showing more susceptibility to the toxins of fungi than the others. Children are the most sensitive in this respect.

There does not exist just one fungal poison, but different species have different toxic compounds with separate influences. There can be

Fig. 27. Nutritional value of some Tanzanian mushrooms analyzed in the State's Technical Research Center in Finland. The figure after the name refers to the corresponding specimen deposited in the Botanical Museum of the University of Helsinki; asterix refers to a specimen purchased as dried. The specimens are arranged according to the amount of proteins. The value are expressed in grams per $100 \mathrm{~g}$ dry weight, energy value is $\mathrm{kJ} / 100 \mathrm{~g}$. The values of cultivated champignon, printed in boldface, is added for comparison. 
poisonous species in different parts of the fungal system, although some genera like Amanita and Lepiota have several poisonous species. Some toxins can be destroyed by boiling, but some are very stable. The fungal poisons can be divided into different groups according to their influence. We discuss such groups which are essential for Tanzanians.

\section{Cell damaging poisonings}

The cell damaging or cytolytic poisons destroy especially the cells of liver and kidneys that have a high metabolic activity. The most dangerous poisonous mushroom in the world, Amanita phalloides (UYOGA MAUTI WA INZI), belongs to this group. It has caused more deaths than all the other poisonous mushrooms together. It is not indigenous to Tanzania, but in his book "Preliminary Agaric Flora of East Africa" D.N. Pegler mentions that it was found in 1968 in Eucalyptus and Acacia plantations in Mufindi, in Iringa District. That is why we include its description in this guide (see page 59), although we have not found it in Tanzania ourselves.

The toxic compounds in Amanita phalloides are amatoxins and phallotoxins. The mushroom does not irritate the stomach at first so that a person would begin to vomit. The first symptoms usually begin within $8-15$ hours after eating. The symptoms are: stomach pains, nausea, vomiting, diarrhoea and intense thirst. This is followed by an apparent recovery, but unnoticed, the poison effects the liver. After about three days, when the liver damage has occurred, the symptoms begin again and often death results.

If the poisoning has been noticed in good time, vomiting and the eating of activated charcoal to absorb the poison from the digestive system can be used as treatment. A simple and safe method to cause vomiting is to drink lots of clean water and then insert the patient's fingers deep in the throat until vomiting starts. If the poisoning is noticed later, these activities do not help but might only tire the victim out. The patients of this type of cell damaging poisoning should always be taken to hospital. Taking care of the dehydration of the patient is essential for recovery. Big doses of penicillin and a relatively new medicine, sibilin, are used as treatment in western countries.
If Amanita phalloides has been or if it will be accidentally introduced to Tanzanian tree plantations, the people seeking for ULELEMA (Amanita zambiana) should be aware of its characteristics, because there are certain resemblances between these two species.

Several small species of the genus Lepiota also contain cytolytic poisons. They do not resemble closely any mushrooms eaten in Tanzania, but might attract ignorant children. They are mostly very pretty mushrooms with a scaly cap and a ring on the stem. Their cap is mostly under $5 \mathrm{~cm}$ in diameter and the gills are white. They might be confused with small champignons (Agaricus species), which most Tanzanians, in contrast to Europeans, do not eat. Fully developed champignons have dark brown gills. Some Tanzanians eat the big relatives of the genus Lepiota, the Macrolepiota.

\section{Psychotropic poisonings}

The psychotropic mushroom poisons effect the nervous system. The symptoms might be like those caused by alcohol (which also is a fungal product produced by a yeast fungus). The stimulation of the nervous system may cause sweating, salivation, dizziness, difficulties in seeing and low blood pressure. Hallucinations and possibly also delirium may occur. The most famous poisonous mushroom of this type is the Red Fly Agaric, Amanita muscaria, UYOGA MWEKUNDU WA INZI. This mushroom has in earlier times been purposely used in northern Siberia and Europe to induce hallucinations.

The poisons involved are muscimol, ibotenic acid, muscazone, and muscarine in very small amounts. The symptoms appear within twenty minutes to four hours after eating the mushroom, and usually last only a couple of hours and often cause unconsciousness. According to western literature, recovery is usually good without risk of permanent injuries. In Tanzania, however, several deaths have occurred. This mushroom is not indigenous to Tanzania, but has been accidentally introduced in some pine plantations.

Another famous group of psychotropic mushroom poisons includes psilocin and psilocybin that Meso-American Indians have used for centuries to intoxicate themselves for religious rituals. Psilocybe cubensis is the best 
known species of this kind. We did not find any hallucinogenic use of mushrooms in Tanzania and not even accidental poisonings. Several species of Psilocybe grow in Tanzania. From Kenya some poisonings by a species Psilocybe merdaria have been reported. The poison was described as effecting the central nervous system, causing fits of laughing and crying and loss of muscular coordination, but no vomiting. Species of Psilocybe are relatively small, brown mushrooms with violaceous brown spores which make the mature gills dark. Most species grow on dung. Some have a ring. Tanzanians do not eat mushrooms like this. We, however, wish to warn about little brown mushrooms growing on dung. Among them there are also other poisonous species, not only the Psilocybe.

\section{Hemolytic poisonings}

Hemolytic poisons result in the breaking up of red blood cells and in this way lead to anaemia. The best known poisonous mushroom of this type in Europe is Amanita rubescens, commonly used for food. The poisonous qualities of this mushroom have been detected only recently since the poisons are inactivated by heat and are effective only in raw or poorly cooked mushrooms. It is suspected that also Amanita vaginata contains this kind of poison. Tanzanians eat many species of the section Vaginatae, including the highly appreciated WIGWINGWI. Just to be sure, we advise: Never eat even a familiar Amanita without proper cooking.

\section{Poisonings causing gastrointestinal symptoms}

Gastrointestinal symptoms mean the irritation of the digestive system. The symptoms, stomach pain and vomiting, begin soon (twenty minutes to two hours) after eating this poisonous mushroom. Usual food poisoning caused by rotten mushrooms also has symptoms like this. Vomiting removes the mushrooms from the stomach and no special treatment is needed. Resting and giving activated charcoal to absorb the poison may help. If the vomiting is very severe, it may cause dehydration. This can be cured in hospital by giving intravenous fluid. Recovery from this type of poisoning is usually complete.

Chlorophyllum molybdites, a widespread tropical species causes a gastrointestinal upset of varying severity involving thirst, nausea, vomiting and diarrhoea. It is common in Tanzania growing in groups among the grass. It is a beautiful mushroom with relatively large fruit bodies, with a long, thin stipe and a movable ring. The cap is cream-coloured and scaly. The gills of the fully developed fruit body are pale green. It resembles some tall edible Macrolepiota. Many Tanzanians to whom we showed Chlorophyllum knew that it is poisonous. Some considered Macrolepiota as edible; others as poisonous. This shows that probably these two species have often been confused. People who use Macrolepiota for food, should be careful not to collect mushrooms with greenish gills.

\section{The macroscopic identification of mushrooms}

The most important thing when collecting mushrooms is the correct identification. If you cannot recognize the specimen in the field you can study it at home. For that purpose you have to take a couple of undamaged fruit bodies with you, preferably placed in a separate paper bag. Specimens have to be dug up unbroken from their substratum and they have to be handled carefully so that all the necessary features remain and can be observed later.
To identify mushrooms, you must be familiar with the characters and terms used for this purpose.

\section{Cap (pileus)}

Size. The size of fruit bodies varies considerably and is rarely used alone for identification. The size range given in the description should not be 
taken literally since the size depends on the age and growing conditions of the mushroom. Size dimensions are taken by measuring the widest diameter of the pileus, and with conical or bellshaped caps also its greatest height.

Shape. The shape of a young and old cap can be so different from each other that a range of shapes is usually given in the description. The commonly used terms about cap shape can be seen in Fig. 28.

Colour. Colour is an essential character in species descriptions, but often very difficult to express. A problem is that common terms for colours are not used uniformly. Standard colour charts exist but are neither very practical nor easily obtainable. More practical is to relate colours to everyday objects.

The colour of the cap varies with age and growing site. It can be different in the central part and margin and in a wet or dry condition. In species of Russula the colour pigments are soluble and during heavy rains colours may fade strongly.

Surface. The surface of a cap is called shiny when it looks as if it were polished, silky, when it looks like it is made of silk and matt or matted, when it lacks luster.

The surface may be dry or wet. If the cap surface has absorbed much water and resembles liquid glue, it is called glutinous, and gelatinous when it is jelly-like. A viscid surface has absorbed less water and feels sticky when touched. In very dry weather a viscid surface dries up. You can guess its original nature from the dead leaves and other particles stuck to the surface.

When the surface of a cap is split or cracked, it usually happens radially. Areolate means that irregular splits and cracks divide the surface into small areas resembling a mud flat when it dries up. The surface may have small depressions, then it is called scrobiculate, or it may be marked with different lines, ridges, grooves or wrinkles. If the cap has none of these features it is smooth.

The hyphae on the outer surface of a cap can form different textures. If the surface looks absolutely bald and smooth it is said to be glabrous. If it has a powder- or flour-like covering, the surface is called pruinose or pulverulent. If the powder is larger, like sand, then it is called granular. When the hyphae endings stick together laterally and push through the cap surface the cap is, more or less hairy. Fibrillose is used when the surface is covered with silk-like fibres, floccose refers to a cottony appearance, velvety or velutinous describes a surface with compact, short and soft hairs. When only the tips of the hyphae stick together, scales are formed and the terms squamose or scaly are used. Scales may be flattened, erect or curved.

The occurrence of veil remnants on the cap surface is typical in several genera (for example Amanita). The veil that covers a young mushroom during its early stages ruptures as the mushroom develops and patches of it may stay attached on the cap surface (see Fig. 29).

Margin. When young, the cap margin of a fruit body is usually entire, unbroken. As it develops and gets larger it may become broken off in different ways. If the margin has a broadly wavy form it is called undulating. If the interruptions are regular, rounded projections, the margin is said to be crenate. If the projections are very small the term crenulate or crisped is used. If the margin is irregular, it is said to be eroded. Sometimes remains of the partial veil may stay attached at the edge of cap forming a fringed margin called appendiculate.

The surface of the margin may be smooth, split or marked with different radial lines, grooves or ridges at the cap surface. A cap, with lines at the margin is called striate.

If the cap is cut in half it can be seen how the margin is curved. Different types of cap margins can be seen in Fig. 28.

\section{Gills and pores}

Gills (lamellae, sing. lamella) and tubes on the underside of the cap are the place where spores developed. Boletes and polypores have tubes. Gills have more characteristics than pores and they are important in identifying mushrooms.

Spacing of gills. Crowded means that the gills are so close to each other that no space between them can be seen. For other types of spacing of gills see Fig. 28.

There are gills of several lengths because all of them do not extend from stipe to cap margin. Short gills are called lamellulae (sing. lamellula). If the gills branch into two parts they are said to be forked or dichotomous. 


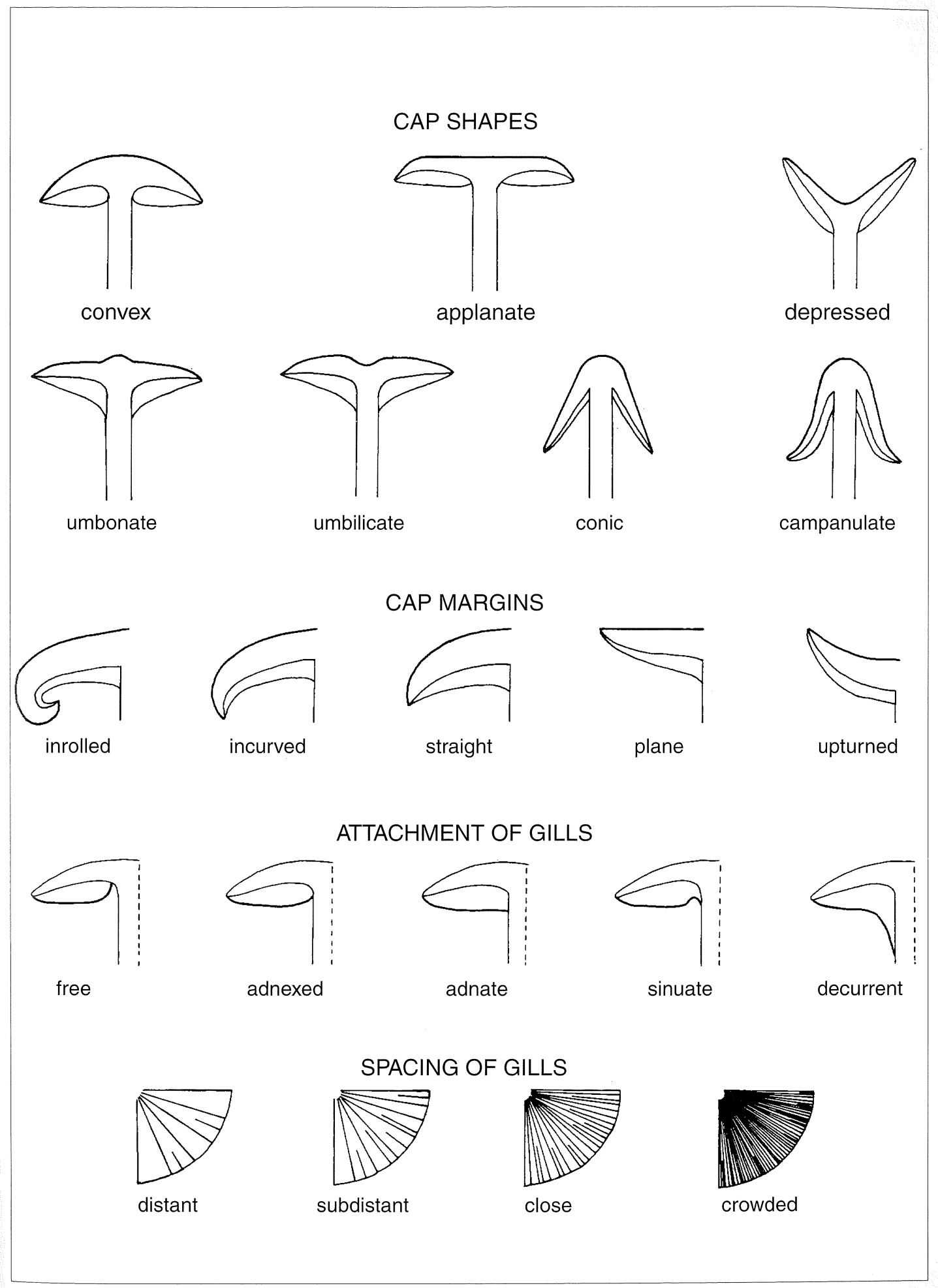

Fig. 28. Significant characteristics of cap and gills. 


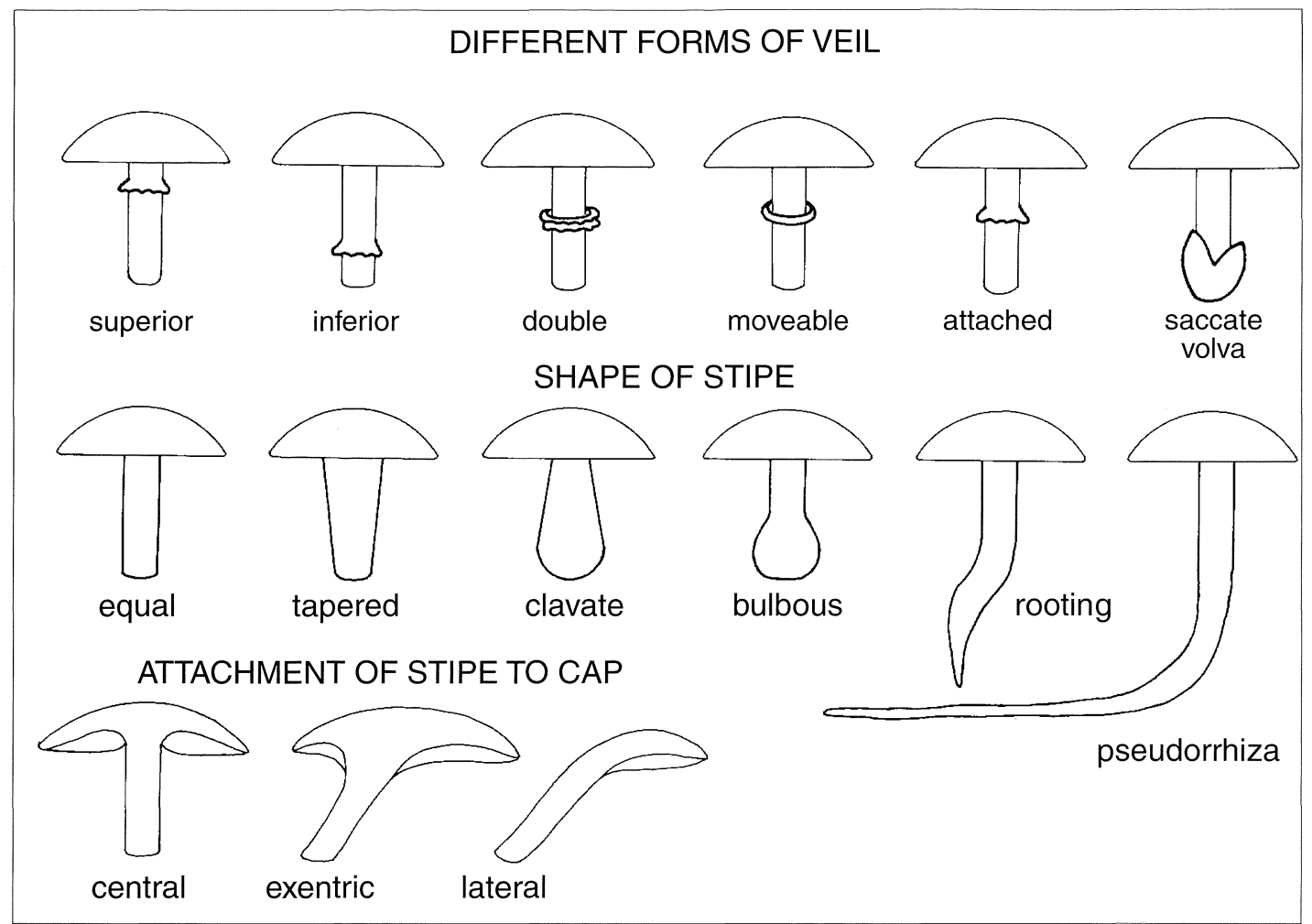

Fig. 29. Important craracteristics of stipe.

Attachment. To see how the gills are attached to the stipe the specimen has to be cut longitudinally. Different types of attachment are illustrated in Fig. 28.

- Free gills do not meet the stipe at all and a circular gap is formed around the stipe.

- Adnexed gills are narrowly attached, so that the uppermost part of their width only joins the stipe.

- Adnate gills are widely attached, so that the entire width joins the stipe.

- Sinuate gills are notched at the point where they meet the stipe and the gills are attached only narrowly.

- Decurrent gills extend downward on the stipe, if only shortly the term subdecurrent is used.

Margin of gills. Many species have fairly smooth gill edges, but they may also be inter- rupted to a certain degree. If the edge is minutely torn or ragged it is called fimbriate, if edged with teeth, like a saw, the term serrate is used. The edge may be wavy. If the waviness is irregular with fringed waves it is called eroded, when regular with rounded teeth it is crenate. When the teeth are very small and delicate the term crenulate or crisped is used.

Sometimes the margin is coloured differently from the rest of the gill, then it is called marginate.

Colour of gills. Gill colour is an important feature. There may be a difference between the colour of the margin and side and a difference between the colour of immature and mature gills. In older caps spores dye the gills. For instance the unique green colour of the gills in Chlorophyllum molybdites is notable not until the green spores are mature.

In many species of the genus Coprinus the gills turn into a black, ink-like liquid after the spores have matured. 


\section{Stipe}

With the aid of a stipe a fungus is attached to its substratum. Different types of attachment of the stipe to the cap can be seen in Fig. 29. Gillbearing fungi are seldom without stipes, but polypores are usually stipeless or short-stiped.

Size and shape of the stipe. When giving the size of a stipe, its length from the substratum to the attachment of gills and diameter are measured. The diameter is usually measured at the apex, middle and base. The measurements vary a great deal and often a general description of the appearance, such as stout or thin, tells a lot.

Different types of stipe can be seen in Fig. 29. Sometimes the narrowed stipe base is elongated and buried deeply into the material, forming a rooting stipe. In the genus Termitomyces the rooting part in most species extends to the underground termite nest and is called pseudorrhiza.

The same terms used for the surface of the cap can be used for the surface of the stipe.

\section{Veils}

The presence or absence of veils is linked with the development of a fruit body. See page 24 and 25.

When the partial veil, which covers the developing gills, ruptures, remnants may be left on the cap margin and on the stipe as a ring.

In some fungi the ring is hardly noticeable whereas in others (for instance Macrolepiota) it is distinctive and important in identification. Different placements and forms of rings can be seen in Fig. 29.

If present the universal veil envelopes the entire immature fruit body (see Fig. 21) and ruptures as the mushroom matures leaving remnants on the cap surface and/or around the stipe base. A cup-like structure surrounding the stipe base is called volva. It is characteristic of certain genera, of which Amanita is one.

\section{Context (flesh, trama)}

You can see the context by cutting the fruit body. The colour and possible colour changes are typical to species. If colour changes occur they may happen immediately, after a couple of minutes or there may be several stages.

Consistency of the flesh can vary between genera and species. For instance in the genera Russula and Lactarius, a brittle, non-fibrous context is characteristic. Consistency of the cap may as well be soft, fibrous, firm, tough or rubber-like. For the stipe the term solid is used if the flesh is compact but if the center becomes empty it is called hollow. An intermediate stage between these two is stuffed where the central part is filled with cottony tissue. If separate cavities are formed in the stem, it is called chambered.

Smell and taste also need to be recorded. Smell is best experienced from the gill side or breaking a piece of cap with your fingers. Some mushrooms have a typical smell, for example that of Termitomyces letestui resembles fresh groundnuts. It is practical to describe smells by refering them to everyday objects. Often one can only say if the smell is pleasant or unpleasant. Sometimes the smell is not detectable until the mushroom has dried.

Taste can be experienced by chewing a small piece of a cap. If the mushroom is unfamiliar never swallow but spit every fragment out! There are three basic tastes: mild, hot or peppery and bitter. Remember that taste is seldom used as the first criterion when identifying mushrooms and mild taste is not a guarantee of the edibility. Many poisonous species have a mild taste.

Latex. Some fungi (for instance Lactarius) have lactiferous hyphae in their trama that contain milk-like juice. When the fruit body is cut or broken, this liquid exudes from it. The amount of milky latex can vary a lot according to species, age and place of trama. The colour of the latex and possible colour changes should also be noted.

\section{Growth habit}

For some species it is typical that fruit bodies grow solitary, far away from each other so that they appear alone (see Fig. 30). If several fruit bodies are situated here and there, at moderate distances, the growth habit is called scattered. When fruit bodies are in groups where individuals are close together but not attached, the term 


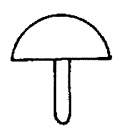

solitary

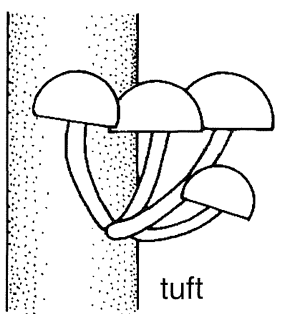

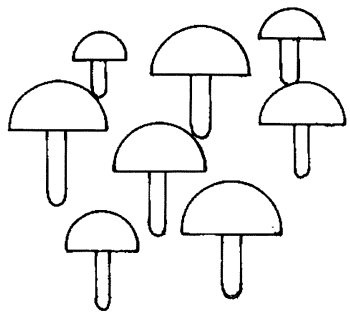

gregarious

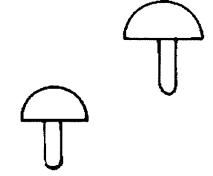

scattered
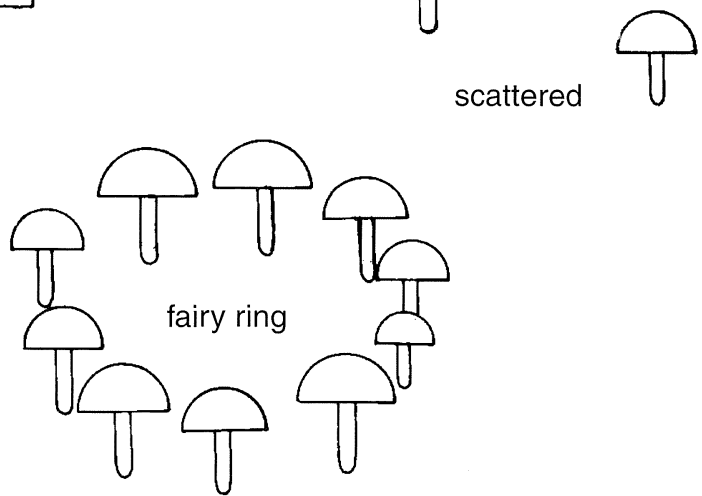

Fig. 30. Growth habit of mushrooms.

gregarious is used. If they are so close that the base parts of the stipes are attached to each other, the mushrooms are said to grow in tufts or clumps. The tufty growing habit is typical for some wood-inhabiting mushrooms.

Some mushrooms produce "fairy rings" as they grow. These circles, frequent in grass, are formed because the mycelium grows always outward from the point it started.

\section{Spore print}

The classification of the fungi is based partly on the colour of the spore print. Spore prints can be taken from agarics, boletes, chanterelles, and polypores, but not from puff balls. Every genus has its own typical spore colour, although different shades may exist. The following are the categories that are commonly used:

1) Spores white, cream, yellowish, or greenish

2) Spores pink

3) Spores various shades of yellow-brown or brown

4) Spores purple-brown to black

To take a spore print you must select a mature and fresh fruit body. Cut the cap from the stipe and place it on a piece of paper with the gill-side down (see Fig. 31). Then put the specimen in an undisturbed place and cover it with some vessel or jar to prevent the air currents. The fresh cap shoots actively ripe spores from the gills onto the underlying paper. After a couple of hours you can already tell the colour of the spores, but to get a perfect spore print, let the spores discharge over night.

Sometimes you may tell the colour of the spores already by looking at the gills. If the mushrooms grow in tufts and caps are piled on top of one another, spores can be found on the surface of the lower caps.

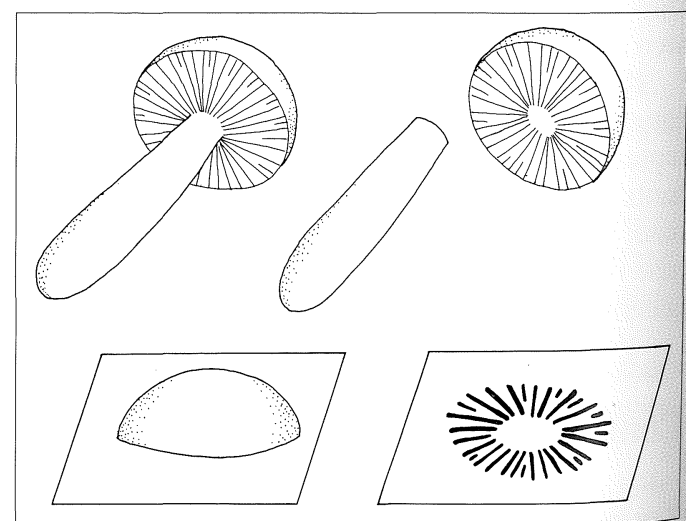

Fig. 31. How to take a spore print. 


\section{The microscopic identification}

The naked eye is not always enough for identification. A microscope, equipped with a micrometer for measuring, is used. Nowadays the classification of fungi is largely based on the microscopic features.

Material to be examined, often tiny fragments of fungal tissue, is placed on a glass slide onto which drops of a selected chemical are added. Chemicals are used in mycology to wet or swell the dried material, to stain hyphae and structures to make them better distinguishable, or as a reagent to show different reactions.

\section{Spores}

Colour, size, ornamentation and shape are important when studing spores. In the species descriptions the given spore features are based on mature spores. If you study spores from a spore print most of them are mature, but a slide made of a gill fragment contains spores of all stages.

When determining spore size, the length and the width of the spore are measured. The length of basidiospores varies from 2 to $50 \mu \mathrm{m}$. The measurements are taken from spores which can be seen profile.

The spore wall may be smooth or may have protrusions of different size, shape and regularity which form the ornamentation. In Figs. 39-41 different types of ornamentation are shown.

Spore shape can vary greatly from globose through cylindrical to angular. The spore may be symmetrical or asymmetrical.

Chemical reactions of spores are usually determined with Melzer's reagent, Cresyl Blue and Cotton Blue.

Amyloid spores turn greyish to blackish blue in Melzer's reagent. Inamyloid spores do not react at all and they stay yellow (the colour of the Melzer's reagent). In some fungi (e.g. Macrolepiota) spores turn strong reddish brown. These are called dextrinoid (pseudoamyloid).

\section{Basidia}

Basidia develop on gills or tubes side by side forming a spore-bearing layer, the hymenium (Fig. 20). In agarics and boletes basidia are single-celled, have usually four spores and are clavate in shape (Fig.35). Each spore is born by an extension of a basidium called sterigma. Young, immature basidia, basidioles, are similar in shape to basidia but smaller and lack sterigmata.

\section{Cystidia}

Cystidia are differentiated, sterile cells occuring on any surface of a fruit body, either as terminal cells in the hymenium or at cap or stipe surface. The function of cystidia are for the most part unknown but they are useful in the identification. Some of the cystidia are smooth and thin-walled like basidia, but usually cystidia can be distinguished from basidia on the basis of their larger size and different shape. Some of the cystidia may be thick-walled and/or they are covered with encrustations at the apex. Some may have visible contents.

Cystidia have been classified and named according to several features. One of the classifications is based on their position. 1) Dermatocystidia (dermis $=$ skin) occur on the surface of a fruit body. There are two types: pileocystidia, those on the surface of the cap, and caulocystidia, those found on the surface of the stipe. 2) Hymenial cystidia occur in the hymenium. There are two types: cheilocystidia, those at the edge of a gill, and pleurocystidia on the side of a gill.

Shapes of cystidia are numerous. Some of them are illustrated in Fig. 33.

\section{Other features}

Features concerning the outer surface and inner part of the fruit body are widely used and important when studing fungi under a microscope.

Pellis or cuticle is a sterile, cellular covering of the basidiocarp which sometimes may be peeled off. It is distinguished according to its position. The pellis of the stipe is called stipitipellis and that of the cap is called pileipellis.

The inner part of the fruit body is called context, or flesh or trama. The context consists of hyphae. In the genera Lactarius and Russula there are also globose sphaerocytes besides hyphae, which explain the brittle nature of the flesh. 

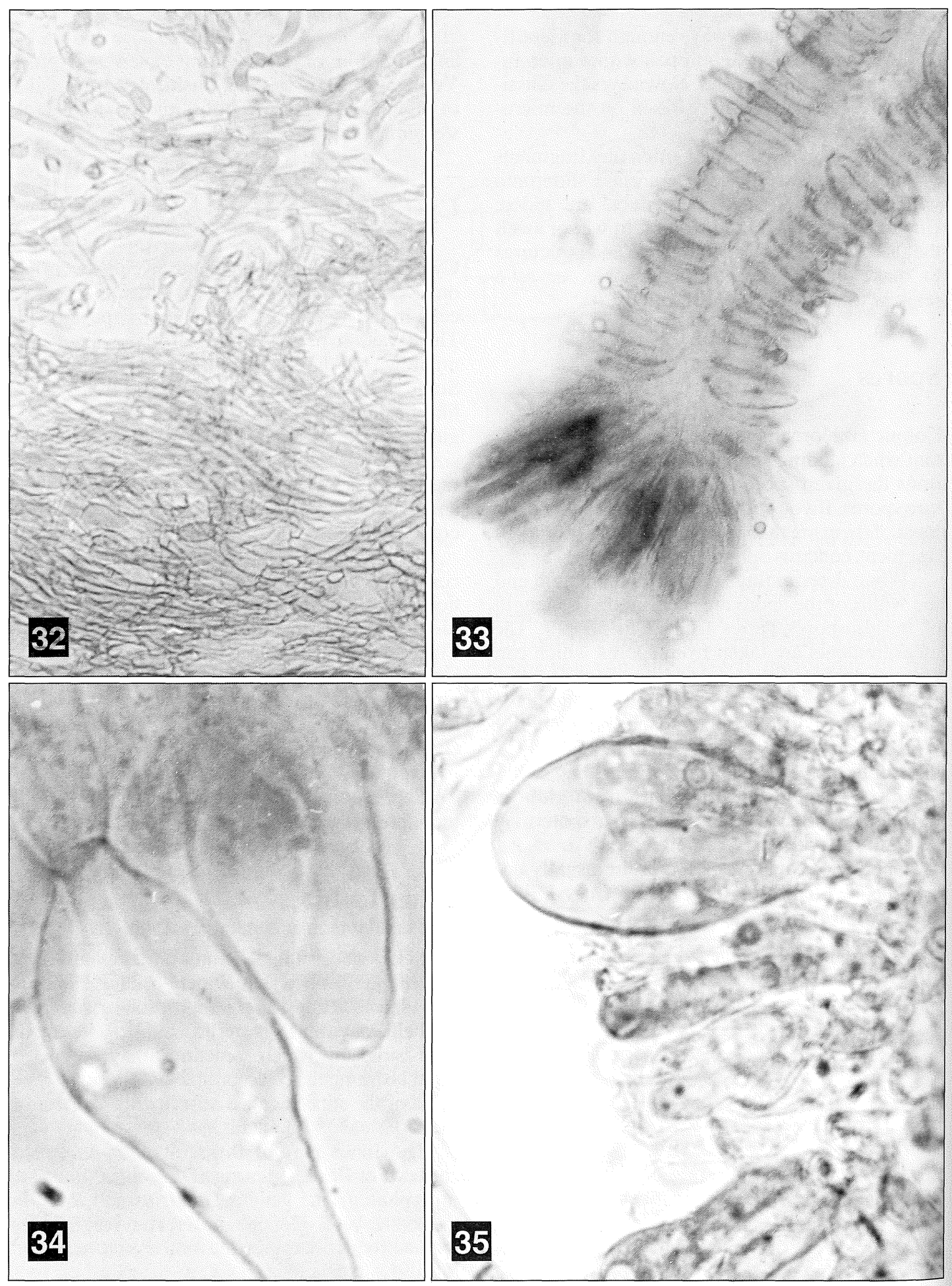

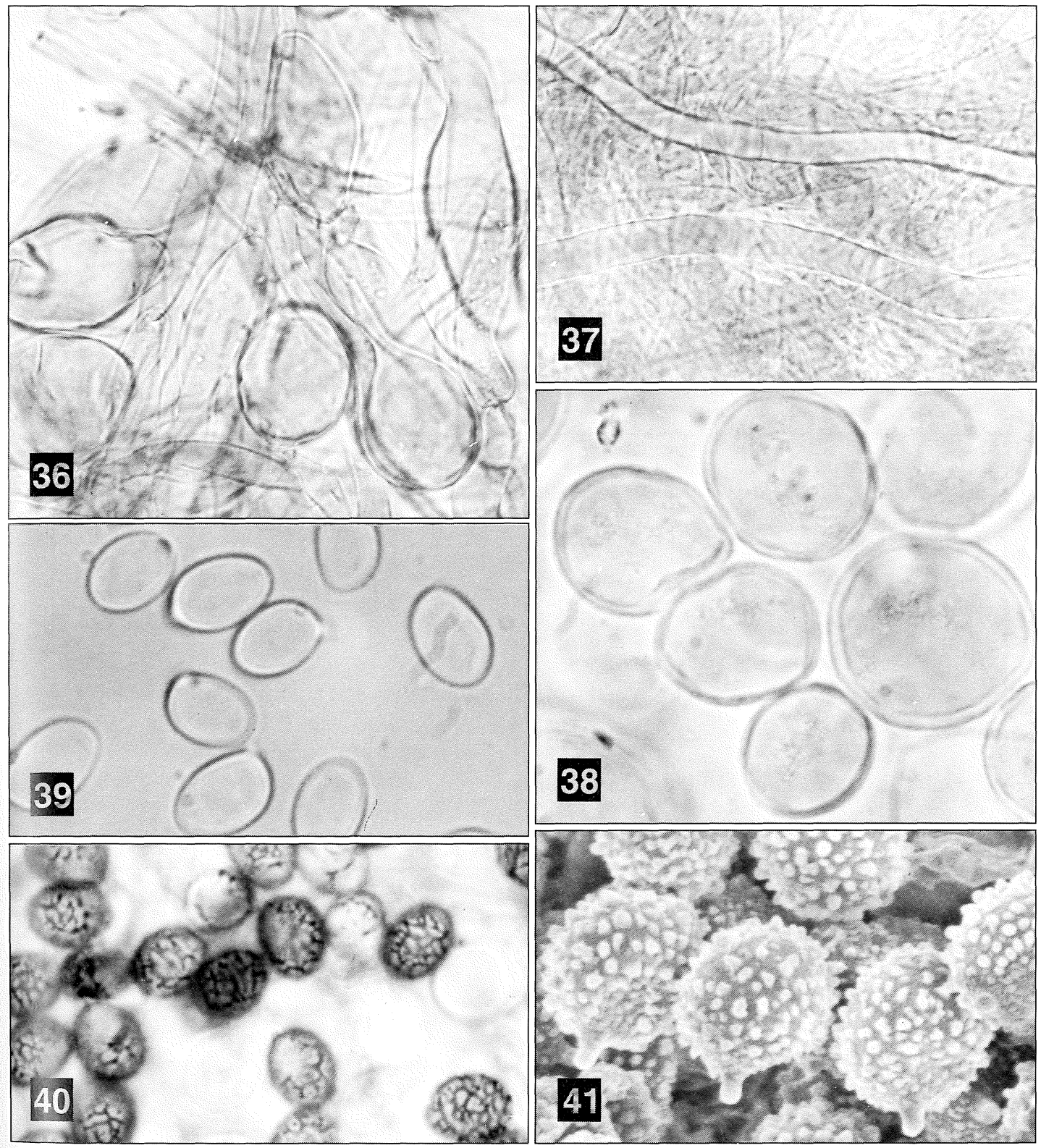

Figs. 32-41. Some microscopic details photographed from Tanzanian specimens. - 32: The hyphae in longitudinal section of the pileipellis of Termitomyces singidensis. - 33: A section of a gill of Russula subfistulosa. On the sides of the lamella, there are very large cystidia. The apex of lamella is entirely occupied by large pigmented marginal cells. - 34: Cheilocystidia from the gill apex of Termitomyces singidensis. - 35: Pleurocystidium (the large cell) and basidia from the gill side of Termitomyces singidensis. - 36: Inflated cell endings of the hypha from the stipe of Amanita tanzanica. - 37: Lactiferous hyphae of Amanita tanzanica. - 38: Sphaerocysts from the annulus of Termitomyces singidensis. - 39: The smooth spores of Amanita mafingensis. - 40: Reticulate spores of Lactarius luteopus Verbeken. - 41: A SEM photo of the strongly ornamented spores of Russula usambarae Buyck. 


\section{Descriptions of the species}

The stars $(*, * *, * * *)$ after the name refer to the edibility of the species according to the interviews held among Tanzanians.

$$
\begin{array}{lll}
* & = & \text { edible } \\
* * & =\text { good } \\
* * * & =\text { delicious }
\end{array}
$$

Poisonous mushrooms are indicated as follows:

$$
\begin{array}{rll}
\dagger & = & \text { weekly poisonous } \\
\dagger \dagger & = & \text { very poisonous } \\
\dagger \dagger \dagger & = & \text { deadly poisonous }
\end{array}
$$




\section{Termitomyces}

\section{UYOGA-MCHWA}

This is a tropical genus and well represented in Tanzania. Typical of it is the symbiotic life together with termites. Termites cultivate the mycelium in their nests and fruit bodies can be seen arising on or near the mounds. Due to this symbiosis, species of Termitomyces possess a characteristic that distinguishes them from all other gilled fungi: a central stipe which is prolonged into an underground pseudorrhiza, a root-like extension, connected to the fungus comb. Other features of the genus are a prominent, often very sharply differentiated umbo or perforatorium on the cap, free gills and a pinkish spore print.

All species are edible and most are considered superior to all other mushrooms. Also their nutritive value is very good as can be seen in Fig. 27.

\section{Termitomyces aurantiacus Heim}

MGUNDA ** Fig. 42

Vernacular names: WIDUNGU (Bena), KIGONG'ONGO (Bondei), VIDUNGWE (Hehe), KAKUO (Ndendeuli), MANDONDO, MGUNDA, UNGALA, VIGONG'ONGO (Ngoni), VIGONG'ONGO (Sambaa).

Edibility: edible. This is one of the first species to occur at the beginning of the rains and much used. According to local people the taste of it is average compared to other Termitomyces species.

Cap 4-9 cm in diameter, at first subglobose to conical, then convex-applanate with a small conical, pointed perforatorium; surface ochre to orange, darkening reddish brown on the perforatorium, radially fibrillose-striate and often concentrically scrobiculate, usually splitting at edge, slightly viscid when moist,

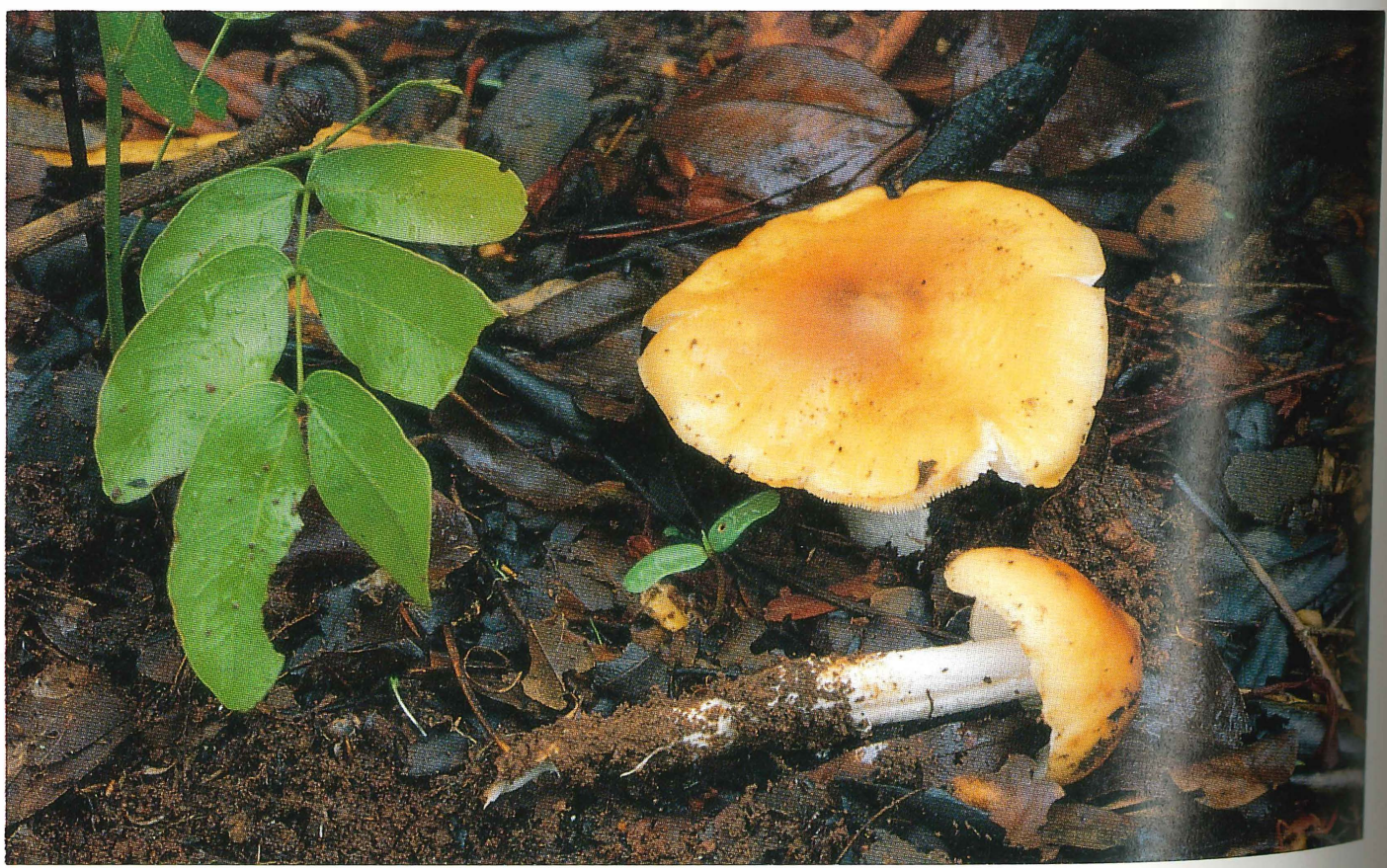

Fig. 42. Termitomyces aurantiacus, MGUNDA, is one of the first mushrooms to appear in the fields at the beginning of the rains. This specimen was photographed in Mtonya village in Songea district. 
peeling up to the umbo. Gills crowded, free to sinuate, serrate, whitish, fairly thin, up to 7 $\mathrm{mm}$ broad. Stipe variable in length, cylindric, up to $12 \mathrm{~mm}$ in diameter, sometimes slightly swollen before tapering into a slender, white pseudorrhiza; surface white, often marked with fine tufts of veil remnants. Context white, thin and firm in cap; fibrous in stipe. Smell rubber-like or mushroomy. Taste mild. Spore print pinkish cream.

Habitat: most often in areas cleared for cultivation.

This species occurs in many parts of Tanzania. It is common at the beginning of the rains. It occurs scattered most often in cultivated fields occupied by termites.

Spores 6-7.2 × 3.5-4.5 $\mu \mathrm{m}$, ellipsoid, hyaline with few contents. Basidia 20-26 × 6-8 $\mu \mathrm{m}$, clavate, 4-spored.
Lamella edge with basidia and numerous cheilocystidia. Cheilocystidia $17-48(-73) \times 10-22(-31) \mu \mathrm{m}$, variable in shape, pyriform, clavate, ovoid or utriform, usually with one pedicellate cell. Pleurocystidia similar to the cheilocystidia. Hymenophoral trama subregular. Pileal surface gelatinized, consists of uninflated septate hyphae, 2-8 $\mu \mathrm{m}$ in diameter. Hyphae without clamp connections.

Termitomyces eurrhizus (Berk.) Heim

KIMELO *** Fig. 43

Vernacular names: CHOVA (Hehe), LUTUTELU, UNGUBALI, USUMBA (Kinga), KIMELO (Nyakyusa), KICHOGA CHA NG'OMBE (Pare).

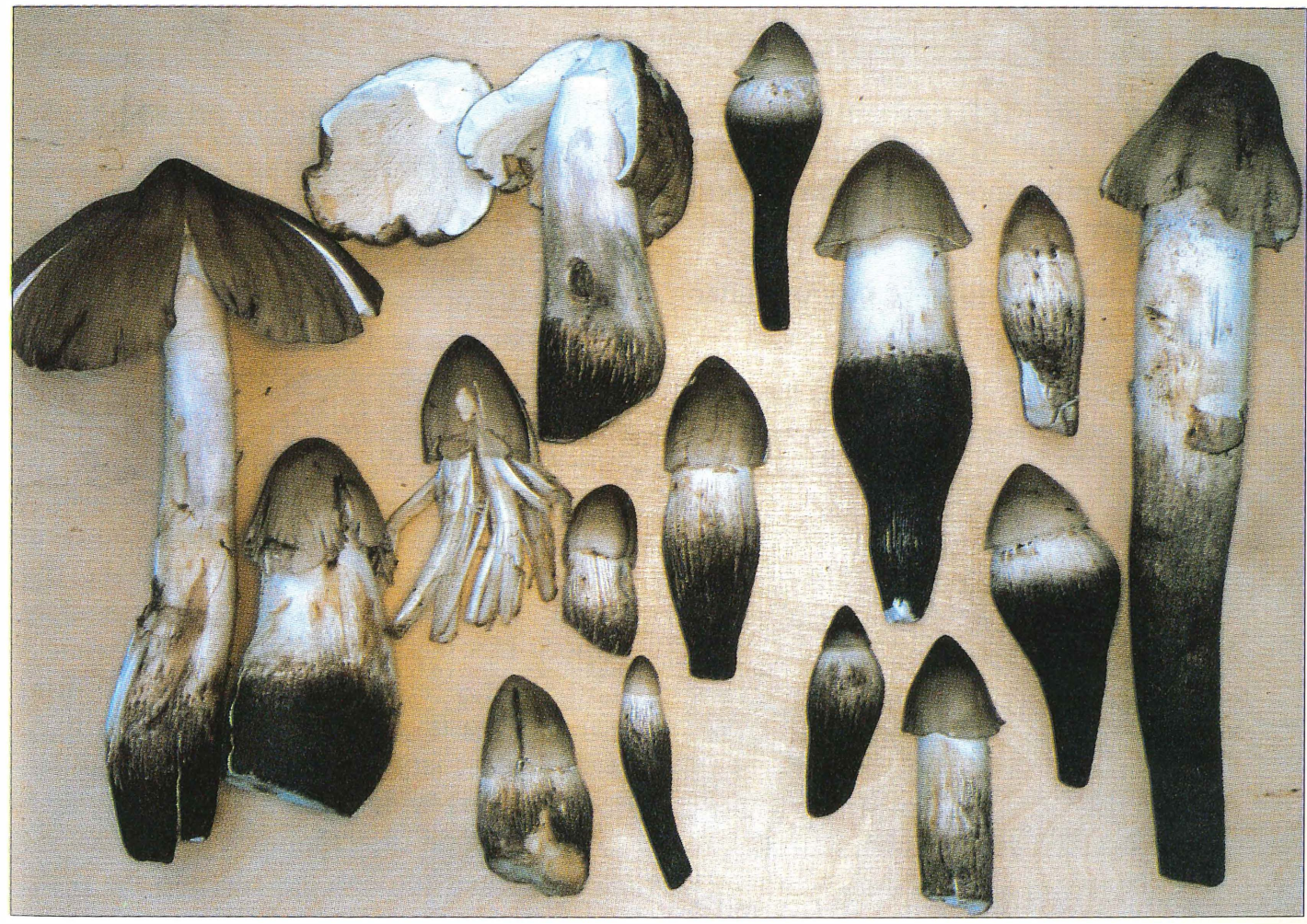

Fig. 43. Termitomyces eurrhizus, KIMELO, is common in mountain areas. These specimens were collected by children on the Pare Mountains, all around the village of Mbaga Manka. Local people call it cow's mushroom, KICHOGA CHA NG'OMBE in Pare language. 
Edibility: edible and delicious. The mushroom has to be dug with care from the soil, as there is much to eat in the underground parts. The root-like pseudorrhiza is scraped with a knife to remove the soil. This species needs long cooking, at least half an hour, because of the firm flesh. The food resembles that made of chicken. This species is seldom preserved for later use.

Cap 7-22 cm in diameter, at first conic to campanulate, then flattened with a broad perforatorium; surface dark greyish brown over the perforatorium becoming usually paler towards the margin, sometimes entirely brown, radially rugose and silky striate, viscid when moist; margin slightly incurved, splitting with age. Gills adnate to free, crowded, first cream then pinkish, later with a rusty tint, up to $12 \mathrm{~mm}$ broad. Stipe above ground level cylindric, $1-4 \mathrm{~cm}$ in diameter at central part attenuating slightly towards the apex, surface white, fibrillose; below ground level the stipe expands up to $4.5 \mathrm{~cm}$ in diameter before tapering to a narrow, black striate pseudorrhiza. Context fleshy and firm, up to $10 \mathrm{~mm}$ thick, white; in stipe fibrous, solid, white. Smell mild and weak. Taste mild, pleasant. Spore print brownish pink.

Habitat: cultivated fields, vicinity of underground termite nests.

The special character of KIMELO is the thick pseudorrhiza, which is black below ground level. It is a common species in the mountainous areas and esteemed as delicacy by the local people. In the North Pare Mountains mushroom food is given to women after childbirth to help in recovery. In the South Pare Mountains this species is used for skin diseases in a mixture with other ingredients. Another related species Termitomyces globosus has the same vernacular name. The relations between these species need a scientific revision.

Spores 6.8-10 × 4.1-6.0 $\mu \mathrm{m}$, ellipsoid, hyaline, smooth. Basidia 20-28 × 7-10 $\mu \mathrm{m}$, clavate, 4-spored. Lamella edge sterile with crowded cheilocystidia. Cheilocystidia 15-57 $\times$ 7-27 $\mu \mathrm{m}$, mostly pyriform, also obovoid. Pleurocystidia 20
$56 \times 9-29 \mu \mathrm{m}$ pyriform. Hymenophoral trama regular of hyphae $3-5 \mu \mathrm{m}$ in diameter. Pileal surface composed of hyaline, repent hyphae 2-7 $\mu \mathrm{m}$ wide, covering radially parallel hyphae with inflated cells up to $20 \mu \mathrm{m}$ broad. All hyphae lacking clamp connections.

\section{Termitomyces letestui (Pat.) Heim}

MKUFU *** Fig. 44

Vernacular names: UKURU, WIKULU, WIKULWE (Bena), KITUNDWI (Bondei, Sambaa), CHIKUFU (Gogo), WIKULWE (Hehe), WIKULWA, UNYANYARUSI (Kinga), NEMBO (Kwere, Ngulu), KIBWAGALE, NNG'UVU, UYOGA NYIKA (Luguru), MKUFU, VITUNDWI (Ngoni), BUHIMA, KITUNDU, NYAMUKUNDI (Nyamwezi), UVUMBU (Nyiha), VITUNDWI (Sambaa), BUHIMA (Sumbwa), NG'UVU, TEMBO (Zaramo).

Edibility: edible and highly prized. Prepare as KIMELO (page 47).

Cap at first subglobose and involute then convex to applanate, up to $34 \mathrm{~cm}$ in diameter when fully opened, always with a blunt, cylindric or convex perforatorium. Surface cream to light-brown at margin becoming brown to sepia towards the center, sometimes concolorous, matted-fibrillose, felted tomentose becoming finely squamulose at the disk. Gills free, whitish to cream with pinkish tint, crowded, thin, up to $12 \mathrm{~mm}$ broad, edge sometimes slightly crenulate. Stipe 5-15 $\times 1-3.5 \mathrm{~cm}$, cylindric, solid, white or whitish, tapering gradually into a long pseudorrhiza up to $1 \mathrm{~m}$ long. Annulus thick, membranous, striate above, superior, and pendant. Context white, firm to soft in cap, up to $25 \mathrm{~mm}$ thick, in stipe fibrous. The fibrous context continues through the cap into the perforatorium. Smell strong and pleasant, like fresh peanuts. Taste mild, pleasant. Spore print pinkish cream. 


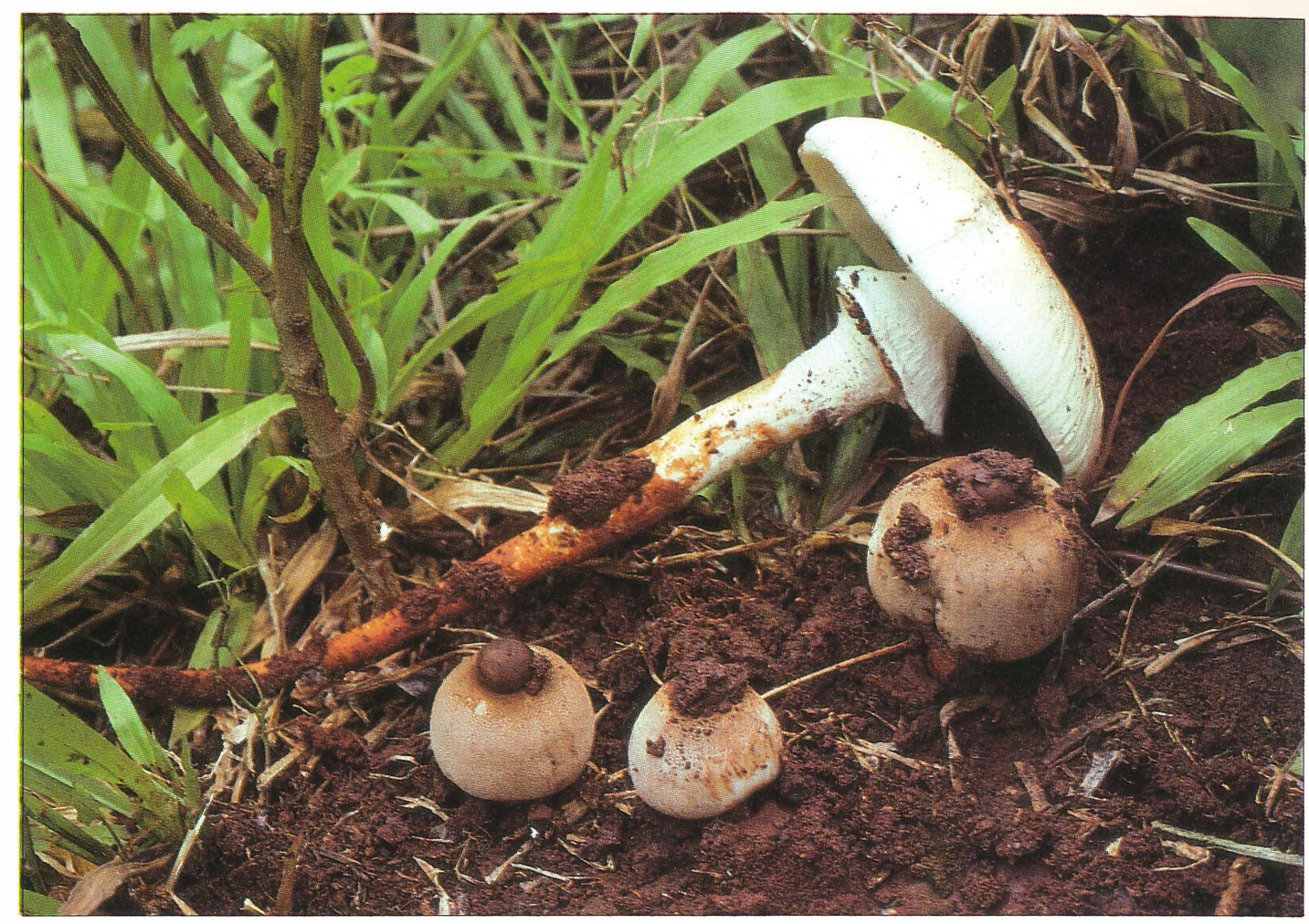

Fig. 44. Termitomyces letestui, MKUFU, is easy to recognize by the navel-like perforatorium. The long root-like pseudorrhiza has carefully been dug out from the ground because there is a lot to eat in it. The photo was taken in Misongeni village, East Usambara Mts.

Habitat: cultivated fields and edges of forests.

This species is easily recognized by the large and fleshy cap with a distinctive perforatorium, and by the thick, sheathing annulus. T. letestui is one of the first mushrooms to appear at the beginning of the rains. It is offered for sale in markets and on roadsides at quite an expensive price.

Spores 6-8.5 × 3.3-4.5 $\mu \mathrm{m}$, ellipsoid to oblong-ellipsoid, hyaline. Basidia $20-27 \times 6-8 \mu \mathrm{m}$, clavate with four sterigmata. Lamella-edge heteromorphous with crowded cheilocystidia. Cheilocystidia $18-52 \times 9-22 \mu \mathrm{m}$, mostly pyriform to broadly clavate, hyaline, and thin-walled. Pleurocystidia 35-54 × 9-21 $\mu \mathrm{m}$, cylindric, fusoid, pyriform or utriform, hyaline. Pileal squamules consisting of tufts of unbranched chains of subglobose to cylindric elements, 7-35 $\times 4-11 \mu \mathrm{m}$, with a slightly tickened wall.

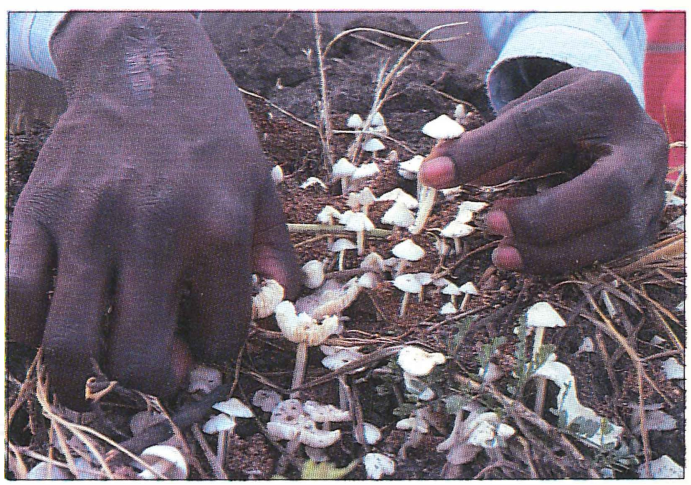

Fig. 45. Termitomyces microcarpus, BUSOLELE, is very small and time consuming to collect. 


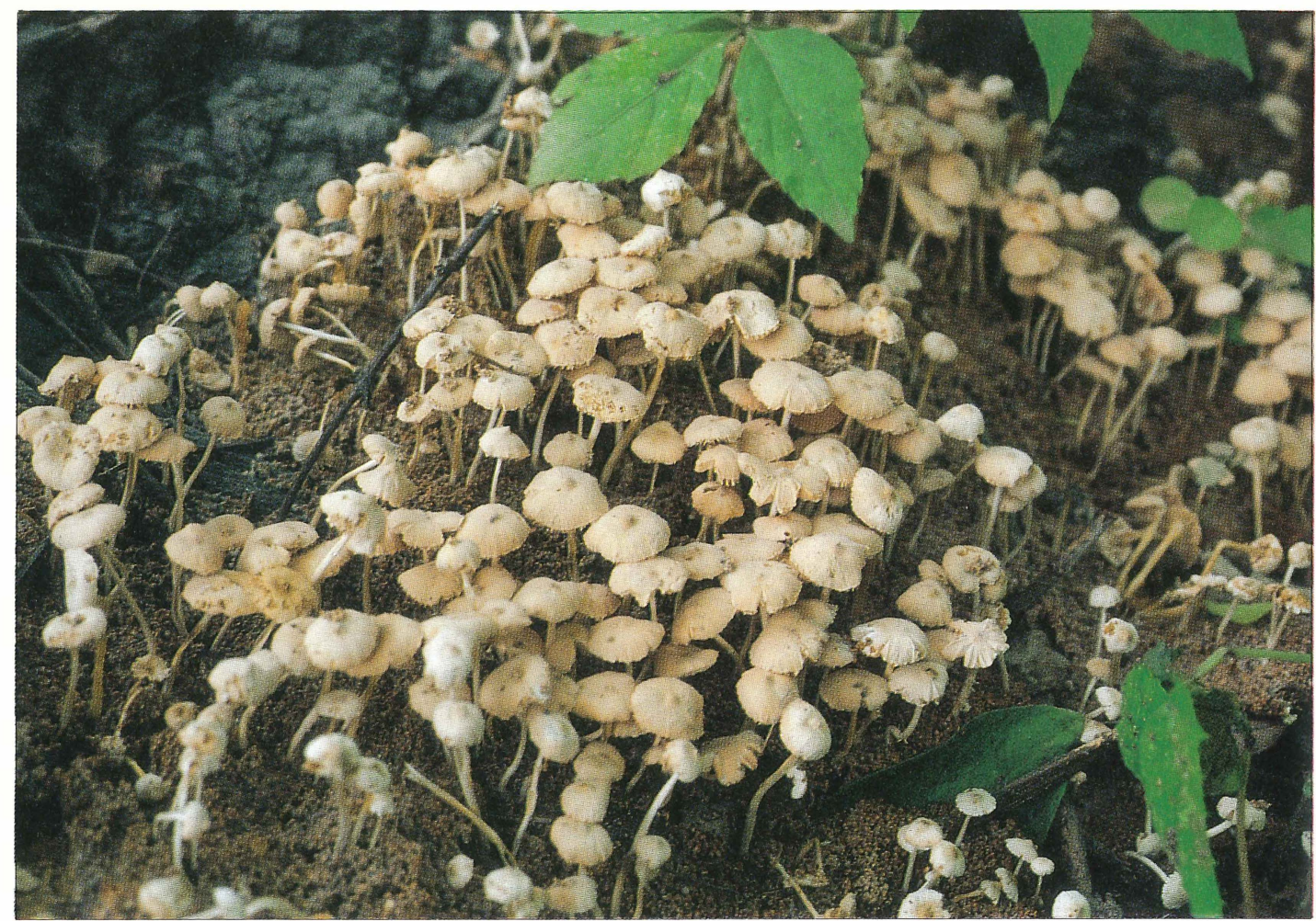

Fig. 46. Termitomyces microcarpus, BUSOLELE, grows in large groups on termite hills like these specimens in Mbozi, in Mbeya district.

Termitomyces microcarpus (Berk. \& Br.) Heim

\section{BUSOLELE **** Figs. $45 \& 46$}

Vernacular names: UNYONSO (Bena), UBUSHOKERA (Ikizu), KOROWERE (Ngindo), UNYASUA(Nyiha), BUMEGERE, BUSOLELE, KANSOLELE (Nyamwezi), VIGAMBE (Pare), BUMEGERE, BUSOLELE, BUTUYA (Sukuma), BUMEGERE (Sumbwa), BUMEGERE (Zinza).

Edibility: edible and well-liked, but very time-consuming to pick. Easy to dry in the sun.
Cap 9-27 $\mathrm{mm}$ in diameter, first campanulate then convex to applanate, with a mucronate or sometimes rounded perforatorium, white, cream or grey, darkening slightly towards the center, surface striate, splitting. Gills free, moderately crowded, white turning pinkish. Stipe $20-40(-65) \times 1-2 \mathrm{~mm}$, equal, sinuous, surface white and smooth, lacking pseudorrhiza. Context white, thin, fibrous in stipe. Smell sometimes odorless, sometimes pleasant, like fresh peanuts. Taste mild.

Habitat: on or near termite mounds.

Typical of this small Termitomyces species is to occur in dense troops, numbering often several thousands, and the absence of pseudorrhiza. 


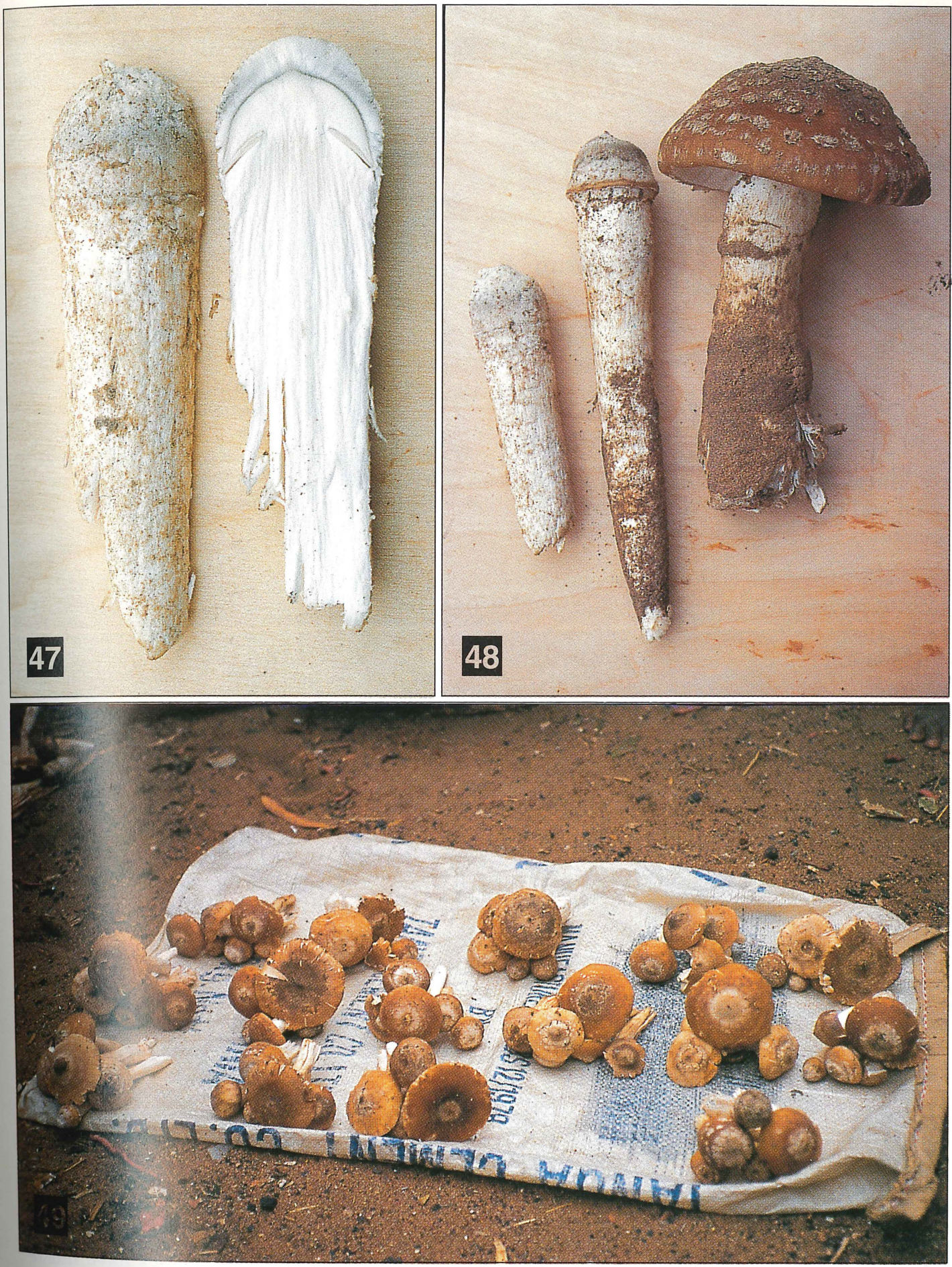

Figs. 47-49. Termitomyces singidensis, IMPORA, has been scientifically described as late as 1994. - 47: A young cap is covered with a thick, fluffy veil. -48 : There is a range of varying stages of fruit bodies. - 49: Typical small heaps of mushroom are offered for sale at market in Singida. 
Spores 5.8-8.3 $\times 3.5-5.0 \mu \mathrm{m}$, ovoid to ellipsoid, hyaline, with usually one refractive guttule. Basidia 20-29 × 7-9 $\mu \mathrm{m}$, clavate, 4-spored. Lamella-edge usually fertile, sometimes with few cheilocystidia. Cheilocystidia and pleurocystidia similar, rare, pyriform to cylindric, hyaline, $20-39 \times 7-15 \mu \mathrm{m}$. Pileal surface an epicutis of radially parallel, hyaline hyphae, 3-5.8 $\mu \mathrm{m}$ in diameter.

Termitomyces singidensis Saarim. \& Härk.

IMPORA *** Figs. 47-49

Vernacular names: WITALI (Bena, Hehe), IMPOTA, IMPORA (Turu), ULOZE (Iramba).

Edibility: edible and highly prized. Sundried and preserved when collected in great quantities.

Cap 4-8(-10) $\mathrm{cm}$ in diameter, convex to flat, sometimes conical, with a small, pointed perforatorium. Young pileus totally covered with whitish, thick and fluffy veil which remains on the brown, matted surface as pruinose and squamulose patch around the disc and concentric but fugacious, pustulate squamules; often carrying pieces of soil. Margin entire or cracked, sometimes appendiculate or overhanging the gills. Pellicle thick and peeling. Gills free to adnexed or sinuate, crowded, thin, white to greyish white, up to $10 \mathrm{~mm}$ broad, margins entire. Stipe central, equal above ground level, (5)11-28 mm in diameter, white, smooth, solid, fibrous, sometimes slightly expanded below ground level before tapering to a long, white pseudorrhiza. Annulus absent or sometimes veil remnants form a superior, membranous ring around the stipe. Context in pileus white, firm, up to $12 \mathrm{~mm}$ thick, in stipe white, fibrous. Smell faint, rubber-like. Taste mild, pleasant. Spore print pinkish cream.

Habitat: (degraded) woodland or bushland in vicinity of termite nests.

This species is easily recognized by the whitish, woolly velar remnants which remain as a distinct, more or less squamulose covering around the small and sharp perforatorium and as concentric but fugacious squamules over the brown surface of the pileus. In Singida area this fungus is very common at the beginning of the rains and is harvested for home consumption as well as for sale.

Spores $5.9-8.5 \times 3.5-5 \mu \mathrm{m}$, ellipsoid to broadly ellipsoid, thin-walled, inamyloid. Basidia 23-31 × 6.0-9.0 $\mu \mathrm{m}$, clavate, with four sterigmata. Lamella edge heteromorphous to sterile with crowded cheilocystidia. Cheilocystidia $20-75 \times 10-27 \mu \mathrm{m}$, variable in shape, pyriform, ventricose or broadly clavate. Pleurocystidia 33-70 × 12$35 \mu \mathrm{m}$, ovoid or pyriform. Hymenophoral trama subparallel, hyphae hyaline, thin-walled, 3-5 $\mu \mathrm{m}$ in diameter, often inflated, and then up to $22 \mu \mathrm{m}$ in diameter. Subhymenium pseudoparenchymatous. Pileal surface an epicutis of repent, subparallel, hyaline, septate hyphae, 3$5 \mu \mathrm{m}$ in diameter. Velar squamules on pileus surface composed of an aggregation of subglobose sphaerocysts, $9-60 \times 7-49 \mu \mathrm{m}$. Ring consists of similar sphaerocysts.

\section{Amanita}

\section{UYOGA WA INZI}

The identification of this genus is quite easy. The most striking characteristic is the volva, the sac-like structure at the stipe base, which surrounds the developing fruit body (see page 25 ). In some species the volva is not very clear and only zones and scales may be observed. Another character of Amanita is the ring on the stipe, a remnant of the veil covering gills during the development. The ring is not always present. Important characteristics are also a possibly striate margin, marked with delicate lines, and pieces or patches which may have adhered onto the cap surface. The spore dust is white in the genus Amanita, gills being white or yellow, but not even in old specimens brown or black.

Species of Amanita are mycorrhizal. They are common in miombo woodlands, many of them being delicious and appreciated edible mushrooms. Exotic tree species have mushroom associations different from those of natural forests. This is why the poisonous $A$. muscaria, not indigenous to tropical Africa, 

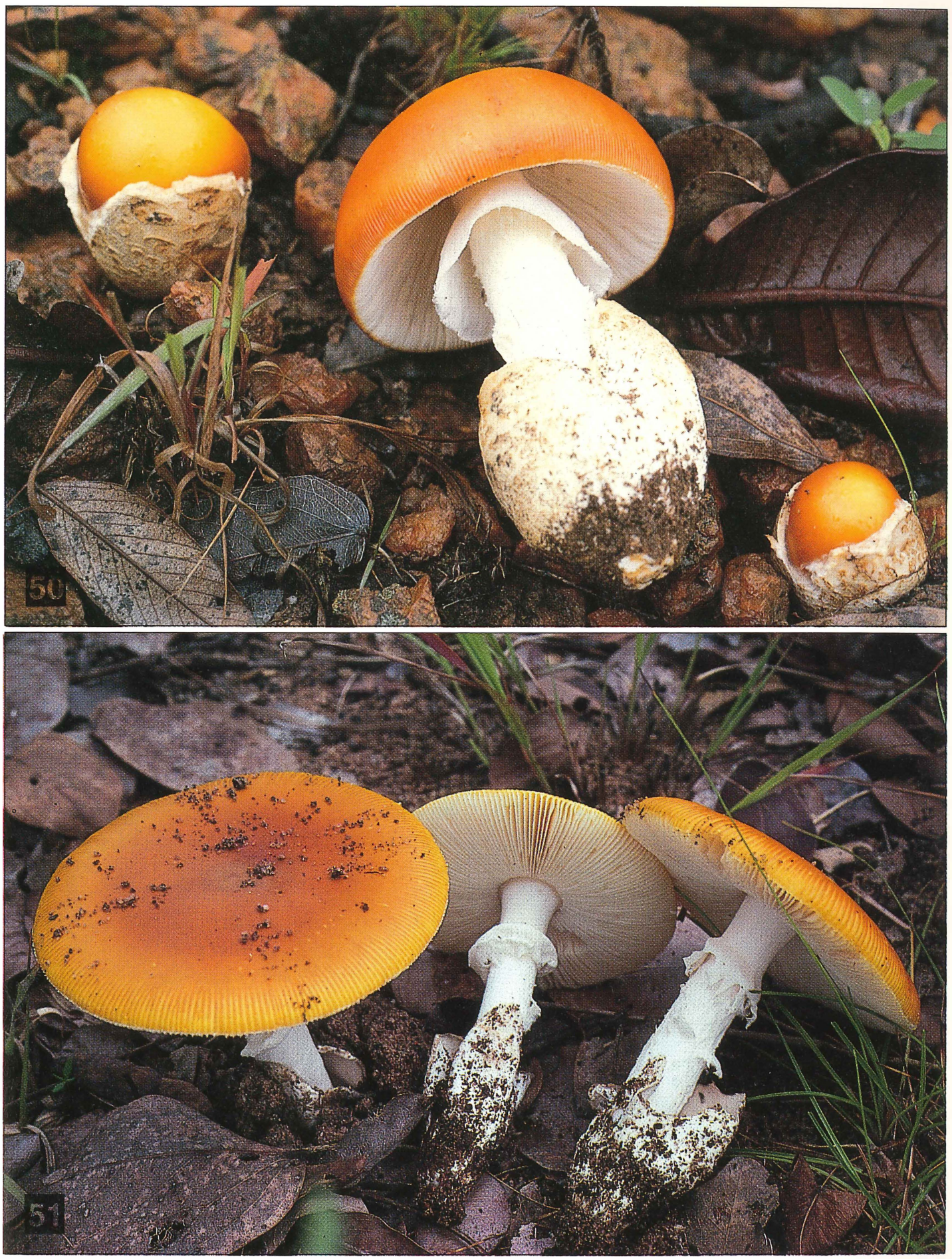

Figs. 50-51. Amanita tanzanica, WIGWINGWI, has white gills, stipe and annulus. - 50: Young fruit bodies photographed in miombo woodland in Kidugala, Njombe district. - 51: Older, somewhat faded fruit bodies from Tunduru district can be seen. 
is growing in pine plantations in Iringa District. The most poisonous mushrooms known, $A$. phalloides, has been recorded from the same district as well.

Amanita tanzanica Härk. \& Saarim.

WIGWINGWI ** Figs. $50 \& 51$

Vernacular names: UNYANGONGOLYA, UGONGOLI, WIGONGOLI (Bena), WIGWINGWI (Hehe, Sangu), NAKAJETE, WONGOLO (Makonde), KAKONGOLO, UNG'ONGOLO, UKONGORO (Ndendeuli), UGONGORO (Ngoni), NAKAJONGOLE, NAKAJONGOO, NAKAYONGOLO (Yao).

Edibility: edible, most people use only the cap. WIGWINGWI deteriorates rather soon and so it is not suitable to be preserved by drying.

Cap 5-11 cm in diameter, first convex, becoming flat; surface bright orange to dark orange, becoming paler and having more ochre tint with age, silky, smooth, sticky, seldom with one or a few big patches of white veil remnants; margin striate. Gills free, white, fairly crowded and thin, up to $9 \mathrm{~mm}$ wide, margin smooth. Stipe 8-13 $\times 0.5-$ $2 \mathrm{~cm}$, equal but extreme base attenuate; surface white, above ring finely striate, below it slightly floccose. Ring superior, hanging, white, thin and very finely plicate. Volva attached to the extreme point of the stipe, white to dirty white, big, saccate, lobed, thick. Context in cap fairly firm, white but yellowish under pellicle; in stem white, brittle fibrous, later hollow. Smell slightly earthlike. Taste mild, pleasant. Spore print white.

Habitat: miombo woodland.

Possibilities of confusion: WIGWINGWI can be confused with Amanita muscaria which, however, usually has white flecks on its red cap (see Fig. 56). The best difference is the growing site - A. muscaria always grows with planted trees, never in miombo woodland. The sac-like volva and the clearly striate cap margin of WIGWINGWI further distinguish it from A. muscaria.

Spores $8.5-12.5 \times 5.5-8 \mu \mathrm{m}$, ellipsoid to slightly elongate, smooth, hyaline with usually one big guttule, inamyloid. Basidia 30-45 × 9-13 $\mu \mathrm{m}, 4$-spored. Subhymenium of irregularly subglobose to angular cells, $5-15 \mu \mathrm{m}$ in diameter. Pileal surface strongly gelatinized in upper part, of fading, repent hyphae $2-5 \mu \mathrm{m}$ in diameter, mostly without but occasionally with clamps.

\section{Amanita masasiensis Härk. \& Saarim.}

\section{WIGWINGWI *** Fig. 52}

In miombo woodland there are several Amanita species which are called by the same vernacular name WIGWINGWI. They are closely related to Amanita tanzanica, and are equally edible. Amanita masasiensis Härk \& Saarim. has orange-yellow pileus, and brightyellow gills, ring and stipe. Amanita mafingensis Härk. \& Saarim. has brownish pileus and pale yellow gills, stipe and ring. Microscopically they are very similar to Amanita tanzanica, which has white gills, stipe and ring. All these species are related to Amanita hemibapha (Berk. \& Br.) Sacc., a highly prized edible mushroom in Southern Asia.

Amanita masasiensis has orange-ylleow pileus, and bright-yellow gills, ring and stipe. Microscopically it is close to A. tanzanica.

\section{Amanita mafingensis Härk. \&} Saarim.

\section{WIGWINGWI ** Fig. 53}

Amanita mafingensis has brownish pileus and pale yellow gills, stipe and ring. It is closely related to Amanita tanzanica, and A. masasiensis, described above. 


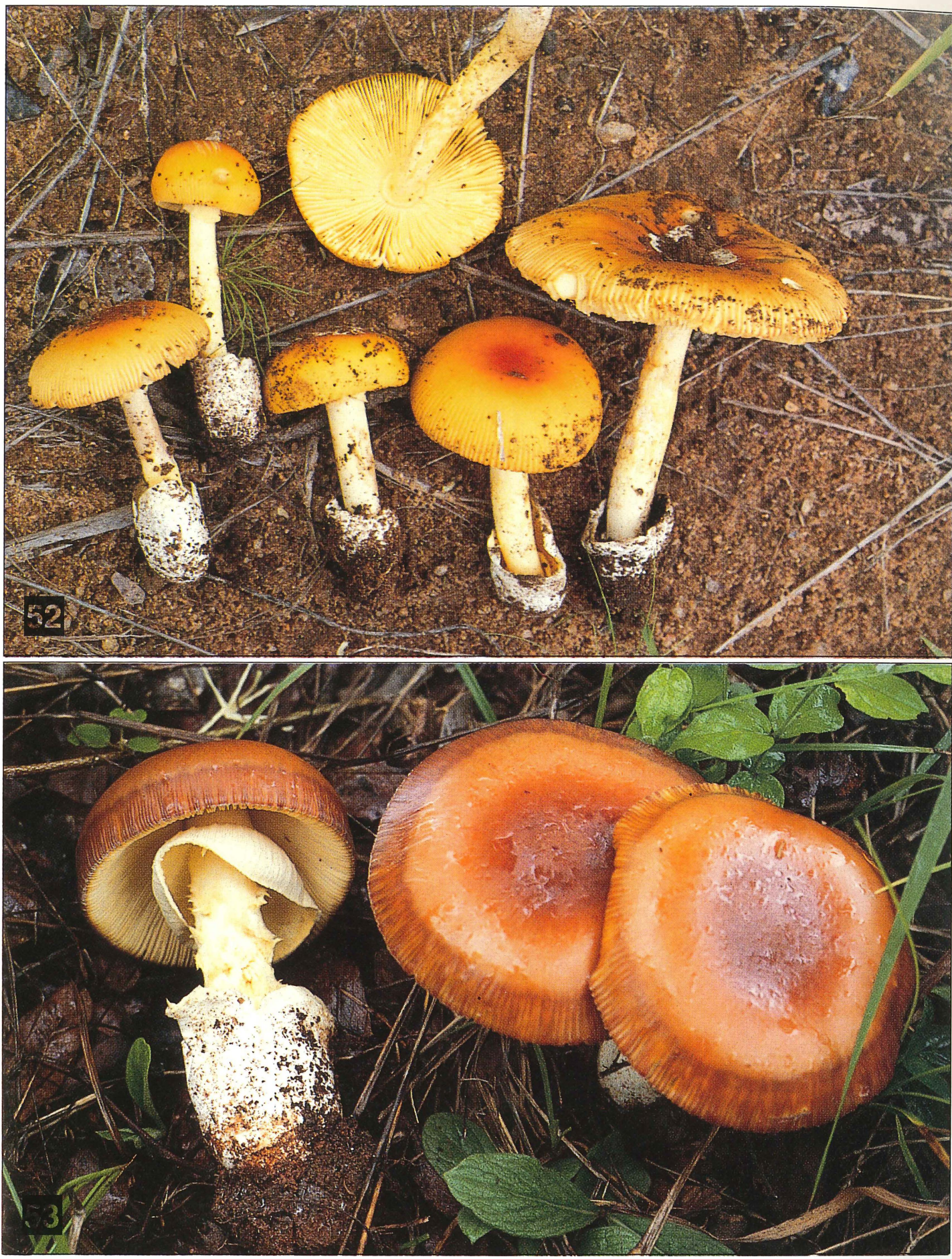

Figs. 52-53. - 52: Amanita masasiensis, has a yellow stipe, gills and annulus but is otherwise so near to A. tanzanica that it is called with the same vernacular name. This specimen was photographed in Kigweje village, Masasi district. 53: Amanita mafingensis, is a close relative of A. tanzanica and A. masasiensis having a brown cap and pale yellow stipe, gills and annulus. This specimen grew in miombo woodland in Kidugala, Njombe district. 

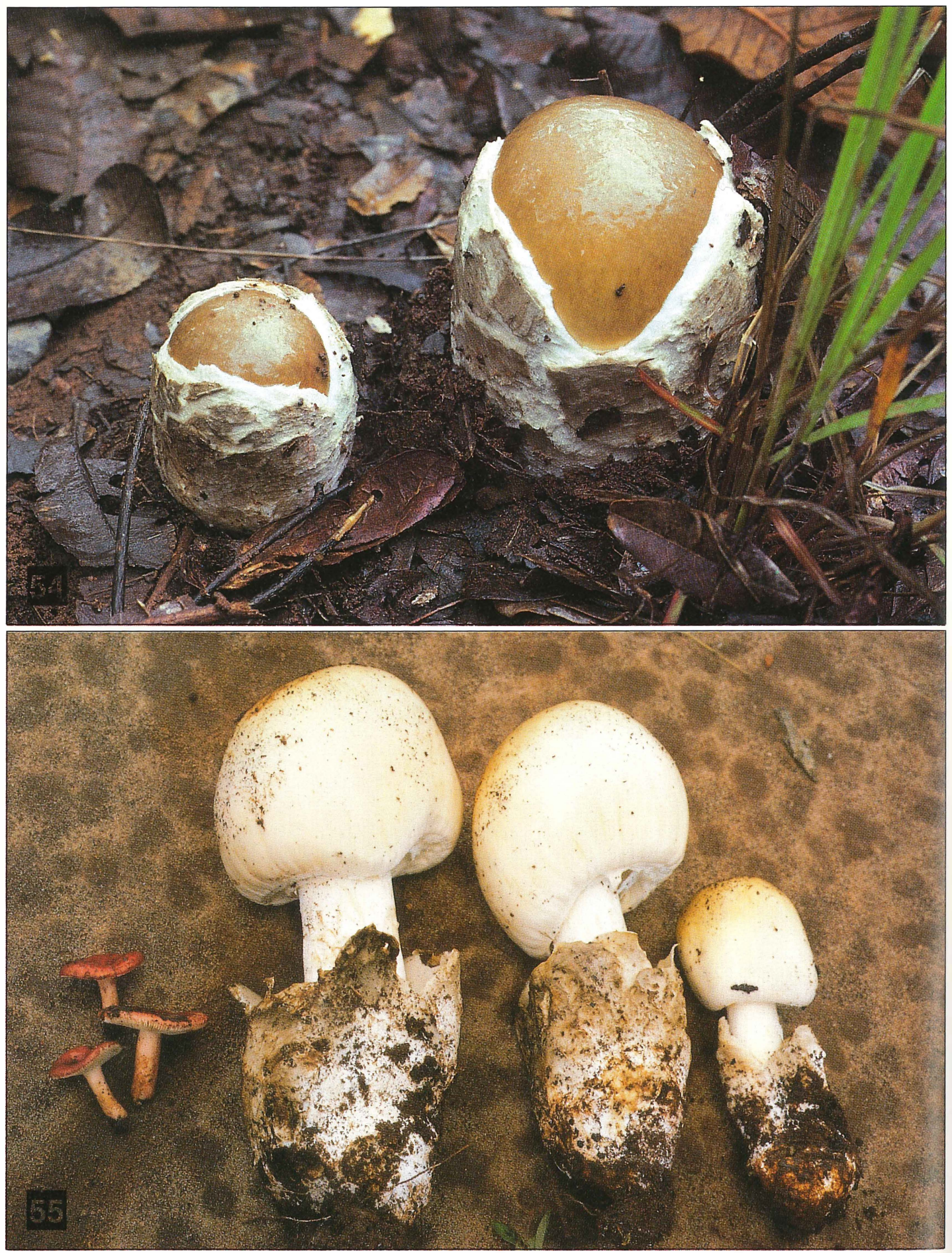

Figs. 54-55. Amanita zambiana, ULELEMA, is a large, slimy mushroom. Brownish in colour when young like the specimens in Fig. 54. The fruit bodies are just pushing out from their universal veil. The mushrooms turn whitish when they become older like the ones in Fig. 55 photographed near Songea. The size of ULELEMA can be estimated when compared to Russula congoana, USULULA, in the same photo. See also the cover picture (Big white fruit bodies of Amanita zambiana, ULELEMA have been collected for food in Masaulwa village). 
Amanita zambiana Pegler \& Piearce

ULELEMA *** Figs. 54, 55 and cover picture

Vernacular names: WILELEMI (Bena), ULELEMA, WILELEMA (Hehe), NANDELELE (Makonde, Makua), ULELEMA (Mwera, Ndendeuli, Nyamwezi), NADELELE (Yao).

Edibility: edible, considered delicious. Because of the quickly deteriorating context, not easy to preserve.

Cap 9-25 cm in diameter, young fruit bodies hemispherical expanding to convex or applanate, surface olivaceous brown at center fading to ivory towards the margin, viscid, smooth except the striate margin, old specimens nearly white. Gills free, crowded, and thin, up to $19 \mathrm{~mm}$ broad, margin smooth or sometimes crenulate. Stipe stout, $8-18 \times 2-$ $3 \mathrm{~cm}$, white, equal to bulbous with saccate, greyish-white volva. Ring superior, broad, large, thin and white, upper side finely plicate. Context in cap white, soft to firm, up to $12 \mathrm{~mm}$ thick; in stipe white, fibrous and relatively brittle, usually hollow. Smell and taste mild. Spore print white.

Habitat: miombo woodland.

Possibilities of confusion: Problems arise when one goes and collects whitish mushrooms in tree plantations, since the highly poisonous Death Cap, Amanita phalloides (see page 59), has been found under Eucalyptus and Acacia, at least in Mufindi (Pegler 1977). It looks similar to A. zambiana in having an olivaceous cap surface and a stipe with a white ring and a loose volva. The fruit bodies are much smaller than those of $A$. zambiana and the smell is strong and sweet but unpleasant. The most distinctive characteristic is the striate cap margin of $A$. zambiana.
Spores 10-12 × 7-9 $\mu \mathrm{m}$, subglobose to broadly ellipsoid, hyaline, with usually one big guttule, inamyloid. Basidia 40 $54 \times 12-14 \mu \mathrm{m}$, clavate, 4 -spored. Lamella edge sterile, with numerous cheilocystidia. Cheilocystidia 27-35 × 13-21 $\mu \mathrm{m}$, globose to pyriform, hyaline. Hymenophoral trama bilateral, subhymenial layer pseudoparenchymatous, up to $20 \mu \mathrm{m}$ wide. Pileipellis gelatinized, of repent hyphae $1-3 \mu \mathrm{m}$ in diameter, with clamps.

Amanita muscaria (L.:Fr.) Pers.

UYOGA MAINZI MWEKUNDU $\uparrow \uparrow$ Fig. 56 $\& 57$

\section{Vernacular names: MAKOKOGANGI} (Hehe).

Edibility: poisonous, having psychotropic poisons (see page 34 ).

Cap 6-14 cm in diameter, convex to flat; surface bright-red fading to orange or yellow, shiny, slightly viscid, covered with white, small flecks arranged concentrically but fugacious, margin indistinctly striate. Gills free, white, thin, close, up to $13 \mathrm{~mm}$ broad, margin smooth. Stipe $10-17 \times 1.5-3 \mathrm{~cm}$, white with a bulbous base. At bulb several scaly zones as a volva. Ring superior and hanging, white with decoratively serrate margin. Context in cap white, under pellicle yellowish; in stipe white, fibrous, becoming hollow when old, firm in bulb. No specific smell, taste mild and pleasant. Spore print white.

Habitat: Under planted trees, either single trees or plantations.

Possibilities of confusion: This striking mushroom, Fly Agaric, with white flecks on the red cap is easy to recognize in its typical appearance. It is not indigenous but has been introduced into Tanzania with the conifer plantations. It looks very similar to some 


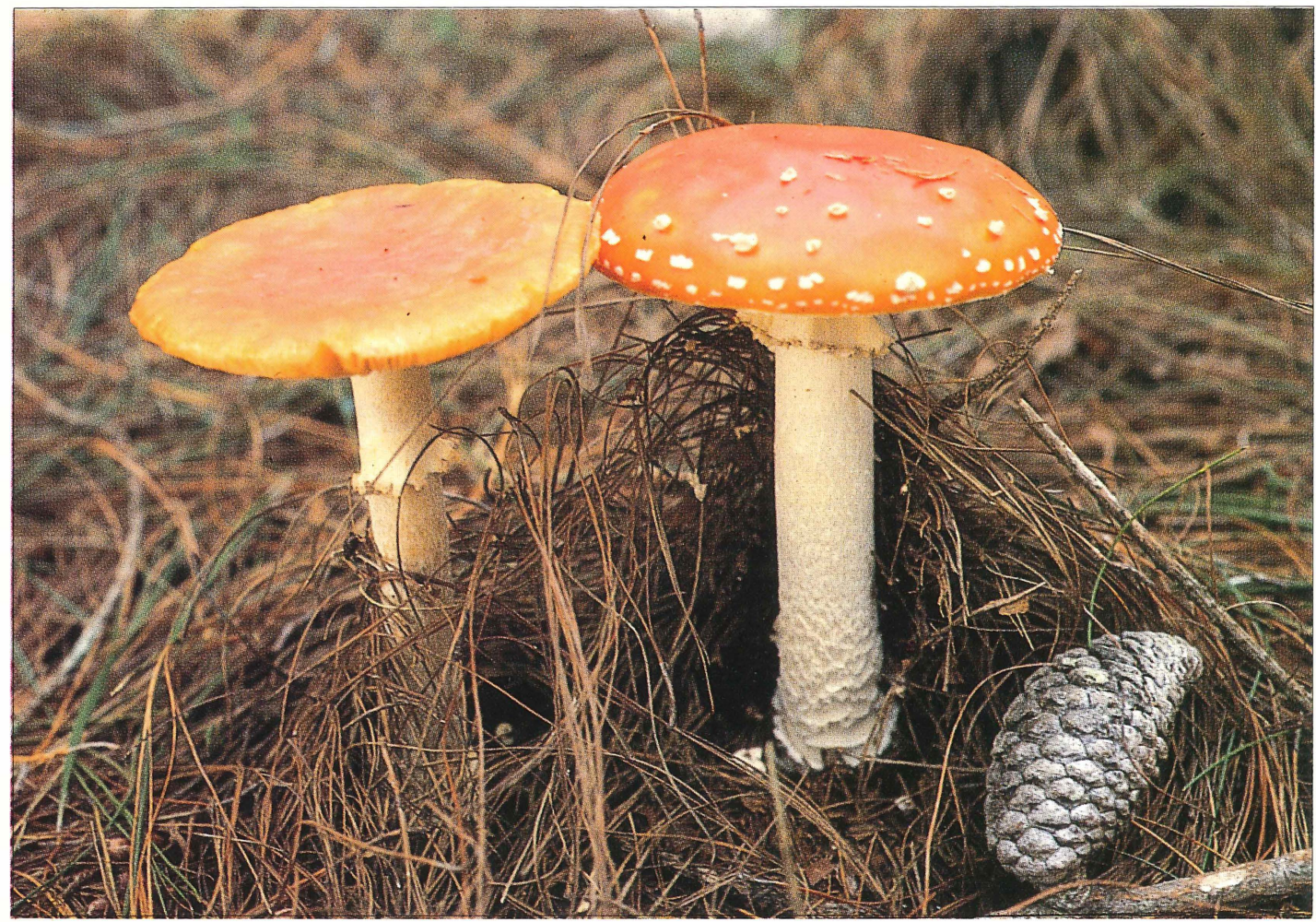

Fig. 56. Amanita muscaria, UYOGA MAINZI MWEKUNDU, is a poisonous mushroom introduced to Tanzania with exotic trees. These fruit bodies push up through needles of Pinus patula in Mufindi. Specimens which have lost the white spots from their cap like the one on the left might be confused with the edible WIGWINGWI.

edible, orange-red Amanita species native to the miombo woodlands (see WIGWINGWI, A. tanzanica on page 54). Confusion may happen if the bright-red cap of A. muscaria has faded to orange and lost the flecks when pushing its way through the thick layer of pine needles. The sac-like volva and clearly striate cap margin of WIGWINWGI are reliable characteristics to distinguish it from UYOGA MAINZI MWEKUNDU.

Poisoning: The symptoms appear within 30 minutes to 3 hours after eating the mushroom with the nervous system becoming affected. Toxins cause confusion, difficulties in speech, and disturbances in vision, also digestive-system symptoms occur. A complete recovery often follows but in some cases the poisoning can be fatal.

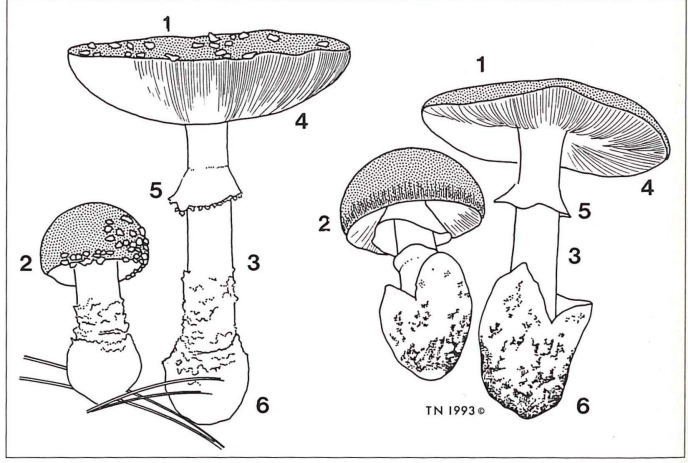

Fig. 57. A comparison of Amanita muscaria (on the left) to WIGWINGWI (on the right). The differences respectively: 1. cap red or orange with white small flecks - no small flecks, a few white patches may exist. 2. Cap margin weakly striate - strongly striate. 3 . Stipe white - white to yellow. 4. Gills white - white to yellow. 5. Ring white with serrate margin - white to yellow, smooth margin. 6 . Base bulbous with white scales and zones - base surrounded by loose, smooth sac. 
First aid: If vomiting does not happen spontaneously, it should be induced to remove the poisonous compounds from the stomach. The simplest method is to drink lots of clean water and then insert the patient's own fingers deep in the throat until vomiting starts. This should be repeated until only water but no more food particles come out. More complicated medicines given to the patient to induce vomiting may be too harsh. Serious cases should be taken to hospital but in every case the essential thing is to empty the stomach as first aid.
Spores 9-11 × 7-8 $\mu \mathrm{m}$, subglobose to elliptic, thin-walled, hyaline, inamyloid. Basidia 38-53 × 11-12 $\mu \mathrm{m}$, clavate, 4spored. Lamella-edge sterile. Hymenophoral trama bilateral. Subhymenial layer pseudoparenchymatous. Pileal surface of interwoven, slightly gelatinized hyphae, 2-4 $\mu \mathrm{m}$ in diameter.

Amanita phalloides (Fr.) Link

UYOGA MAINZI-MAUTI $\dagger \dagger \dagger$ Fig. 58

Edibility: deadly poisonous, poisons of cell damaging type (see page 34 s).

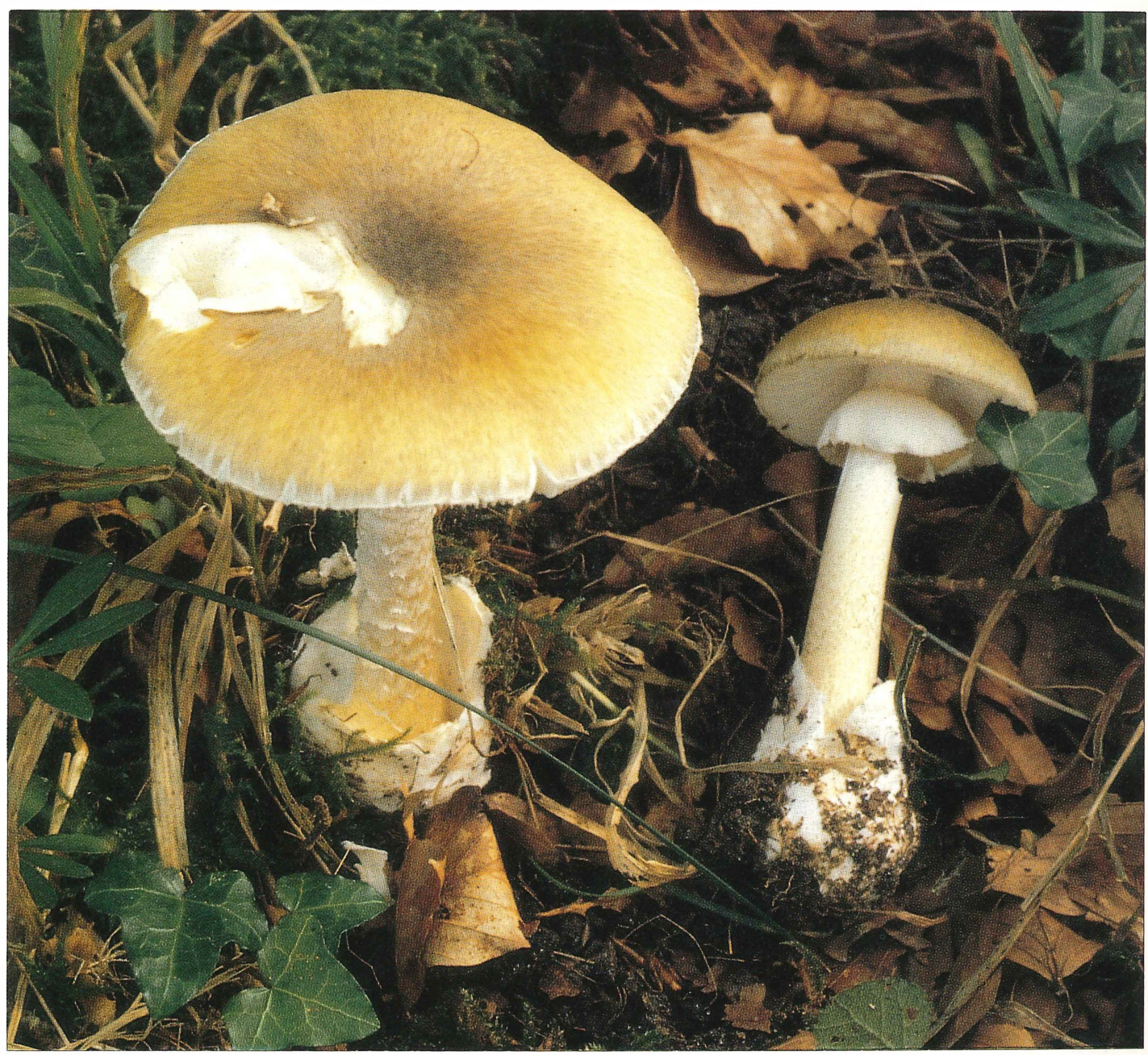

Fig. 58. Amanita phalloides, UYOGA MAINZI-MAUTI, is the most fatal poisonous mushroom in the world. It is a beautiful greenish species with typical characteristics of Amanita: ring and volva. According to literature it has been introduced also to Tanzania. We have, however, not found it there and so this photo has been taken in Denmark. 
Cap 4-12 cm in diameter, at first convex then flattened, usually pale yellowish green but almost white caps may occur. Surface silky smooth, slightly shiny when wet. Gills free, white, crowded. Stipe 5-13 $\times 1-2 \mathrm{~cm}$, cylindric, solid, expanding towards the base, white or greenish. Ring membranous, white, pendant, attached near the top of the stipe. Volva saccate, white, lobed. Context white with a slight yellowish flush under cap surface, fleshy. Smell sickly sweet, resembling honey. Taste mild or slightly bitter. Spore print white.

Habitat: under broadleafed trees and sometimes conifers. In Tanzania there are a few records from Acacia and Eucalyptus plantations. As, with A. muscaria, this fungus represents an introduced species.

Possibilities of confusion: There is a great danger in confusing this deadly poisonous mushroom with ULELEMA (Amanita zambiana). The most distinctive characteristic is the clearly striate cap margin and the inamyloid spores of $A$. zambiana.

\section{Always pick species of Amanita for food from miombo woodlands, never from the plantations of exotic trees.}

Poisoning: This is the most poisonous fungi known, even very small quantities can cause death. Symptoms appear in two phases. In the first phase, after 8-15 hours, symptoms include stomach pains, nausea, vomiting, diarrhoea and dryness of the mouth. Symptoms can be very severe but in a couple of days an apparent recovery follows. During this period, however, the poison affects the liver and kidneys after which the symptoms begin again and often death results.

First aid: In the early stages vomiting (see the instructions on page 34) and medical treatment (activated charcoal) is required to absorb the poison from the digestive system. The poisoning is so severe that a specialized treatment in hospital is always needed.
Spores 8-12 × 7-9 $\mu \mathrm{m}$, ellipsoid to subglobose, smooth, amyloid. Basidia 40-47 × 10-13 $\mu \mathrm{m}$, clavate, with four sterigmata. Lamella-edge sterile with loosely attached, hyaline, inflated elements. Hymenophoral trama bilateral. Subhymenial layer well developed, pseudoparenchymatous. Pileal surface a nongelatinized epicutis of radially parallel hyphae, 3-15 $\mu \mathrm{m}$ in diameter.

\section{Macrolepiota}

Representatives of this genus have large, expanded convex caps and accordingly are called Parasols in English. The caps are scaly or granulose, around the smooth umbo. Typical is a moveable thick ring on a cylindric stipe. These fungi are saprophytic and grow on different sites on rich soil. Most of them are edible and many are highly prized in Europe, Asia and Africa. In Tanzania the attitude towards Macrolepiota species is contradictory, some tribes finding them delicious, some treating them with suspicion.

\section{Macrolepiota dolichaula (Berk. \& Br.) Pegler \& Rayner}

UNYASENGA ** Fig. 59

Vernacular names: BUNYASENGA, UNYASENGA, WINYIMBONDO, WUNYISWALE (Bena), UNYASENGA (Hehe).

Edibility: edible, only the cap is eaten, the stipe being fibrous and hard.

Cap 10-17 cm in diameter, at first subglobose becoming convex to flat at maturity, with a prominent umbo; surface dark brown and entire at the umbo, elsewhere whitish, covered with numerous, concentric, minute brown scales; margin appendiculate. Gills 


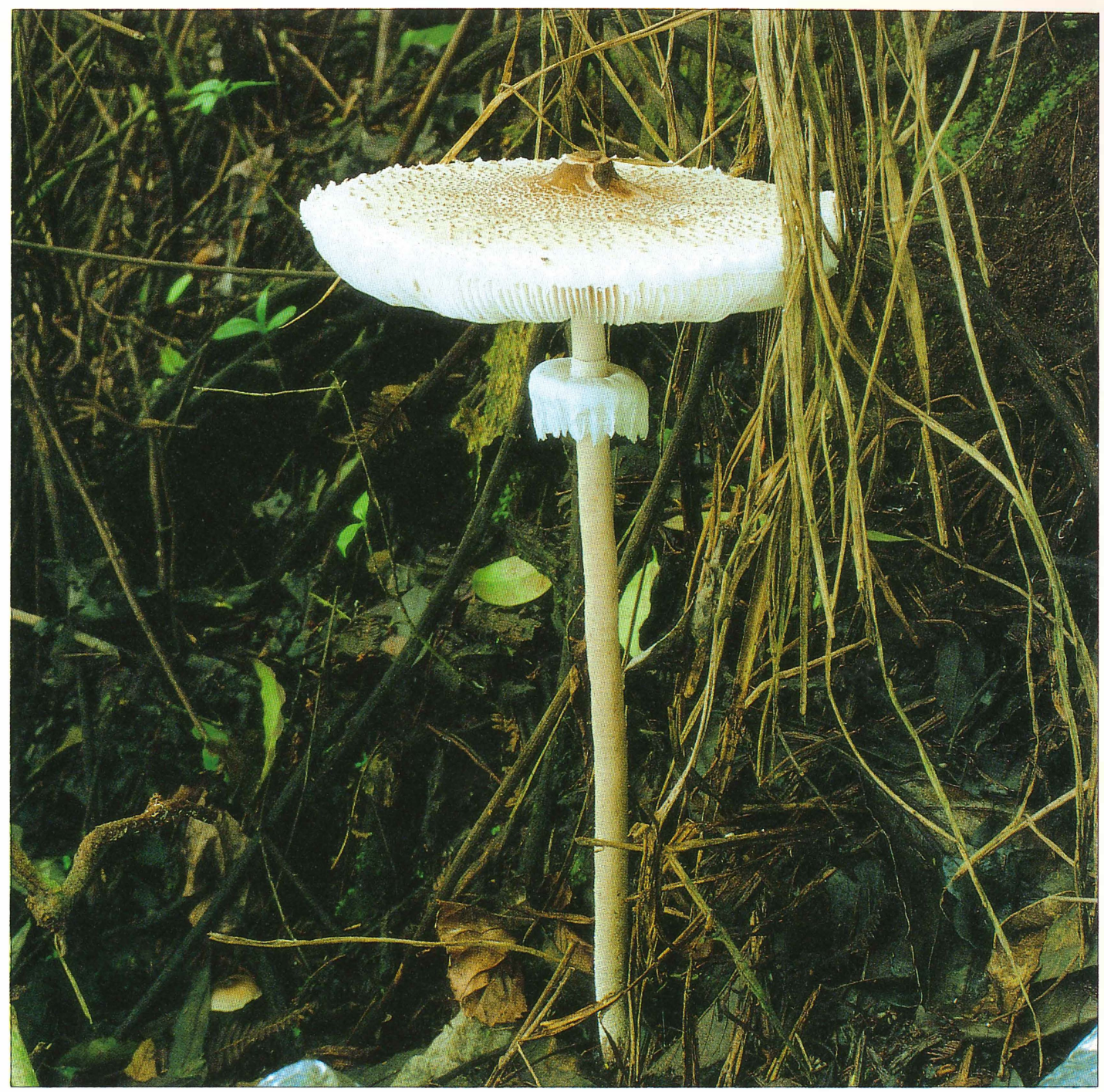

Fig. 59. Macrolepiota dolichaula, UNYASENGA, is tall and thin and has a movable ring. It is eaten by some Tanzanians, but some reject it, maybe because it resembles the poisonous Chlorophyllum. This picture was taken in Mpepera, Pare Mts.

free, remote, white, densely crowded, thin, up to $15 \mathrm{~mm}$ wide, margins smooth. Stipe 17-39 $\mathrm{cm} \times 8-13 \mathrm{~mm}$, cylindric except for the bulbose base $1.5-2.7 \mathrm{~cm}$ in diameter; surface silky, smooth, whitish to smokybrown. Ring persistent, superior but moveable, white, fleshy. Context in cap white, soft, up to $12 \mathrm{~mm}$ thick; in stipe white, fibrous, hollow, penetrating deep into cap context. Smell pleasant, peanut-like. Taste mild. Spore print white to pale pink.

Habitat: on soil in natural forests, woodlands, and grasslands, also in tree plantations.

Possibilities of confusion: Species in the genus Macrolepiota can be confused with 
similar-looking, poisonous Chlorophyllum molybdites (see page 86). The best characteristic to distinguish these mushrooms is the greenish colour of the gills in mature fruit bodies of $C$. molybdites. When young the gills are still white, and extreme caution should be exercised if these mushrooms are picked at their early stages. Compare the descriptions carefully.

Spores 11.5-15(-17) × 8-10(-11.5) $\mu \mathrm{m}$, ellipsoid, thickwalled, with a small germ-pore, usually containing one large, irregular oil-guttule. Basidia $29-41 \times 12-14 \mu \mathrm{m}$, broadly clavate, 4-spored. Gill edge sterile, crowded with cheilocystidia. Cheilocystidia 25-35(-40) $\times 9-14(-16) \mu \mathrm{m}$, pyriform to clavate, thin-walled. Pleurocystidia absent. Pileal surface consist of vertically arranged short chains of cylindric cells, 10-37 ×4-14 $\mu \mathrm{m}$.

\section{Armillaria}

These mushrooms occur usually in dense clusters or in small to large troops, but rarely solitary. They are either saprophytes or parasites growing on buried woody debris or directly on stumps or trunks. The fungus forms black, root-like mycelial strands, rhizomorphs, by which it can spread in the soil from one tree to another. The genus has a worldwide distribution and is responsible for economic losses in the timber industry and gardening. Nowadays several species are recognized, formerly considered as variable forms of Armillaria mellea.

An interesting feature typical of this genus is the luminescence. The wood in which the mycelium grows glows in the dark. The phenomenon is chemical and is similar to that of the fire beetle and glowworm. It has frightened people but the properties have been utilized, for instance in the early days in Europe forest paths were marked with pieces of glowing wood so that travellers could find their way in the dark. The luminescence is familiar also to Tanzanians. In the West Usambara Mountains local people have observed the glowing but do not have any practical use for it.

Fruit bodies are usually considered edible but only young caps are tasty; tough stipes and old caps are useless. In Tanzania Armillaria is eaten only in mountainous areas. Elsewhere wood-inhabiting fungi generally cause suspicion.

\section{Armillaria mellea (Vahl) Fr. s. lat.}

\author{
MANJULUGO * Fig. 60
}

\section{Vernacular names: MANJULUGO (Sam- baa).}

Edibility: edible, only young caps are used.

Cap $1-15 \mathrm{~cm}$ in diameter, convex, flat to umbonate or depressed at center. Surface cream, brownish yellow to dark brown, with darker squamules or scales. Gills adnate to decurrent, but often with a slight sinuation, whitish to light brownish, often spotted with age, close to subdistant, moderately thick. Stipes clustered, central, fibrous with age. Ring white or yellowish, cottony, sometimes fading. Context soft fleshy, whitish. Smell inconspicuous. Taste in young specimens mild, in old specimens at first usually mild, but aftertaste may be metallic, acrid or unpleasant. Spore print white.

Habitat: on wood.

Possibilities of confusion: There are many other fungi growing in clusters on decaying trees. Many of them are inedible, some even poisonous. For instance Hypholoma subviride is common in Tanzania. It has smooth, greenish yellow caps and a very bitter taste. Its close relative, Hypholoma fasciculare, has caused poisonings of a gastrointestinal type in Europe. Several species of Pholiota occur in Tanzania as well. Some of them have a ring but some do not. To be sure of Armillaria mellea check the presence of the ring and the colour of the spore print, which is white in Armillaria, brown in Pholiota and violaceous black in Hypholoma. 


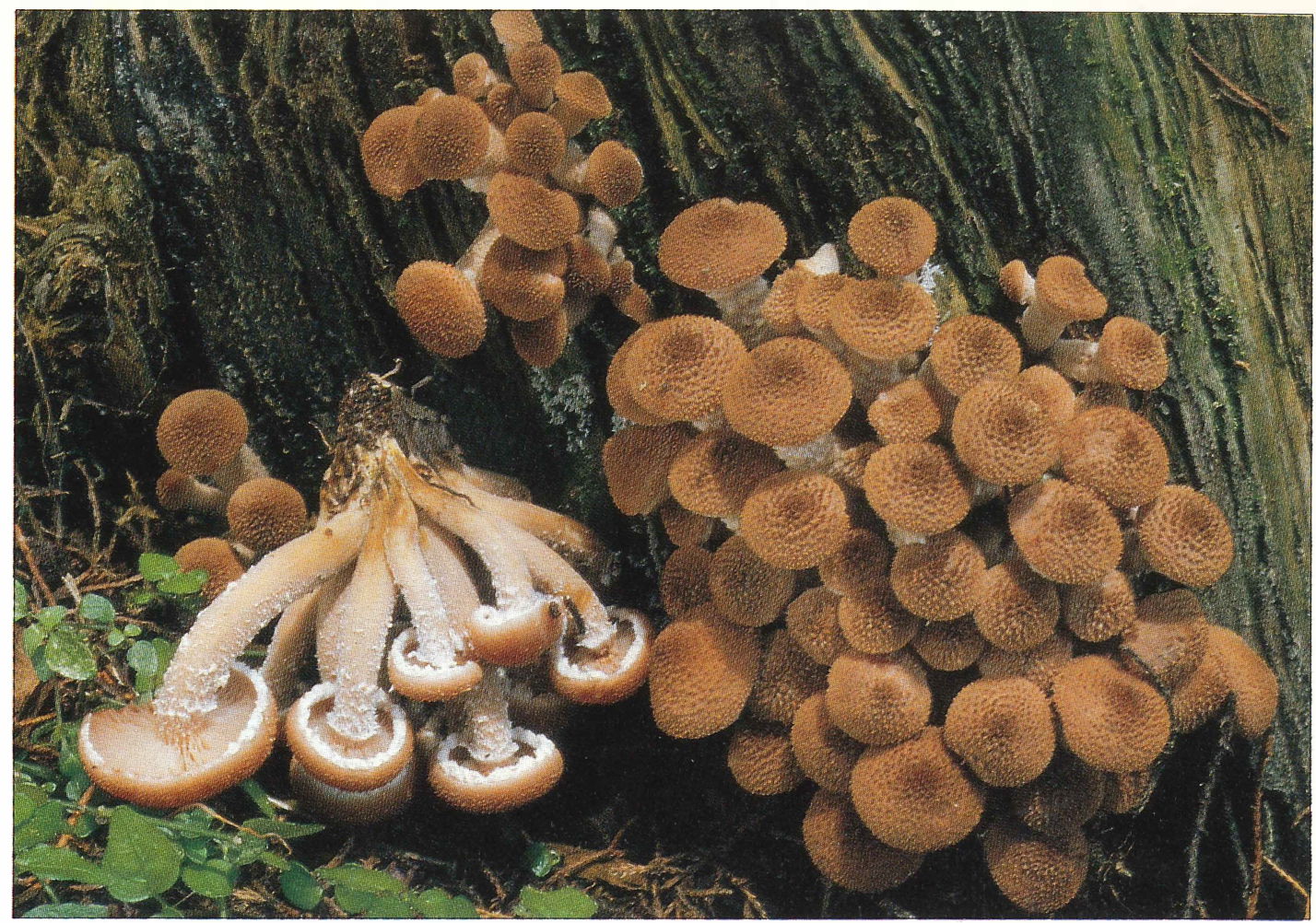

Fig. 60. Armillaria mellea s. lat., MANJULUGO, grows typically in dense clusters on wood, like this specimen which is decaying planted pines in Olmotonyi, on Mt. Meru. One troop has been turned upside down to show the ring on the stipe. Young caps like these are tasty.

\section{Coprinus}

This genus is characterized by the deliquesce of the gills on maturity. To release the spores the gills melt away, to become black, ink-like liquid hence the English common name Ink Caps. Maturing happens very quickly and this is why the fruit bodies are short-lived some can vanish in a couple of hours. Representatives of this genus occur all over the world on dung, or on soil, peat, on dead wood and on other decaying plant material.

\section{Coprinus cinereus (Schaeff.) S. Gray} s. lat.

UYOGA TAKA-MKONGE *** Fig. 61-63
Vernacular names: UYOGA WA MATAKA, UYOGA WA MAVI YA KATANI, UYOGA WA UCHAFU WA KATANI, UYOGA WA TAKATAKA (Swahili).

Edibility: edible, must be used in an early stage before the gills turn black. Young, white, egg-shaped fruit bodies are dug up from sisal waste. Must be prepared for food the same day. Cannot be preserved by drying.

Cap at first egg-shaped to elongate, then campanulate, $15-40 \mathrm{~mm}$ high and $10-30 \mathrm{~mm}$ wide, finally flattened into a thin, ruptured and revolute plate impossible to measure. Colour at first creamy white and then changing into bluish grey. The surface at first silky tomentose, later smooth, densely striate, sometimes with small evanescent, concolorous scales. At the top of the cap a 

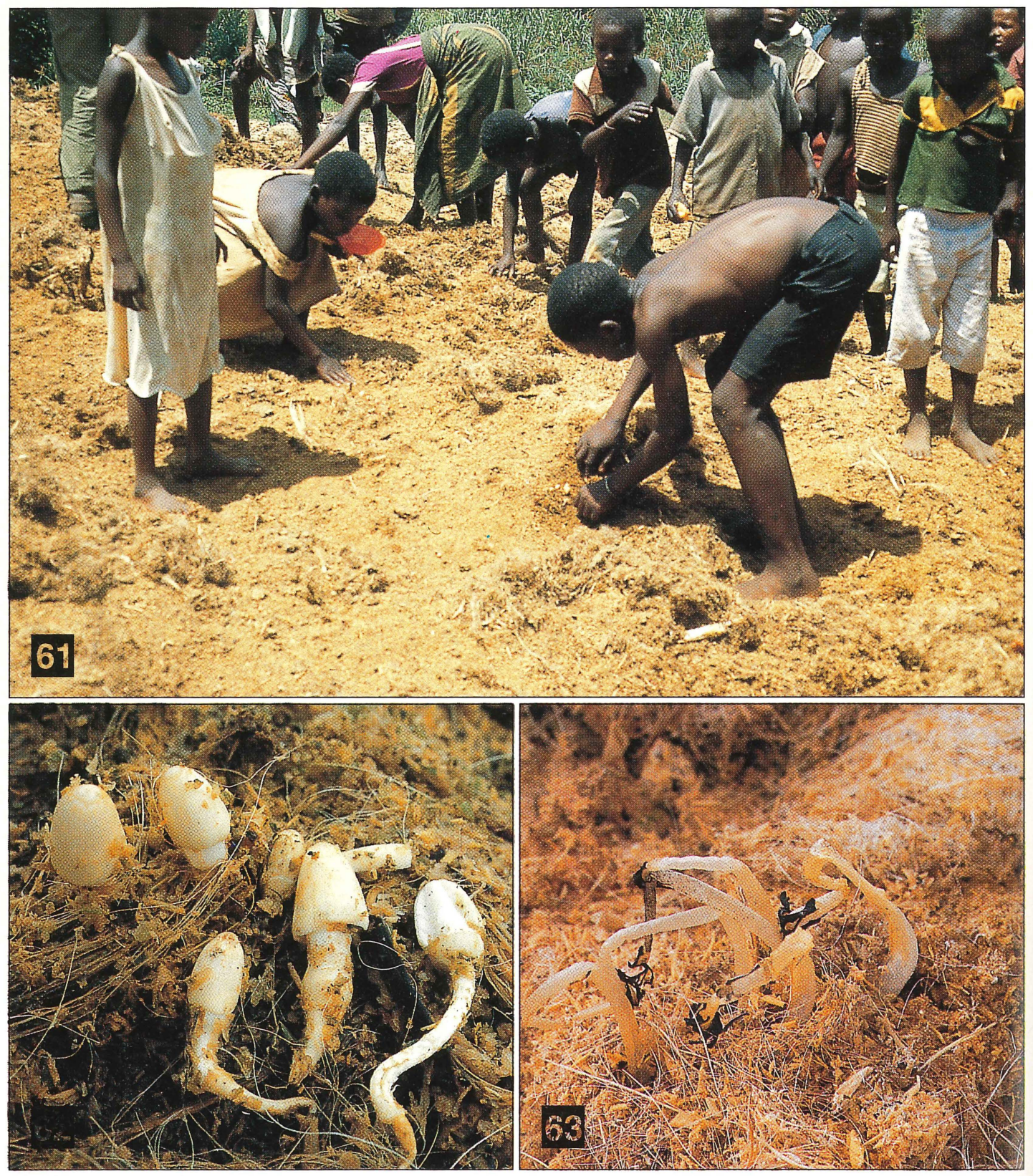

Figs. 61-63. Coprinus cinereus, UYOGA TAKA-MKONGE, is an ink cap growing in sisal waste and is edible in very young state. - 61: You can see a mushroom foray to a waste dump at Kwaduru Sisal Estate near Korogwe in Lushoto district. Boy on the right and girls on the left have dug out small white fruit bodies of an ink cap. — 62: There are young immature fruit bodies, favoured edible mushrooms. - 63: You can see how, after reaching surface of compost, fruit bodies deteriorate and are not edible any more. 
lighter plate, which becomes more prominent when the fruit body gets older. Gills thin and crowded, at first white, then bluish grey, at last black, up to $4 \mathrm{~mm}$ broad, edge smooth. Stipe slightly tomentose to silky, white, in young fruit bodies inside the cap equal, and just under it bulbous and rooting. No ring, but sometimes evanescent veil remnants. Towards maturity the stipe grows from the upper side of the swelling and becomes hollow. The equal part of the stem $2-6 \mathrm{~mm}$ in diameter, the bulb 2-17 mm wide. The tapering pseudorrhiza most often 4-6 cm long, but sometimes much longer. Context thin, brittle, watery white, turning bluish when cut. Taste absolutely mild. Smell, while young and white, none, but becoming strong and sweet like caramel when older and having the bluish tint.

Habitat: in composts of sisal (Agave sisalana) processing factories.

Possibilities of confusion: the growing site is the best characteristic of this mushroom. Also other species of Coprinus can occasionally be found in the same waste heaps. The form of the cap and stipe and the tapering pseudorrhiza are, however, the distinctive features of $C$. cinereus sensu lato. Spore print violet black.

Spores date-brown, ovoid, smooth with a central germ pore, $8-12 \times 6-8.5 \mu \mathrm{m}$. Basidia 4-spored, trimorphic, from clubshaped to short cylindrical with or without slightly inflated base, $20-30 \times 9-12 \mu \mathrm{m}$. Basidioles ovoid or barrel shaped, 18-20 × 8-12 $\mu \mathrm{m}$. Facial cystidia ellipsoid, 40$100 \times 25-60 \mu \mathrm{m}$. Marginal cystidia globose to pyriform, $30-40 \times 16-28 \mu \mathrm{m}$. Cap cuticle of radially arranged, cylindrical inflated cells 5-12 $\mu \mathrm{m}$ wide. Veil remnants of thinner cells than those of cuticle and inflated only at one end.

\section{Russula}

\section{USULULA}

The brittle nature of the flesh and the amyloid ornamentation of the spores are common features of the related genera Russula and
Lactarius. Species of Russula do not exude milk latex as species of Lactarius do. Most Russula species have a smooth, shining or matt cap cuticle, easy to peel. The cuticle can be bright red, yellow, green or violet in contrast with the white or yellow gills, but also pale coloured species exist. The taste of a Russula may be mild or acrid or even burning. There are dozens of Russula species growing in Tanzania. Many of them are difficult to identify and require microscopic examination. The genus itself, however, is easy to recognize. After identifying a mushroom to the genus Russula one can taste it in the field - mild ones can be accepted for food. In the mountain areas we visited, people did not consider the Russula species edible. In miombo woodland area Russula species are collected for food, but not all of them.

\section{Russula cellulata Buyck}

UHINDA *** Fig. 64

Vernacular names: WIGINGILI (Bena, Hehe), UHINDA, USINDA (Makonde), UHINDA (Matengo, Ngoni), UKAU (Ngindo), UTYELELE (Nyamwezi).

Edibility: edible and appreciated. Often sold in market places. Easy to preserve by drying in the sun.

Cap 4-9 $\mathrm{cm}$ in diameter, at first convex then flattened and widely depressed, pale olivaceous brown at center becoming greyish brown towards the margin, matted, edge finely areolate exposing white flesh. Gills sinuate to free, crowded, fairly thin, up to $10 \mathrm{~mm}$ broad, often forked and with lamellulae, cream in colour. Stipe 3-5 $\times 1-2 \mathrm{~cm}$, cylindric, greyish cream, base rounded and ochraceous. Context in cap rather firm, white; in stem somewhat stuffed and white. Smell and taste mild. Spore print white.

Habitat: woodland.

This species occurs singly or in scattered groups, probably all over the Zambian do- 


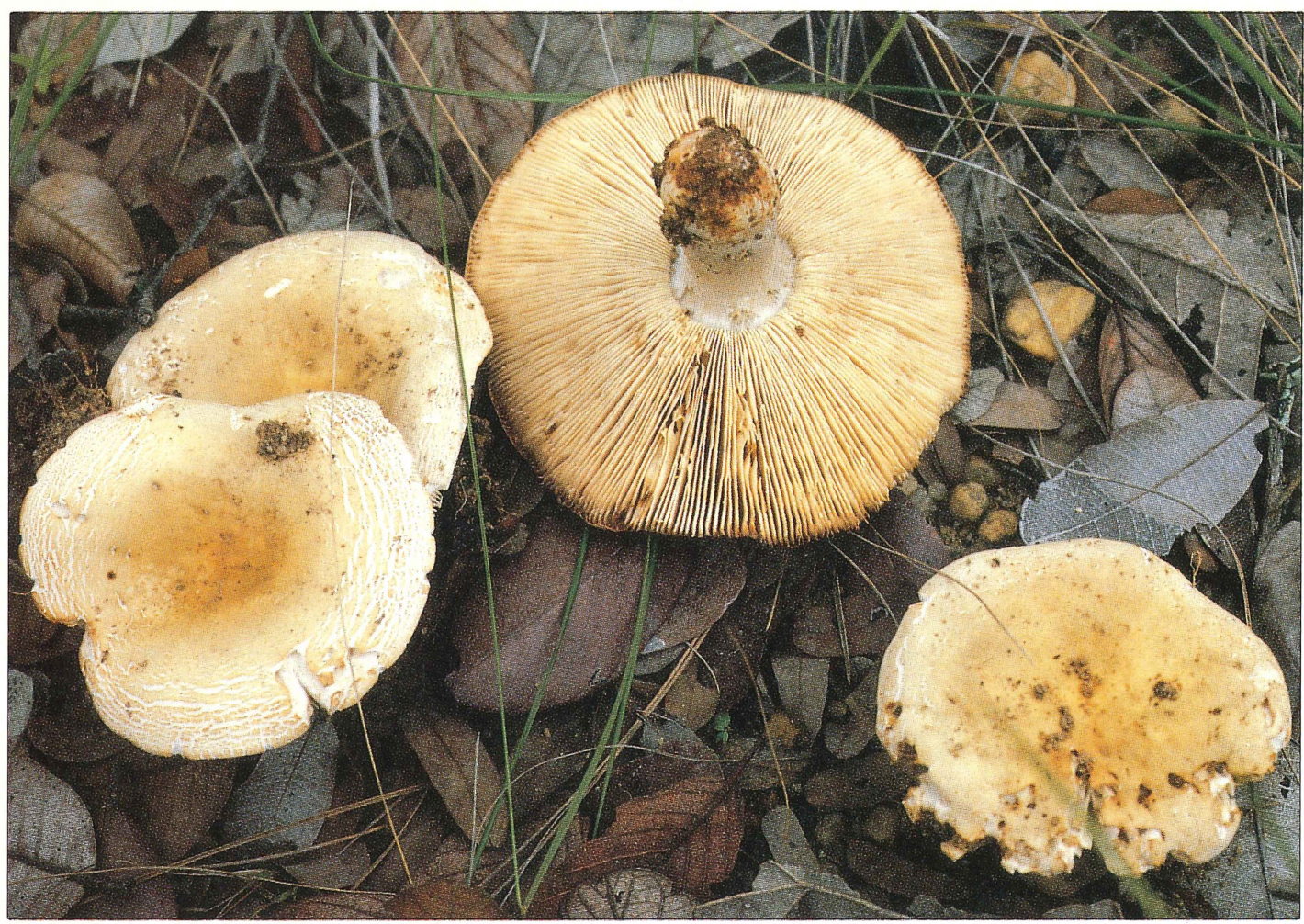

Fig. 64. Russula cellulata, UHINDA, is probably the most appreciated species among the genus USULULA, Russula. This photo, taken in Tunduru, in Iringa district, shows the growded gills and the matted surface of the cap.

main. It is commonly offered for sale in markets, also in the neighbouring countries of Tanzania. It is recognized by the firm, pale yellowish to greyish brown pileus disrupting from the margin towards the center. $R$. cellulata is easily confused with several other Russula species growing in the same habitat many of them being edible as well.

Spores 7.3-8.3 × 5.6-6.6 $\mu \mathrm{m}$, ellipsoid, ornamentation faint, composed of low (up to $1 \mu \mathrm{m}$ ), amyloid, slightly and irregularly convex, sometimes pustulate elements, irregularly interconnected to form short ridges. Suprahilar plage inamyloid. Basidia 35-45 × 9-11 $\mu \mathrm{m}$, pyriform, fourspored. Cystidia numerous, 50-70 × 7-13 $\mu \mathrm{m}$, subfusiform, clavate or pyriform. Pileipellis about $250 \mu \mathrm{m}$ thick; subpellis formed of intermingled hyphae; suprapellis almost pseudoparenchymatous in contact with subpellis, composed of clavate, obpyriform, ellipsoid, spheric, sometimes cylindric cells, 4-15(20) $\mu \mathrm{m}$ in diameter; pileocystidia scattered, (25)30-40(50) $\times(3) 4-5 \mu \mathrm{m}$, cy- lindric to fusiform, capitate, seldom rounded. All hyphae lack clamp connections.

\section{Russula ciliata Buyck}

NCHENGA *** Fig. 65 \& 66

Vernacular names: UDUNGU (Mwera), NCHENGA (Ngoni), UTYELELE (Nyamwezi), BUNITELELE (Sumbwa).

Edibility: edible.

Cap 3.5-4 cm, convex to flat with a central depression, bright yellow-green to yellowish orange, striate at margin, pellicle peeling easily. Gills adnexed, creamish white, close, up to 4 $\mathrm{mm}$ broad, margin entire. Stipe $20 \times 8 \mathrm{~mm}$, 

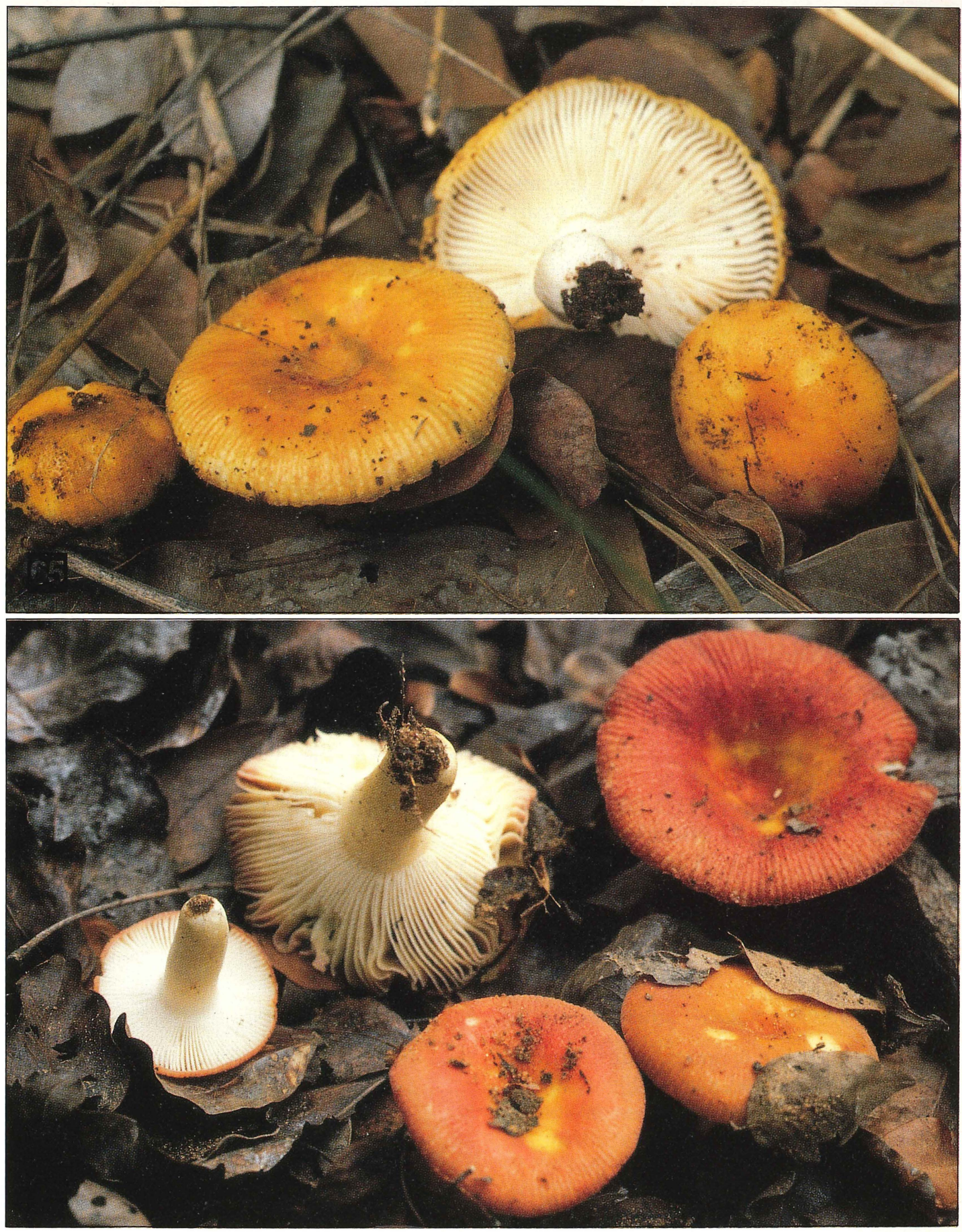

Figs. 65-66. Russula ciliata, NCHENGA, is a small, fragile species the colour of which varies from greenish yellow to orange or nearly red. -65 : Yellow coloured specimens from Rukohe village near Masasi can be seen. -66 : There are examples of the red coloured specimens from the same village. 
cylindric, slightly tapering downwards, white, smooth. Context white, slightly greenish under pellicle, russuloid. Smell and taste mild. Spore print cream.

Habitat: woodland.

This is a small, distinct and common species, often found in large numbers. It is easily recognized by the typical yellow to green colour of the cap.

Spores broadly ellipsoid or finely reniform, 7.4-10.1 ×5.7$7.8 \mu \mathrm{m}$, densely ornamented with low (up to $1 \mu \mathrm{m}$ ), hemispherical, obtuse, amyloid elements which are united into short ridges to form an incomplete reticulum; suprahilar spot inamyloid. Basidia (35-)40-50(-60) × 10-12 $\mu \mathrm{m}$, subclavate, 4-spored. Cystidia optically empty occupying the entire edge, cylindrical; some pseudocystidia-like and immerged in subhymenium and trama, claviform, 60-80 $\times$ 10-15 $\mu \mathrm{m}$. Subpellis formed of hyphae 2-3(5) $\mu \mathrm{m}$ in diameter; suprapellis discontinuous, formed of voluminous extremities which consist of 2-5 subglobose, ellipsoid or cylindric cells, terminal cell long and slender; pileocystidia none.

\section{Russula compressa Buyck}

NITUNDU ** Fig. 67

Vernacular names: NITUNDU, UNYAMGUHU, WIDUNGU (Bena), UDUNGU (Mwera), BUFUTWAMVULA, BUSEGESE, KATUNDU, MNYITUNDU (Nyamwezi), UTUNDULE (Safwa), BUTUNDUTUNDU (Sukuma), NITUNDU (Sumbwa), DAMU YA MZEE (Swahili).

Edibility: edible.

Cap 4-7(-11) cm in diameter, at first convex, then flattened-depressed, margin slightly striate; surface blood-red, darker at center, totally peelable, smooth, viscid. Gills adnate to adnexed to almost free, close, fairly thin, up to $9 \mathrm{~mm}$ broad, white to ochraceous. Stipe $3-7 \mathrm{~cm}$ $\times 7-23 \mathrm{~mm}$, equal to clavate; surface smooth but sometimes indistinctly grooved on the upper part, dirty white, becoming yellowish upon touch. Context fragile, white to yellowish, up to
$5 \mathrm{~mm}$ thick in cap; in stipe chambered. Smell usually none, sometimes fishy; taste mild. Spore print pale cream.

Habitat: woodland.

There are many red-capped edible Russula species occuring in the miombo woodland. Local people understand them collectively as one mushroom type. That is why only one Swahili name is used here for all of them. $R$. compressa differs from the other species either by its larger size, yellowing context or by the absence of the red colour in the stipe.

Spores ellipsoid, 7.8-9.5 × 6.2-7.8 $\mu \mathrm{m}$, densely ornamented with low, irregular and obtuse elements, isolated but often laterally stretched out, locally joined and anastomosing, but not forming a differentiated ridge or reticulum; suprahilar spot amyloid. Basidia 35-40 $(-45) \times$ 10-11 $\mu \mathrm{m}$, subclavate, 4-spored; sterigmata stout, 5-7 $\mu \mathrm{m}$ long. Cystidia dispersed, 60-100 × 8-18 $\mu \mathrm{m}$, clavate, fusiform or irregularly tapering, apex rounded or with a slender projection of variable length. Pileipellis a trichoderm slightly gelified; pileocystidia numerous, unito multicellular, cylindric to clavate, up to $12 \mu \mathrm{m}$ broad, often emerging from subpellis. Clamp connections none.

\section{Russula congoana Patouillard}

NITUNDU ** Fig. 68

Vernacular names: WIDUNGU (Bena), UNYAMIKWE (Hehe), KATUNDU, MNYITUNDU (Nyamwezi), BUTUNDUTUNDU (Sukuma).

Edibility: edible.

Cap 2-5(-8) cm in diameter, at first convex becoming applanate, slightly depressed at the center; surface bright red, smooth with striate margin, sticky and therefore sometimes bearing soil fragments. Gills adnate, fairly crowded and thin, pale cream to ochraceous, margins concolorous with cap. Stipe $2-4 \mathrm{~cm}$ $\times 7-17 \mathrm{~mm}$, cylindric, solid or stuffed, later hollow; surface smooth, pink to reddish. Context white, russuloid. Smell pleasant, taste mild. Spore print ochraceous. 


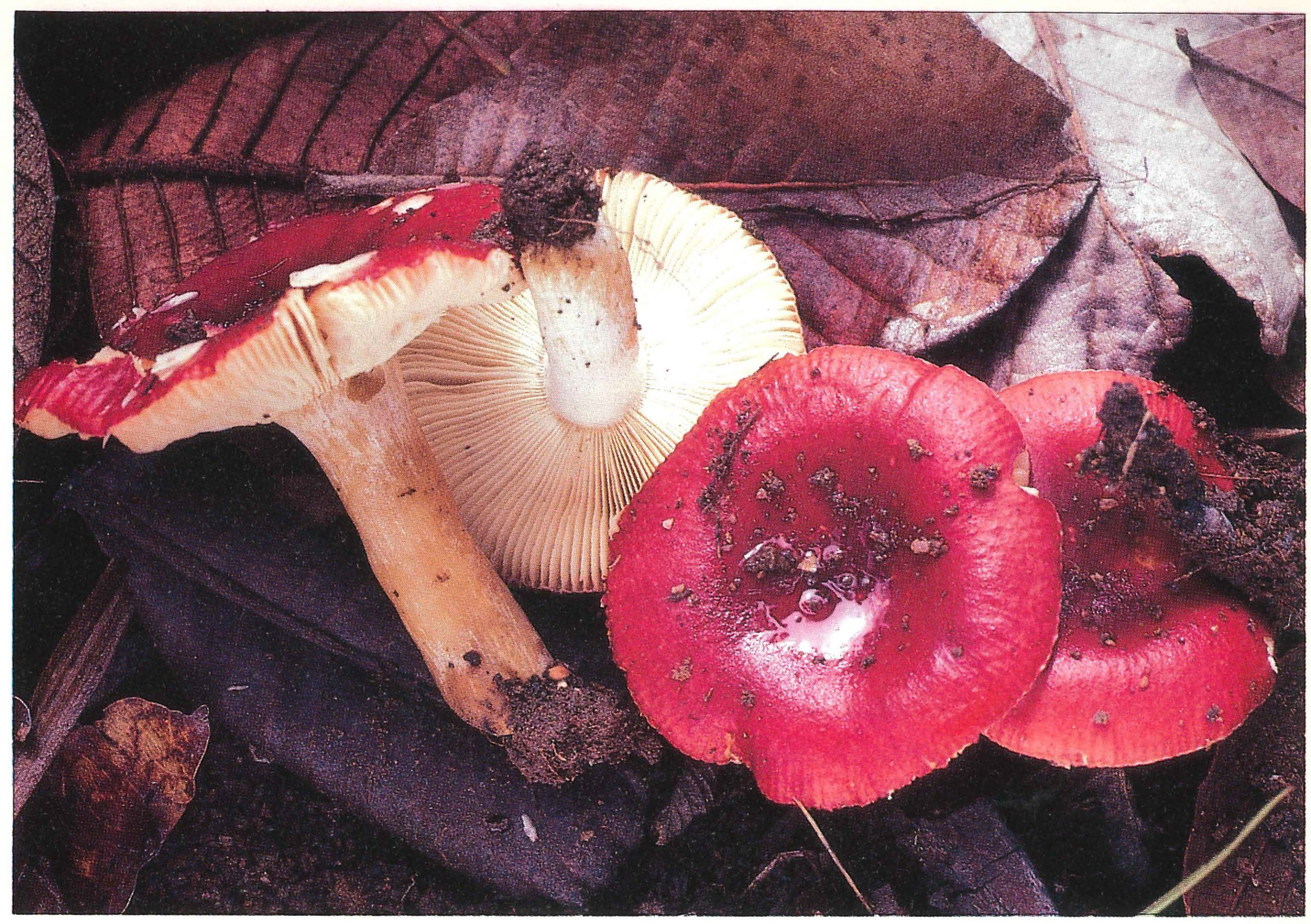

Fig. 67. Russula compressa, NITUNDU, is a blood-red species with dirty white stipe. Stipe turns yellowish upon touch, which can be seen in the photo taken in Mbalali in Njombe district.

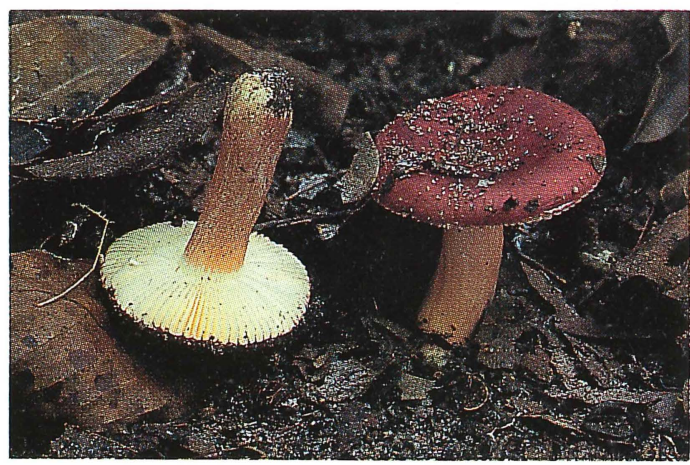

Fig. 68. Russula congoana, NITUNDU. Tanzanians call all red Russula species with the same vernacular name. Russula congoana differs from the other Russula species of this book by having a red stipe as seen in this photo taken in Mpunze in Kahama district.

\section{Habitat: woodland.}

This is a small red-capped species which has, in contrast to $R$. compressa, red colour on the stipe surface.

Spores variable in shape, ellipsoid to oblong, 8.9-10.2 $\times$ 6.9-8.6 $\mu \mathrm{m}$, rather densely ornamented with large ridges, up to $2 \mu \mathrm{m}$ in height, branched, forming locally an interconnected reticulum. Basidia 30-40 × 12-15(-17) $\mu \mathrm{m}$, broadly clavate to piriform, 4-spored, sterigmata stout, 5$7 \mu \mathrm{m}$ long. Cystidia abundant, 45-65(-80) $\times 8-12(-15)$ $\mu \mathrm{m}$, clavate to fusiform, capitate. Subpellis slightly gelatinized, formed of slender hyphae, 2-4 $\mu \mathrm{m}$ in diameter; suprapellis little differentiated, composed of erect, shortly cylindric elements, 3-5 $\mu \mathrm{m}$ in diameter; pileocystidia usually numerous, intermixed with hyphae, variable in size, usually 35-200 $\times 4-8 \mu \mathrm{m}$, even longer for they are submerged into subpellis, cylindric, clavate or fusiform, obtuse or slightly constricted at large apex. Clamp connections none. 


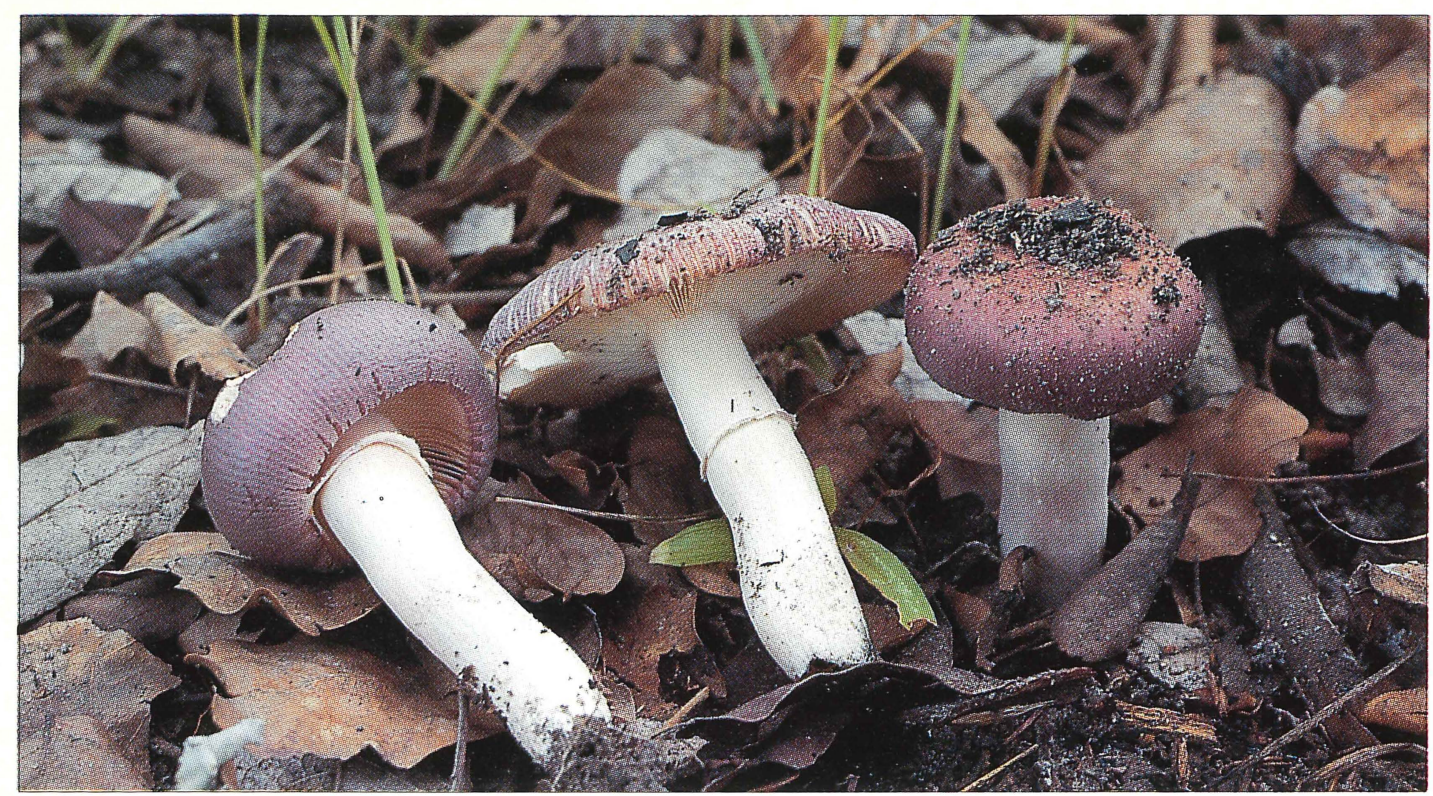

Fig. 69. Russula hiemisilvae, NITUNDU, is a violet red species with a ring. This specimen grew in miombo woodland in Wendelele near Kahama.

\section{Russula hiemisilvae Buyck}

$$
\text { NITUNDU ** Fig. } 69
$$

\section{Vernacular names: NITUNDU (Sumbwa).}

Edibility: edible.

Cap 5-6 $\mathrm{cm}$ in diameter, convex to flat, margin broadly striate, at first involuted; surface greyish violet, distinctly peeling. Gills adnexed, cream, crowded, up to $4 \mathrm{~mm}$ broad, fairly thin; edge smooth, concolorous. Stipe ca. $55 \times 10 \mathrm{~mm}$, equal, tapering at base, white or with a faint violet tone, smooth, becoming hollow with age. Ring narrow, free around the stipe. Context white. Smell none; taste mild.

This species differs of the other NITUNDU species by having a ring.

Spores ellipsoid, $8.4-9.7 \times 7.2-8.4 \mu \mathrm{m}$, rather densely ornamented with conical, obtuse elements up to $1.5 \mu \mathrm{m}$ high, strongly amyloid, distinctly interconnected or united into narrow ridges, completely reticulate; suprahilar spot distinct but not amyloid. Basidia 54-66 × 12-14 $\mu \mathrm{m}$, clavate to pedicellate, 4-spored. Cystidia dispersed, 65-80 $\times 10-14 \mu \mathrm{m}$, clavate to fusiform, usually appendiculate or capitulate, thin-walled; contents distinct. Marginal cells clavate to fusoid, obtuse, distinctly smaller than the basidia. Subpellis gelatinized, composed of slender hyphae, 2-4 $\mu \mathrm{m}$ in diameter; suprapellis composed of short and densely septate extremities; terminal cells more or less capitate; pileocystidia $20-45 \times 5-8 \mu \mathrm{m}$, terminal, fusoid to lageniform, capitulate.

\section{Lactarius}

\section{UYOGA-MAZIWA}

The most typical characteristic of this genus is the white, watery or coloured milk latex that exudes from a fruit body when cut or broken. According to this property some Bena call Lactarius UNYAMAZIWA, meaning a mushroom which gives milk. The colour of the liquid may change in the air after a time. The taste of the liquid may be acrid, bitter or mild. 
The flesh is brittle, not fibrous, breaking equally into every direction when crushed. A good microscopic characteristic is the amyloid ornamentation of the spores.

The family Russulaceae, comprising the two genera Lactarius and Russula, is extremely common among the woodland vegetation in Tanzania and important as ectomycorrhizal partners of trees.

Several species of Lactarius are collected for food in miombo woodland areas. Mild species can be used straight away. Many people use also acrid species, but boil them and throw the water away before using them for food. At markets usually mixtures of dried Lactarius are offered for sale.
Lactarius sp. aff. phlebophyllus Heim

KIKOBA *** Fig. 70

Vernacular names: WIMENDA (Hehe), KIKOBA (Nyamwezi), BUSHIKOBA (Sukuma).

Edibility: edible, can be cooked without parboiling or drying. Often offered for sale in market places.

Cap 5-12 cm in diameter, at first convex with central depression, then depressed to funnel-shaped, margin in old specimens irregular, wavy. Surface dark red-brown, matted, at margin pruinose, in old specimens

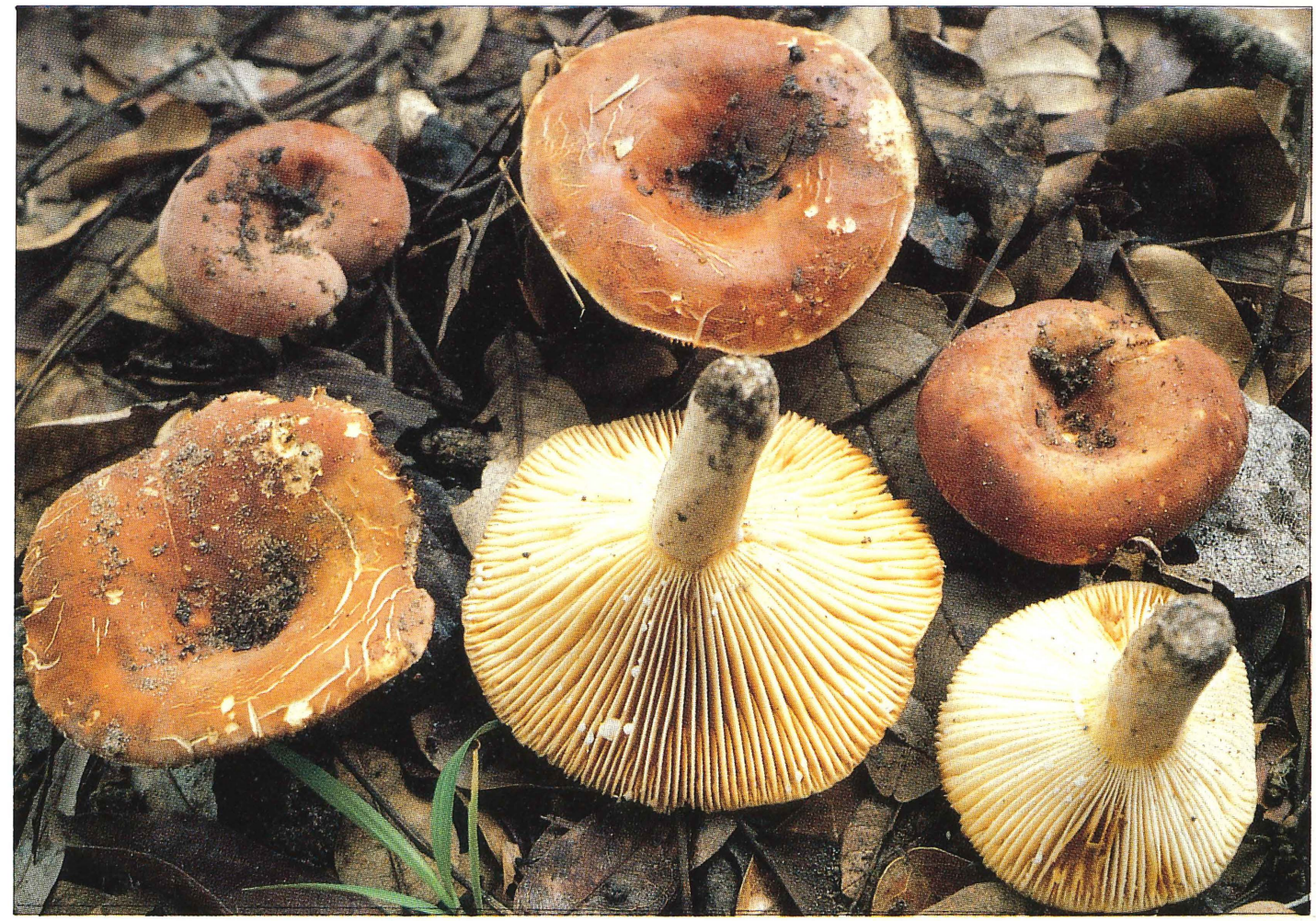

Fig. 70. Lactarius sp. aff. phlebophyllus, KIKOBA, is often offered for sale in market places. Look at the gills of this specimen. Milk latex that exudes from a fruit body when bruised, is a typical characteristic of the genus Lactarius. The photo was taken in Lulanguru near Tabora. 


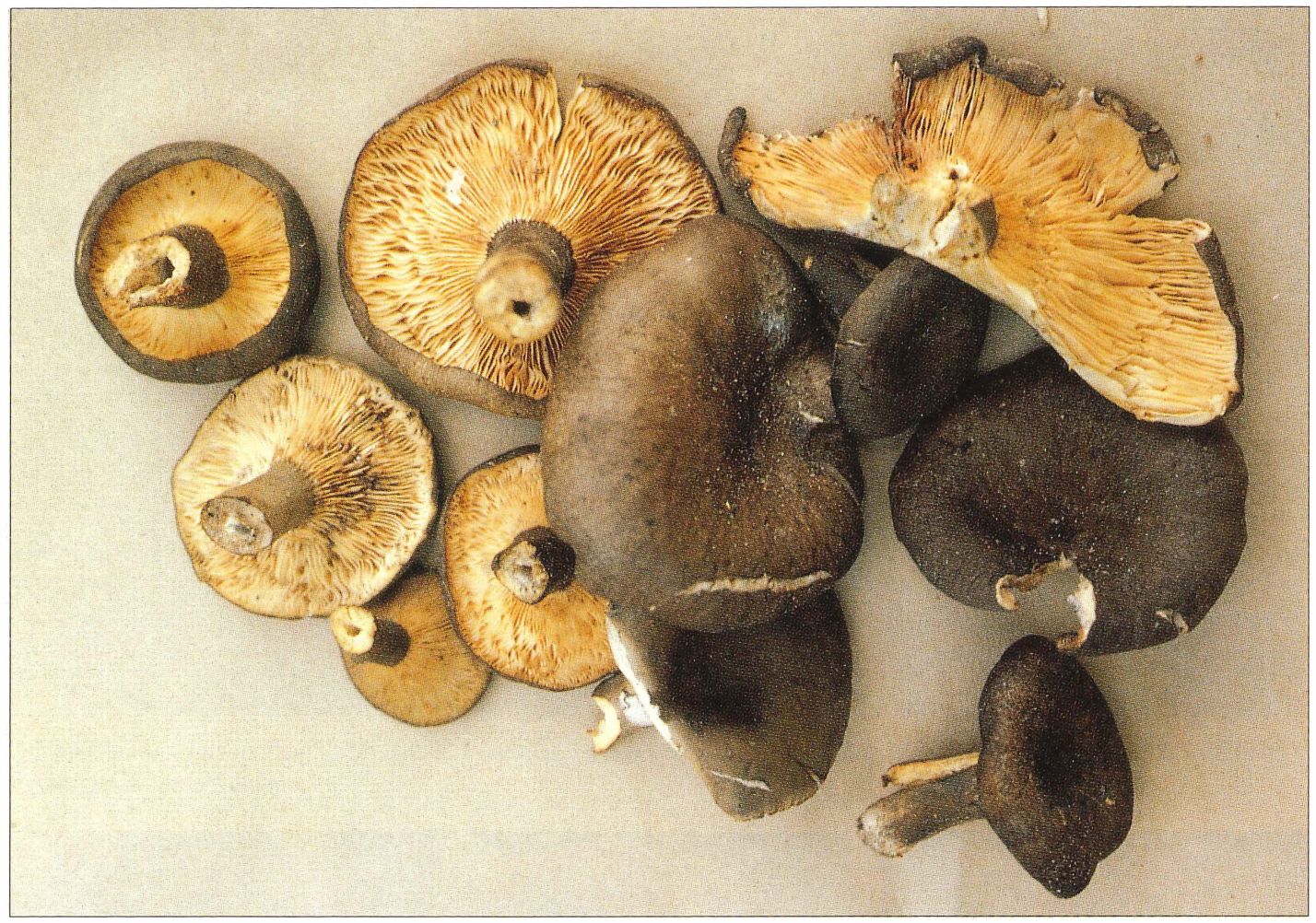

Fig. 71. Lactarius kabansus, UMPALALA, is a very small, dark coloured species. This specimen was purchased in Urambo market. The species is also offered for sale in Zambia where it is commonly eaten raw.

finely areolate. Gills shortly decurrent, subdistant with several lamellulae, fairly thick, up to $5 \mathrm{~mm}$ broad, pale cream, margin entire. Stipe $2-6 \times 1-3 \mathrm{~cm}$, variable in shape, cylindric to tapering, pale ochraceous, matted, weakly scrobiculate. Context in cap up to 13 $\mathrm{mm}$ thick, white, turning ochraceous on bruising; in stipe similar to cap, solid, milk latex white, abundant. Smell fresh, fruity. Taste mild, pleasant. Spore print pale cream.

Habitat: miombo woodland.

Spores 7.5-9 × 5-6 $\mu \mathrm{m}$, ellipsoid, ornamentation amyloid, punctate with few very fine connective lines, suprahilar plage partly amyloid. Basidia 4-spored, 60-70 × 7-9 $\mu \mathrm{m}$. Cheilocystidia cylindrical, $70-80 \times 10 \mu \mathrm{m}$. Pleurocystidia absent. Pseudocystidia abundant, 3-5 $\mu \mathrm{m}$ in diameter. Lactifers $4 \mu \mathrm{m}$ in diameter. Pileipellis trichodermium (thin layer of inflated cells, the apical 1-2 cells oriented in an upright position forming a turf). Pileocystidia $20-35 \times 6-10$ $\mu \mathrm{m}$, clavate, thin-walled. Stipitipellis consist of repent hyphae, the hyphal tips projecting as clusters of caulocystidia. Hyphae lack clamp connections.

This species resembles Lactarius phlebophyllus, but the ornamentation of spores and structure of stipitipellis differ from Lactarius phlebophyllus.

\section{Lactarius kabansus Pegler \& Piearce}

UMPALALA *** Fig. 71

Vernacular names: WISIGISA (Hehe), UMPALALA (Nyamwezi).

Edibility: Edible and popular, does not need to be parboiled. Sold in market places.

Cap $3-8 \mathrm{~cm}$ in diameter, first convex with 


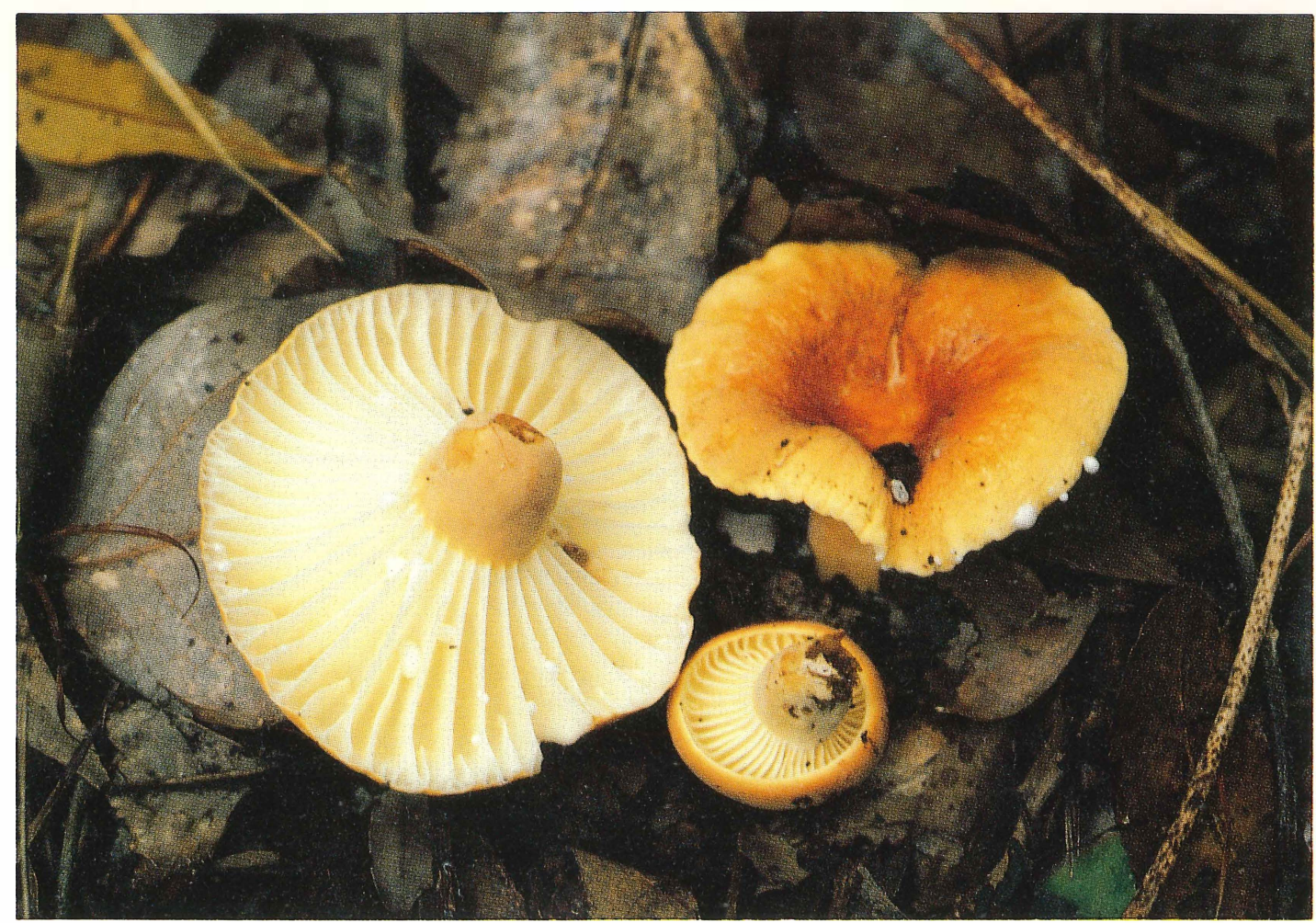

Fig. 72. Lactarius sp. aff. pseudovolemus, MPOFU, is orange-brown mushroom. It is so mild, that hunters may eat it raw in the field. This photo was taken in Mbozi, near Mbeya.

central depression, then uplifted, slightly umbilicate, margin incurved, surface blackish brown, smooth, matted. Gills decurrent, crowded, fairly thin, up to $2 \mathrm{~mm}$ broad, dark buff yellow, margin smooth. Stipe 2-2.5 $\times$ $0.7-1 \mathrm{~cm}$, sub-clavate, concolorous with cap, surface like in cap, apex longitudinally wrinkled. Context in cap white but the colour changes from white to pinkish on exposure to the air, fairly solid, $3 \mathrm{~mm}$ thick; in stipe white. Milk latex scanty, white. Smell acid. Taste mild. Spore print white.

Habitat: miombo woodland.

This small species can be recognized by its dark colour and the context that turns pinkish when bruised.

Spores 7-9 × 5,5-7 $\mu \mathrm{m}$, ellipsoid, ornamentation amyloid, composed of ridges (up to $1 \mu \mathrm{m}$ ) forming an irregularly interconnected reticulum, suprahilar plage inamyloid. Basidia 4- spored, 34-37(-50) $\times$ 9-11 $\mu \mathrm{m}$. Cheilocystidia clavate, hyaline, 13-27 × 6-7 $\mu \mathrm{m}$. Pleurocystidia absent. Pseudocystidia 3-6 $\mu \mathrm{m}$ in diameter. Lactifers 5-11 $\mu \mathrm{m}$ in diameter. Pileipellis trichodermium, pileocystidia clavate to piriform, thin-walled, $22-32 \times 8-14 \mu \mathrm{m}$ with fuscous brown contents. Stipitipellis composed of repent hyphae, 3 $\mu \mathrm{m}$ in diameter. Caulocystidia, the terminal elements of the hyphae, are similar to pileocystidia.

\section{Lactarius sp. aff. pseudovolemus Heim}

MPOFU *** Fig. 72

Vernacular names: UFANYI, WUNYAMAGULU (Bena), MPOFU (Nyiha), USELELE, UTUNDULU (Safwa).

Edibility: Edible. This species is so mild that hunters may eat itraw in the field. Easy topreserve by drying. 


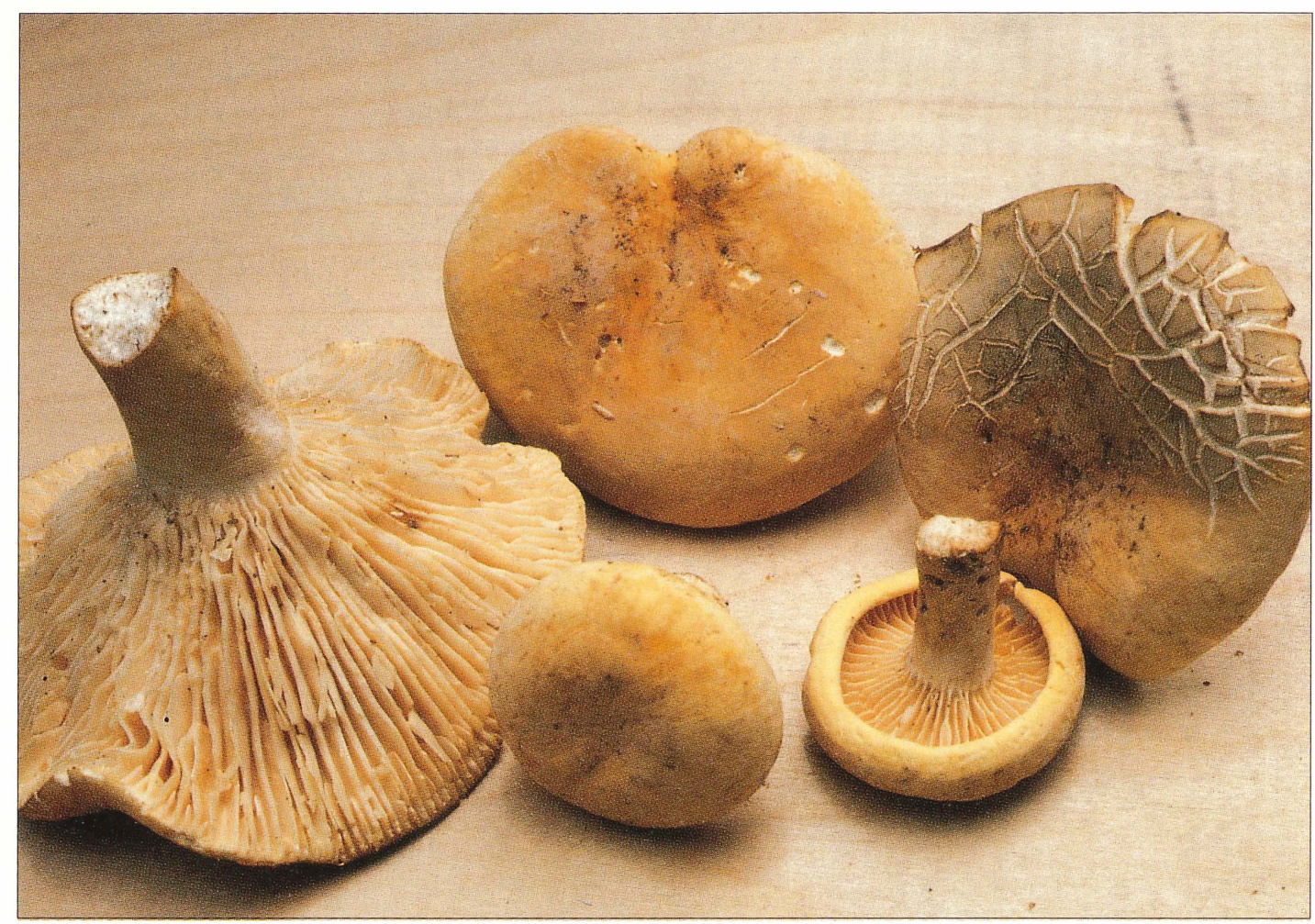

Fig. 73. Lactarius edulis, WISIMBA, is ochraceous, solid and mild mushroom. It is highly appreciated also in Burundi. Local people brought these specimens to us in Sao Hill, Iringa District.

Cap 4,5-9 cm in diameter, first convex, margin first incurved then uplifted and umbilicate. Surface orange or orange-brown, darker at center, tomentose, slightly wrinkled. Gills decurrent, distant, thick, up to $7 \mathrm{~mm}$ broad, white or cream, margin smooth. Stipe $2-3 \times 0,6-2 \mathrm{~cm}$, tapering downwards, concolorous with cap but paler. Context white, brittle, stipe often infested by maggots. Milk latex white and abundant. Smell weak, fishy (like Lactarius volemus). Taste mild.

Habitat: miombo woodland.

This mushroom is said to be very common in the end of the rains.

Spores 8,5-10,5 × 6-8,2 $\mu \mathrm{m}$, ellipsoid, ornamentation amyloid, composed of small warts and thin ridges forming an irregularly interconnected reticulum. Basidia 4-spored,
53-90 $\times 9,5-11 \mu \mathrm{m}$. Gill edge fertile. Pleurocystidia absent. Pseudocystidia 5-7 $\mu \mathrm{m}$ in diameter. Lactifers 6-10 $\mu \mathrm{m}$ in diameter. Pileipellis consists of thick-walled, rounded cells 15-20 $\mu \mathrm{m}$ in diameter with cylindrical, thick-walled, 10-75 $\times 3-6 \mu \mathrm{m}$ pileocystidia. Stipitipellis consists of repent hyphae, the hyphal tips projecting as caulocystidia. Hyphae lack clamp connections.

This species resemles Lactarius pseudovolemus, but the colour of gills, ornamentation of spores and length of basidia differ from Lactarius pseudovolemus.

\section{Lactarius edulis Verbeken \& Buyck}

WISIMBA *** Fig. 73

Vernacular names: WISIMBA (Hehe)

Edibility: Edible. This mushroom is highly appreciated also in Burundi. 
Cap 4-9 cm in diameter, first convex, margin incurved, then uplifted, margin irregular and wavy. Surface ochraceous, darker at center, matted, tomentose, smooth, old fruit bodies areolate. Gills decurrent, fairly distant, fairly thick, up to $6 \mathrm{~mm}$ broad, ochraceous cream, margin entire. Stipe 2,5$4,5 \times 1,6-2,1 \mathrm{~cm}$, equal, excentric, ochraceous cream close to gills, concolorous with cap elsewhere, surface smooth, matted. Context white, solid, in cap $16 \mathrm{~mm}$ thick, milk latex scanty. Smell weak. Taste mild.

Habitat: miombo woodland.

Spores 7,5-9,2 × 6-7,7 $\mu \mathrm{m}$, broadly ellipsoid, ornamentation amyloid, very low, punctate with few very fine connective lines. Basidia 4-spored, 60-78 × 8-11 $\mu \mathrm{m}$. Cheilocystidia clavate, $25-43 \times 7-8 \mu \mathrm{m}$. Pleurocystidia absent. Pseudocystidia 5-6 $\mu \mathrm{m}$ in diameter. Lactifers 5-7 $\mu \mathrm{m}$ in diameter. Pileipellis trichodermial palisade. All the cells are thin-walled. Terminal cells of hyphae cylindrical or tibiiform, $18-43 \times 3-11 \mu \mathrm{m}$. Stipitipellis consists of intertwining hyphae, 5-6 $\mu \mathrm{m}$ in diameter.

\section{Cantharellus}

\section{WISOGOLO}

The genus Cantharellus belongs to the order Aphyllophorales, a group with wide morphological variation. Common to this order is e.g. the absence of true gills. The sporebearing layer may be smooth or have wrinkles, spines, tubes or ridges.

Chanterelles are easy to recognize. Fruit bodies are fleshy, small to medium-sized, often trumpet- or funnel-shaped. Hymenium is sometimes smooth but in most species it is folded into shallow, rounded ridges which are longitudinally and regularly oriented, resembling the construction of agaric gills. Folds may also be irregular, forming a reticulate pattern. Most tropical species are brightly coloured: yellow, orange, pink or red or even black. Smell is usually fruity, very pleasant.

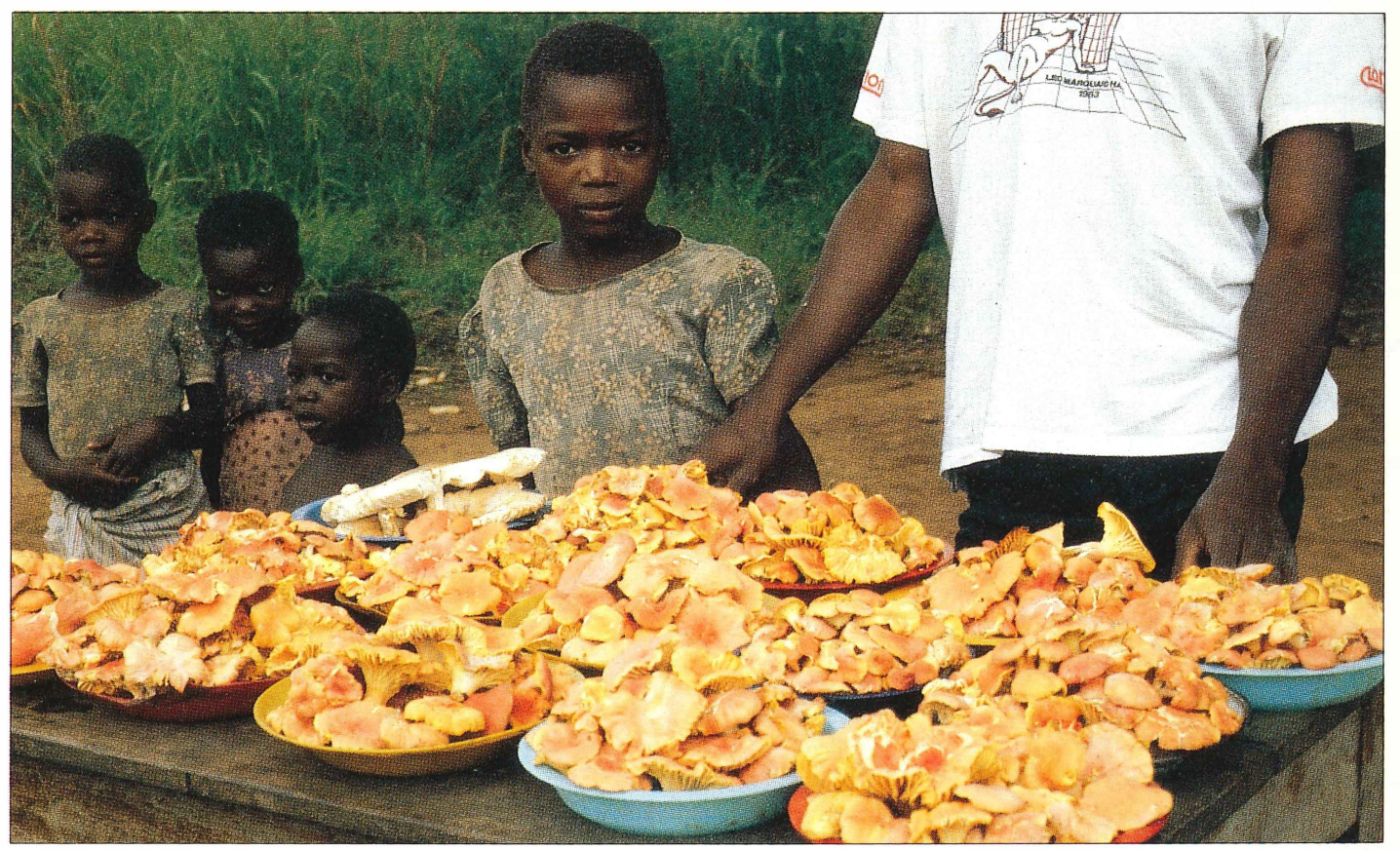

Fig. 74. Chanterelles offered for sale. 


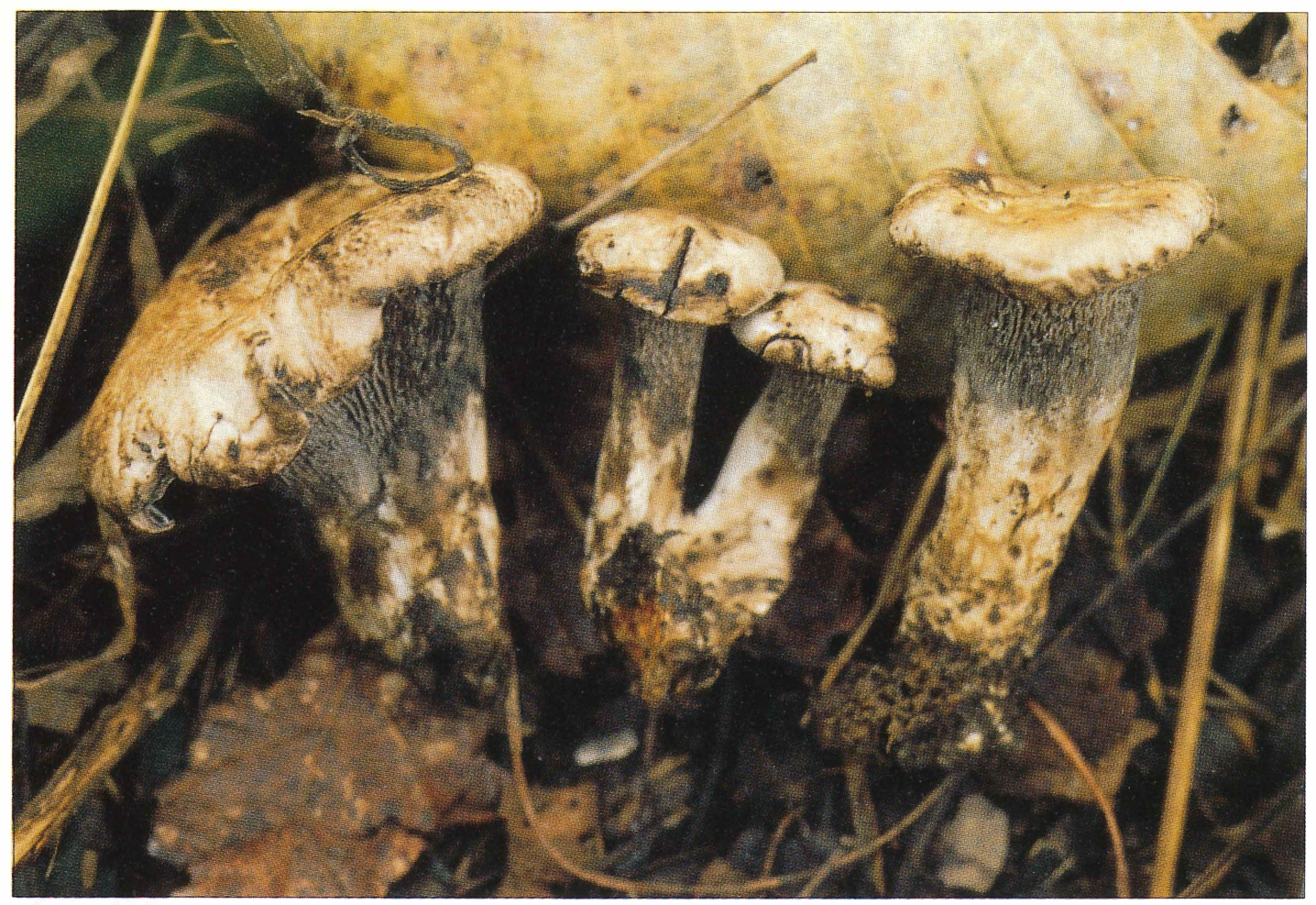

Fig. 75. Cantharellus congolensis, WISOGOLO MWEUSI, photographed near Mbeya, is easily recognized by the greyish brown colour and gill folds that form network.

Chanterelles are common, abundant and popular mushrooms in Tanzania. They are commonly offered for sale either fresh or dried, usually several species mixed together. In spite of the different size and colour the various Cantharellus species have often a common vernacular name. Several Tanzanian species are still scientifically undescribed.

\section{Cantharellus congolensis Beeli}

\section{WISOGOLO MWEUSI ** Fig. 75}

Vernacular names: WIFINDI (Bena), WISOGOLO, WIGINGILI (Hehe), BUKUKWE MWEUSI, BUTOBA (Nyamwezi), MKUKWE (Sumbwa), MADALI (Turu).

Edibility: edible, but not as highly appreciated as the bright coloured species of Cantharellus.
Cap 3-10 cm wide, fairly thick, convex with central depression, becoming concave, margin regular or lobed, surface brownish fuliginous, tomentose with darker flocci becoming black with age or on bruising. Gillfolds decurrent, fairly crowded, narrow and shallow, sooty black, forming network. Stipe cylindric or tapering downwards, concolorous. Context firm and fibrous, greyish, then pinkish, blackening on exposure. Smell acrid, mushroomy, taste slightly bitter when fresh.

Habitat: In groups in miombo woodland.

This species is unmistakable. The greyish brown or black colour distinguishes it from the bright coloured chanterelles, but the appearance of the fruit bodies is otherwise that of a typical chanterelle.

Spores 5.3-7.5 × 3.9-5.0 $\mu \mathrm{m}$, ellipsoid. Basidia 4-6spored, 35-60 $\mu \mathrm{m}$. Hyphae clamped, on surface of pileus 3-13 $\mu \mathrm{m}$ in diameter, with slightly thickened wall, terminal cells clavate or cylindric, sometimes little flexuous. 


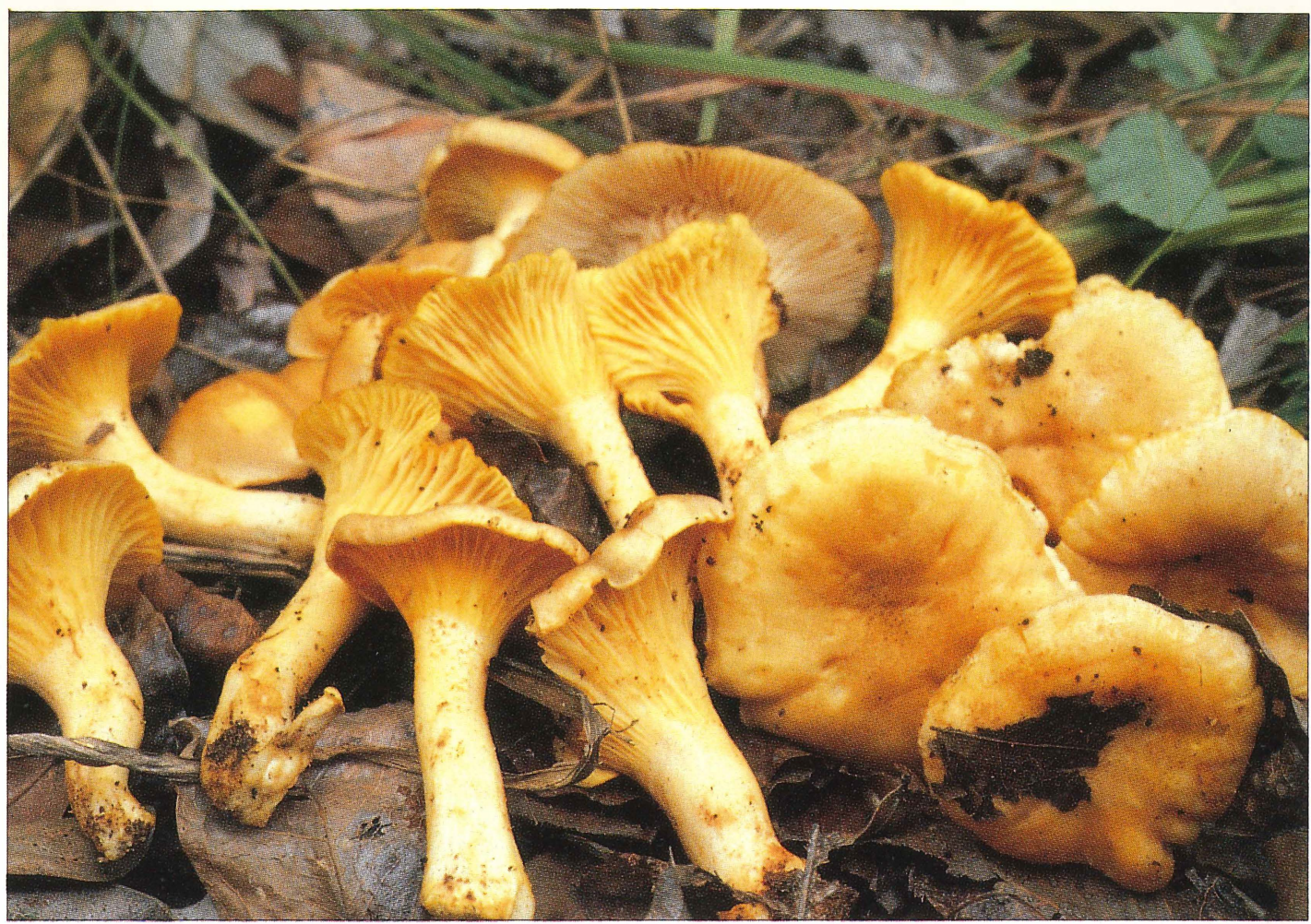

Fig. 76. A typical Cantharellus isabellinus, WISOGOLO WA MANJANO, with brown squamules on the pileus, was photographed in Rukohe, Masasi district.

\section{Cantharellus isabellinus Heinem.}

\section{WISOGOLO W MANJANO *** Fig. 76}

Vernacular names: CHIPATWE, UJAMA, UPATWE (Makonde), UBULUWA (Mwera).

Edibility: edible.

Cap $3-5 \mathrm{~cm}$ in diameter, fleshy in the center, at first convex and slightly depressed in the middle, then irregularly funnel-shaped and wavy. Surface brownish yellow with tiny brown squamules, most abundant in the center. Gill-folds decurrent, subdistant, fairly thin, up to $4 \mathrm{~mm}$ broad, unequal, sometimes forked, intervals faintly veined, at first ochraceous becoming pale yellow and then pale pink. Stipe $3-4 \times 0.8-1 \mathrm{~cm}$, solid, cy- lindric or slightly tapering or thickening downwards, straight or sometimes curved, surface almost white, becoming ochraceous from below upwards, apex hairy. Context soft, rather fibrous, white, turning bright yellow on exposure, especially at stipe base. Smell pleasant, fruity. Taste mild. Spore print pale pinkish ochraceous.

Habitat: miombo woodland.

This species resembles by its colour Cantharellus cibarius, an appreciated edible mushroom in Europe and North America. There are several edible yellow species of Cantharellus in Tanzania.

Spores 7.5-9 × 3.5-4.5 $\mu \mathrm{m}$, cylindric. Basidia 37-63 $\times 7-$ $8 \mu \mathrm{m}, 4-5$-spored. Hyphae on the surface of the pileus with cylindric end-cells, $24-54 \times 6-10 \mu \mathrm{m}$. Oleiferous hyphae present in trama. Clamps not observed. 


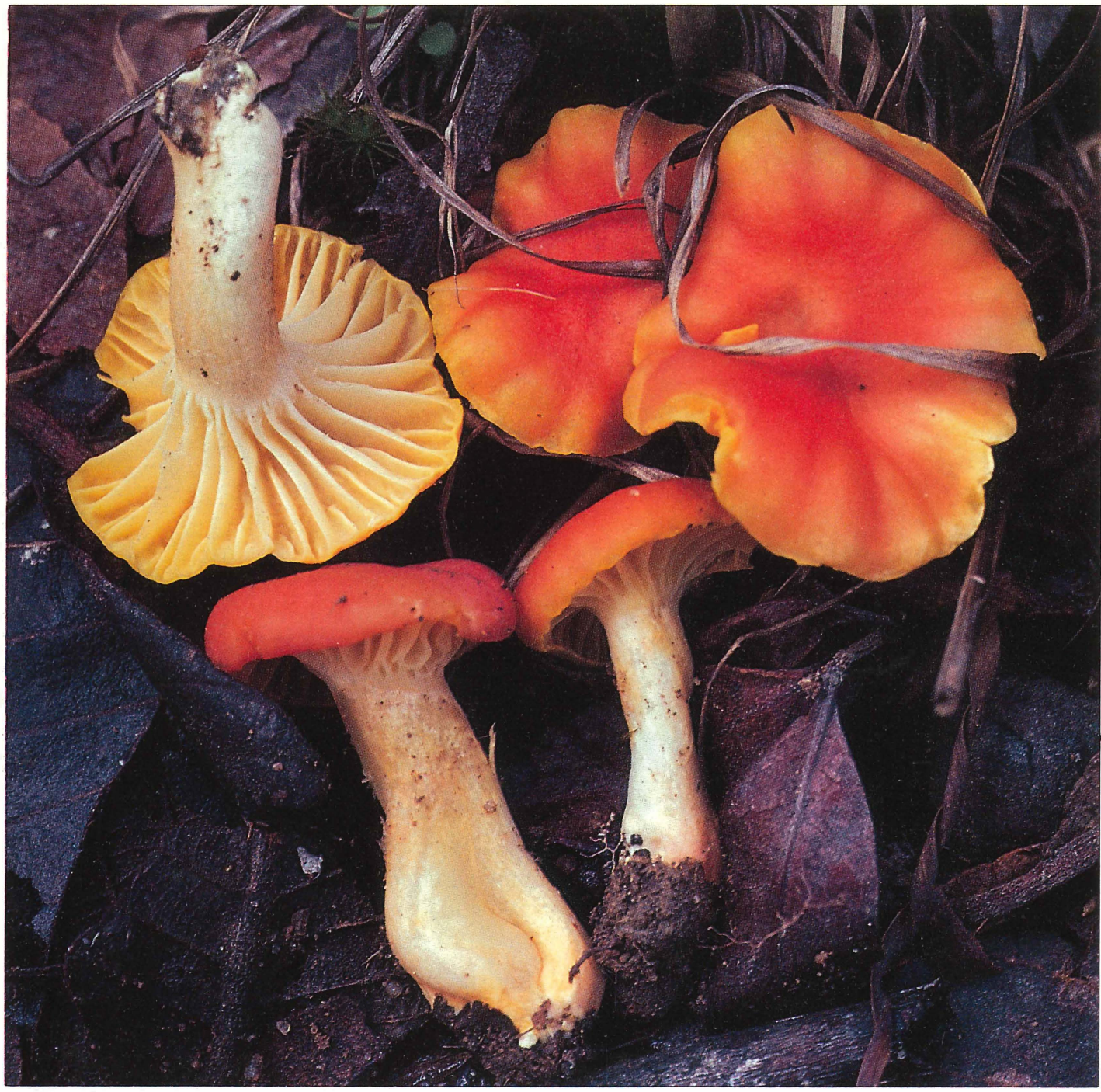

Fig. 77. Cantharellus platyphyllus, WISOGOLO WA RANGI MBILI, one of the bright coloured Cantharellus species, is common in miombo near Kidugala, Njombe district.

Cantharellus platyphyllus Heinem.

\section{WISOGOLO WA RANGI MBLI**** Fig. 77}

Vernacular names: BUNYAMALAGATA, WIFINDI (Bena), WISOGOLO (Hehe).

Cap 2-5(-9) $\mathrm{cm}$ in diameter, fleshy, first convex, at center depressed, margin incurved and often regularly wavy then irregularly funnel-shaped with expanded and undulating margin. Surface red at center becoming orange towards margin, matted, radially furrowed. Gills decurrent, distant (ca. 8 per $\mathrm{cm}$ ), pale to bright yellow, up to $7 \mathrm{~mm}$ broad in the largest individuals, interveined. Stipe $2-4(-7) \mathrm{cm} \times 6-$ $12(-20) \mathrm{mm}$, equal to tapering, often curved, surface smooth, tinged with red, orange or yellow. Context reddish under pellicle, otherwise white, sometimes getting a faint greenish tint when cut. Smell fruity, taste slightly bitter. 


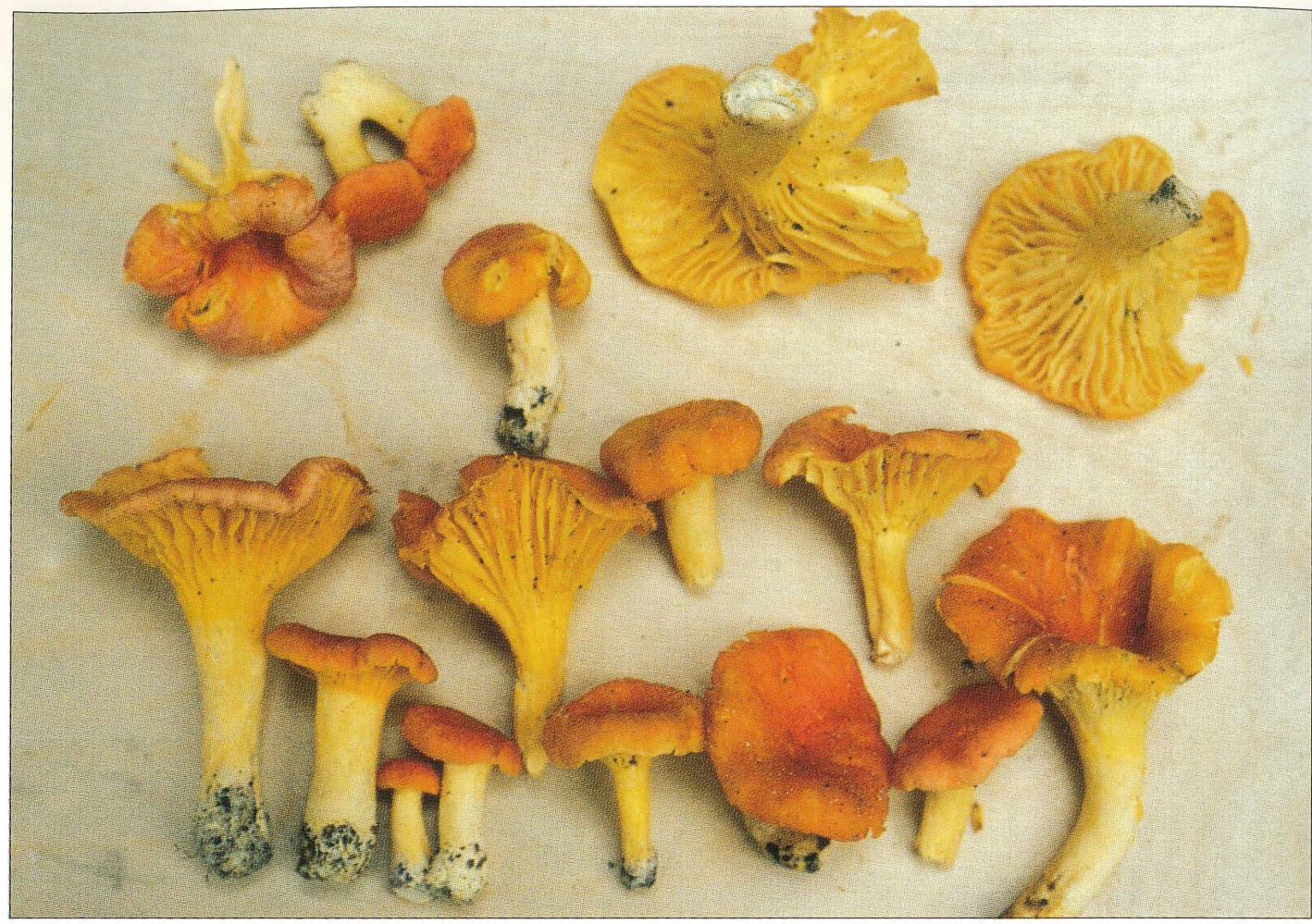

Fig. 78. Cantharellus symoensii, WISOGOLO WA RANGI MBILI, is much appreciated and often offered for sale. This specimen was purchased in Kinondori market, Dar es Salaam.

Habitat: miombo woodland.

This and the following species both have reddish cap surface and yellowish gills and so they have the same Swahili name "two-coloured-chanterelle".

Spores 8-10(-13) $\times 5-7.5 \mu \mathrm{m}$. Basidia oblong, (46-)55-75 $\times 8-10.5 \mu \mathrm{m}, 4-6$-spored. Pileipellis of hyaline, thin-walled, cylindric hyphae; terminal hyphae $20-68 \times 5-11(-13) \mu \mathrm{m}$. Hyphae without clamps.

\section{Cantharellus symoensii Heinem.}

WISOGOLO WA RANGI MBILI* Fig. 78

\section{Vernacular names: WIFINDI (Bena), WISOGOLO (Hehe)}

Edibility: edible.
Cap $2-6 \mathrm{~cm}$ in diameter, thin, depressed at center and convex at margin when young, later strongly funnel-shaped, margin split and slightly flexuous. Surface tinged unevenly with red and orange. Gill-folds decurrent, fairly distant, orange-yellow, thin, up to 5 $\mathrm{mm}$ broad, branched and intermixed. Stipe 1,5-4 cm long, cylindric or tapering downwards, sometimes sinuate, surface smooth, yellow, becoming paler towards the base. Context light-yellow, rather tough, similar in cap and stem. Smell pleasant, fruity. Taste mild.

Habitat: miombo woodland.

Spores 8-11 $\times 4-5 \mu \mathrm{m}$, ellipsoid, sometimes with central constriction. Basidia 35-57 × 6-8 $\mu \mathrm{m}, 2-4-5$-spored. Hyphae on surface of pileus interwoven, cylindric, 3-8 $\mu \mathrm{m}$ in diameter, with clavate end-cells, up to $10.5 \mu \mathrm{m}$ in diameter; without clamp connections. 


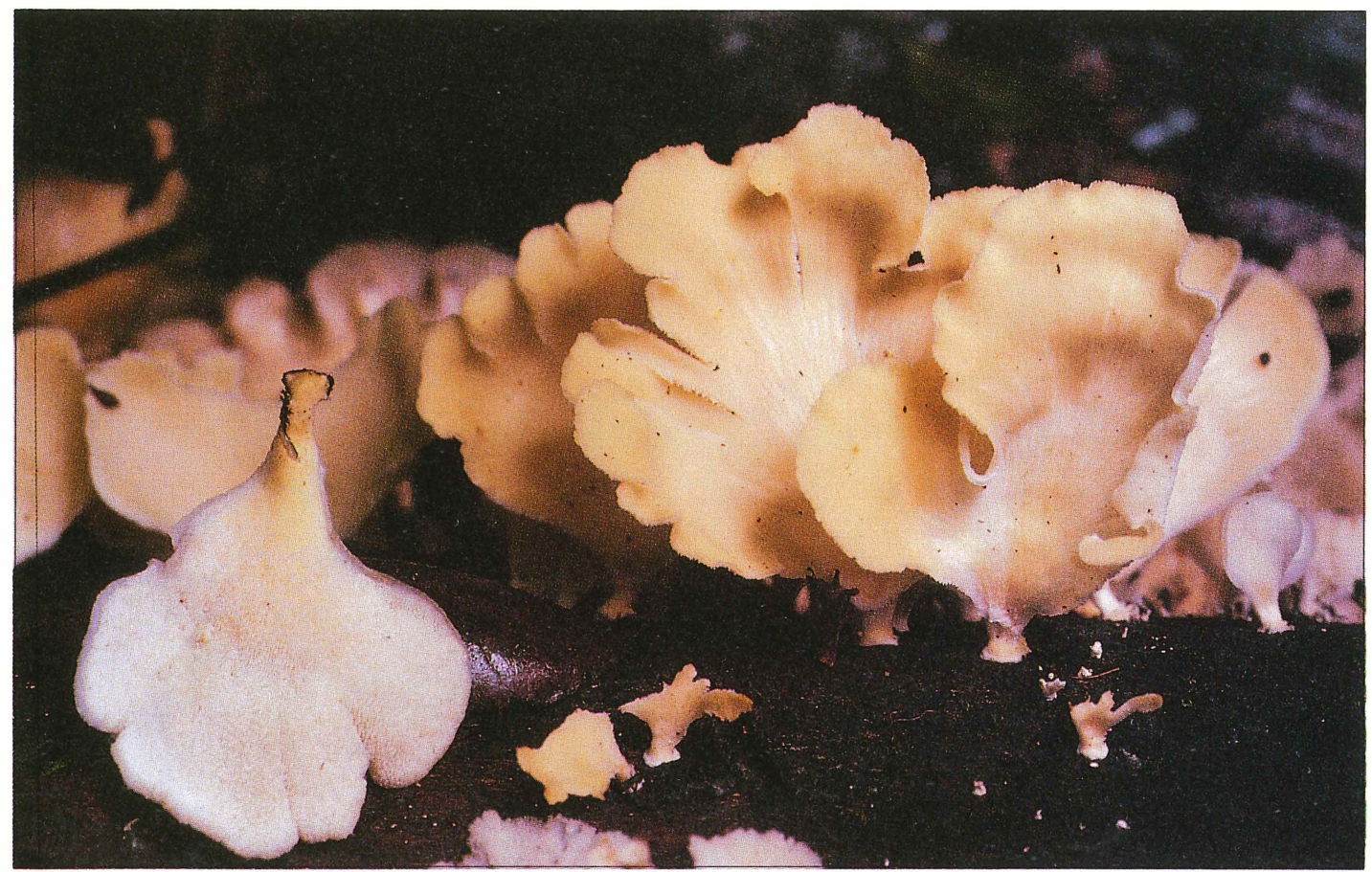

Fig. 79. Polyporus moluccensis, NGAHA, is a flat tough species with pores underside. It grows on decaying wood, and is well-liked in Mazumbai, West Usambara Mts., were this picture was taken.

\section{Polyporus}

The genus Polyporus belongs to the order Aphyllophorales and is nearer the genus Cantharellus than gilled fungi. Fruit bodies are annual, tough when fresh, hard when dry, with well-developed central to lateral stipes. Instead of gills these fungi have tubes with pores. Pores are round or angular, small to large.

Because of the tough texture, only a few species are collected for food, and those only among people living in mountain forests.

\section{Polyporus moluccensis (Mont.) Ryv.}

syn. Favolus spathulatus (Jungh.) Bres.

NGAHA * Fig. 79

Vernacular name: GAHA (Ngoni), NGAHA (Sambaa).
Edibility: edible. Because of the tough consistency fruit bodies are first boiled for about an hour and then pounded after which they are fried and mixed with onions, tomatoes etc. The water used for boiling is added to the stew to give more flavour.

Cap up to $11 \mathrm{~cm}$ across, fan-shaped, spathulate or semicircular, strongly tapering towards the point of attachment. Surface convex to flat, often depressed near the stipe, cream to straw-coloured, becoming brownish when old, strongly radiate-striate from base to margin. Margin acute, incurved or depressed, entire or lobed. Stipe, if present, lateral, short, up to $5 \mathrm{~mm}$ in diameter, concolorous with the cap surface. Pore layer concolorous with the cap or darker, darkening with age, pores hexagonal to radially elongated, at edge about 30 pores per $\mathrm{cm}$, at base less. Context cream to straw-coloured, thin, tough. Smell sour. Taste fairly mild.

Habitat: on decaying wood in moist mountain forests. 


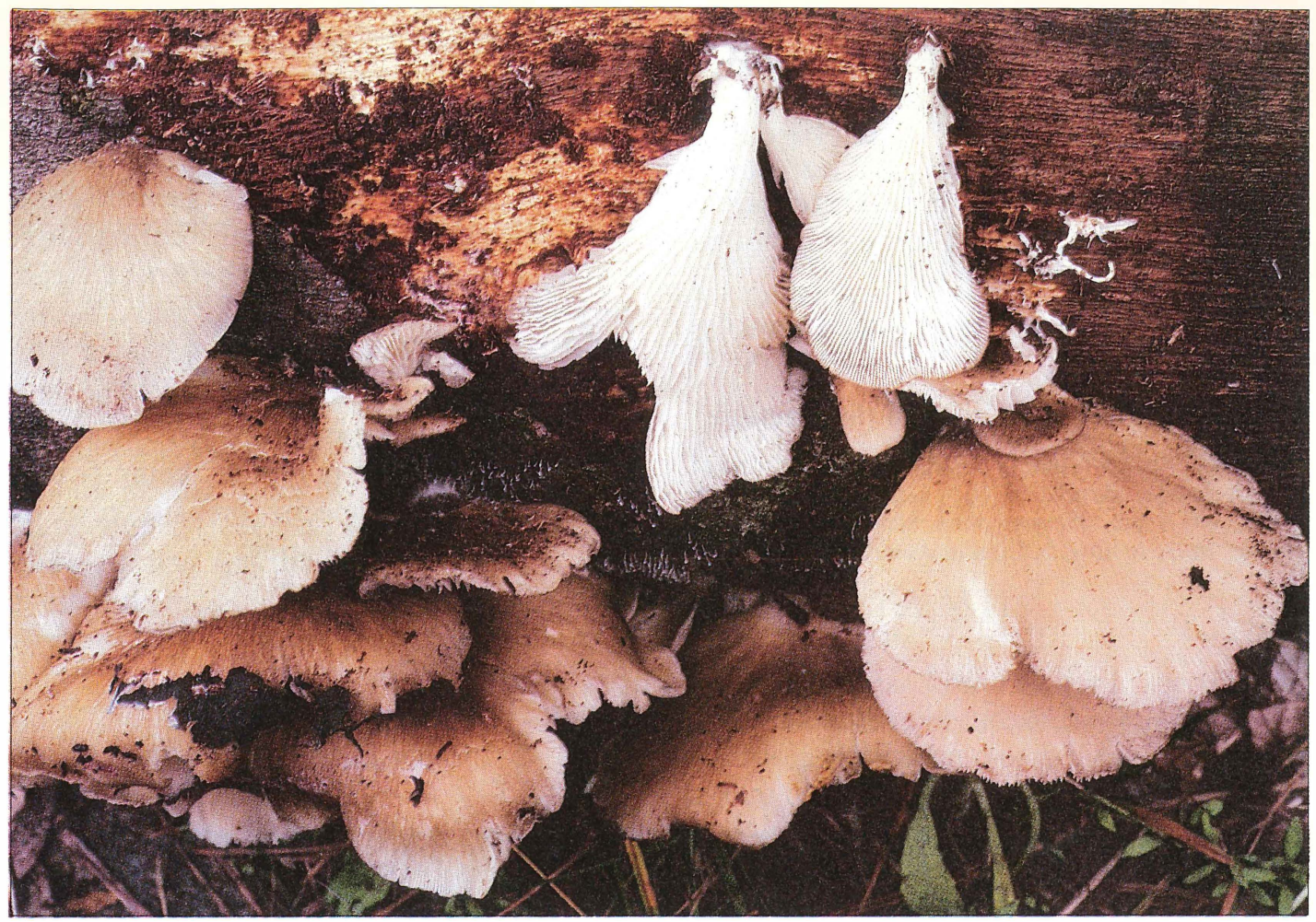

Fig. 80. Pleurotus djamor, MAMAMA, is a pan-tropical species growing on decaying wood. Species of Pleurotus are appreciated in many parts of the world. This picture was taken in Mazumbai, West-Usambara mountains.

The fruit bodies are annual and grow solitary or several together. In the forests of Mazumbai, the West Usambaras, this species is abundant and well-liked by local people. Polyporus tenuiculus (Beauv.)Fr., which is closely related and similar-looking, also occurs in the West Usambaras. Both species are called by the same name and eaten in the same way.

Spores $6.0-10.0 \times 2-3.5 \mu \mathrm{m}$, cylindrical, hyaline, thinwalled. Basidia clavate, $15-25 \times 3-6 \mu \mathrm{m}$ with 4 sterigmata. Hyphal system dimitic with skeleto-binding hyphae.

\section{Pleurotus}

Fruit bodies of this genus are typically fanshaped or semicircular without a stipe or with a stipe attached in a lateral or eccentric manner. They grow on dead wood and the genus has a worldwide distribution.

Many species are edible and some are commercially cultivated in many parts of the world. In Tanzania species of Pleurotus are commonest in mountainous areas where they are collected for food.

\section{Pleurotus djamor}

MAMAMA $* * *$ Fig. 80

Vernacular names: MAMAMA, MAMENO (Sambaa).

Edibility: edible, and stands transport and preserving rather well. 
Cap 3-8 cm across, fan-shaped, surface olicaveous beige, silky-striate, not peelable. Old caps becoming villous at the base. Margin striate, rimose, and white, becoming villous. Gills decurrent, white, fairly crowded (about 13/cm), thin. Stipe lateral, very short, hairy. Context white, thin, tough. Smell mushroomy, taste mild.

Habitat: grows in overlapping groups on dead wood.

\section{This species has a pantropical distribution.}

Spores $6.5-9 \times 2.5-4 \mu \mathrm{m}, \mathrm{Q}=2.33$, cylindric, inamyloid, without guttules. Basidia 15-20 × 4-5 $\mu \mathrm{m}$. Cheilocystidia $15-20 \times 6-8 \mu \mathrm{m}$. Pleurocystidia none. Hyphal system dimitic. Hairs in tufts, $2-5 \mu \mathrm{m}$ in diameter, with clamps.

\section{Boletes}

In spite of some obvious differences, boletes are considered to belong to Agaricales, the same order to which all the gill-bearing fungi belong. Usually boletes have a robust appearance with a hemispherical cap, and a fleshy stipe. Typical of boletes is that instead of gills they have tubes, just like polypores. The tube layer of boletes is easy to remove from the cap context, that of polypores being firmly fixed. In other respects, the structure of boletes is similar to agarics.

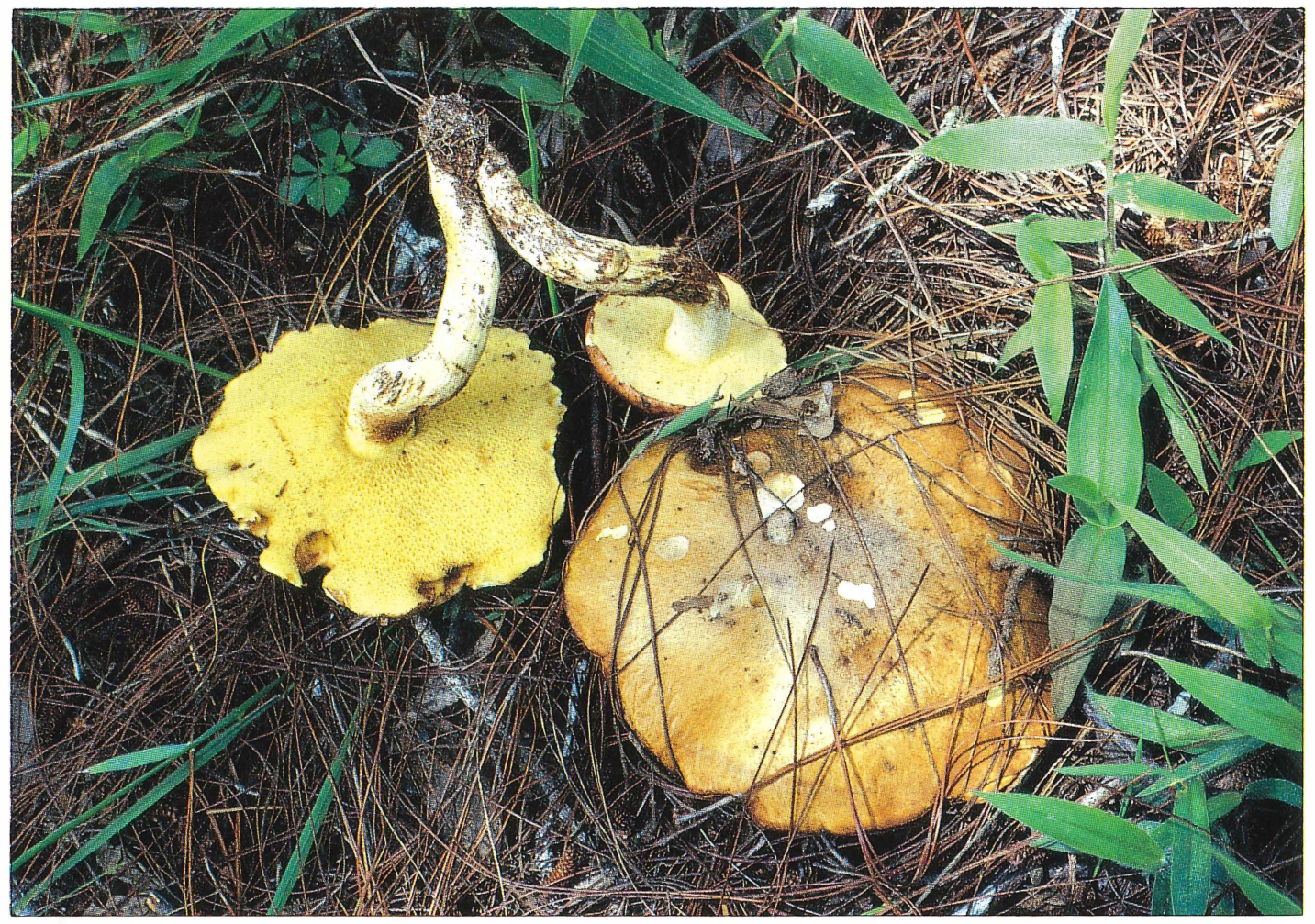

Fig. 81. Suillus granulatus, USUILISI, is not indigenous in Tanzania, but introduced and well established in pine plantations like these specimens growing in Mufindi under planted Pinus patula. It is a slimy mushroom having pale yellow pores under the cap. 
Most of the species are associated with trees. In Tanzania miombo woodland with leguminous trees is a natural habitat of indigenous boletes. In addition some species have been introduced with conifer hosts. Such is Suillus granulatus which grows together with several Pinus species.

Several ethnomycological works from the Eastern and Central African countries reveal that boletes are treated with suspicion and considered inedible or poisonous. The same attitude was found common also in Tanzania among all the tribes we interviewed. Only some Bena, Hehe and Makonde people included a few species in their diet after parboiling them.

\section{Suillus granulatus (L.) Kuntze}

\section{USUILISI ** Fig. 81}

\section{Vernacular names: none.}

Edibility: edible and good. Should be prepared soon after collecting because of the soft, perishable flesh.

Cap 5-10 cm in diameter, convex, brownish yellow to reddish brown, surface sticky, becoming shiny when dry, smooth or slightly wrinkled. Tubes and pores pale or bright yellow, pores small, 1-2 per mm, regular, sometimes exuding pale droplets of liquid. Stipe 4-10 $\times 0.5-2 \mathrm{~cm}$, solid, pale yellow, at apex white or brownish small granules. Context soft, yellowish, unchanging. Smell pleasant, taste mild.

\section{Habitat: Pinus plantations.}

This species, associated always with exotic pines, is commonly ignored by Tanzanians. It is worth introducing, however, since it is edible and nutritionally competitive with wild mushrooms. It is easy to identify by the sticky, brownish cap, yellow tube layer and the yellowish stipe bearing granules. Largescale deforestation and reforestation with exotic trees cause monocultures and destroy the natural vegetation and yields of wild fungi. In these areas $S$. granulatus could be a substitute mushroom and its consumption should be encouraged and popularized.

Spores 7-9 × 2.5-3.5 $\mu \mathrm{m}$, cylindric. Basidia 18-23 ×6$7 \mu \mathrm{m}$, clavate, with four sterigmata. Cheilocystidia fasciculate, $30-50 \times 5-10 \mu \mathrm{m}$, clavate to subcylindric, strongly encrusted. Pleurocystidia similar to the cheilocystidia, encrusted especially towards the base. Pileal surface a gelatinized, loose trichodermium, with hyphae 2$6 \mu \mathrm{m}$ in diameter.

\section{Auricularia}

\section{MASIKIO YA MTI}

The genus Auricularia belongs to the subclass Phragmobasidiomycetidae. Auricularia differ from ordinary mushrooms in having a jelly-like texture and no gills. These fungi grow on the wood of decaying stumps or logs. Fruit bodies are variable in form, from flattened to substipitate cup-, ear- or shell-shaped and folded, occasionally stipitate. They grow solitary or many close to one another or overlapping each other. The outer surface is velvety or hairy and brown in colour. The inner surface, which is spore-bearing hymenium, is smooth or wrinkled, pallid or rosy to brown or black in colour. Texture is rubber-gelatinous when fresh, but thin and hard when dried.

Some of the species are edible and highly prized. Auricularia auricula-judae Bull.:Fr. and A. polytricha (Mont.) Sacc., for instance, are cultivated in China and Japan. The scientific name derives from a legend, according to which Judas Iscariot, after betraying Jesus, hanged himself on the tree where these fungi grew. In Tanzania we were told a story about men who came across an animal in the forest. They killed it but cut its big ears off because they might have scared the women. When they later returned to the same forest several "ears" were growing on the tree trunks.

As with other wood-inhabiting fungi the use of Auricularia in Tanzania is restricted to mountainous areas. The majority of the tribes weinterviewed did not consider these as fungi at all. There are several species having common vernacular names and common use. Three of them are introduced here. 


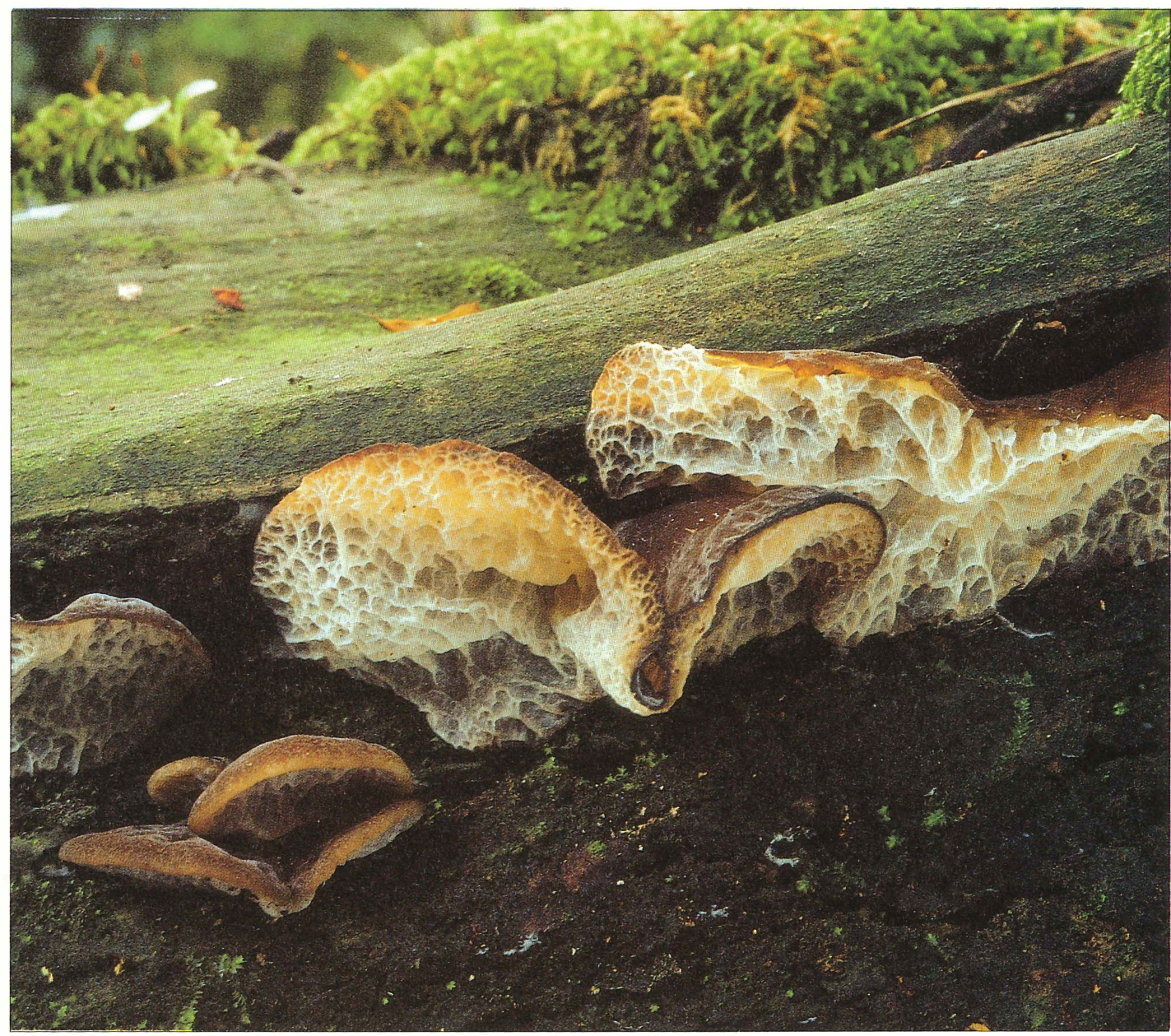

Fig. 82. Auricularia delicata, MANGHWEDE, is a jelly-like mushroom without gills. There are several species under the same vernacular name. Auricularia delicata is easy to identify by the reticulate apperance of its underside. This specimen grew on decaying wood in Olmotonyi on Mt. Meru.

Auricularia delicata (Fr.) Henn.

\section{MANGHWEDE ** Fig. 82}

Vernacular names: MAKUTU MBONGO (Makonde, Makua), MANGAUKAU (Ngoni), PAMPAMLA (Nyiha), MANGHWEDE (Sambaa), UYOGA HINDI (Swahili).

Edibility: all the species introduced here are edible and much used especially in the West Usambara Mountains. These fungi do not have any special taste but it is perhaps the characteristic cartilaginous texture resembling liver that pleases people.

Fruit bodies solitary or growing close to one another; ear-shaped or rounded, 3-6 cm in diameter; fleshy, rubbery and tough gelatinous when fresh, hard and horny when dried; 
upper surface pale to dark brown, with moderately distributed short hairs never in dense tufts; inferior surface whitish, becoming strongly ornamented with a net-like pattern.

\section{Habitat: on decaying wood.}

Because of the reticulate appearance of the hymenium, this species can be readily distinguished macroscopically from other Auricularia species.

Zona pilosa with hairs variable in length, 50-155 $\mu \mathrm{m}$ long, 4-7 $\mu \mathrm{m}$ in diameter, hyaline, thick-walled with rounded tip. Zona compacta $25-40 \mu \mathrm{m}$ wide. Zona subcompacta superior 40-50 $\mu \mathrm{m}$ wide, hyphae loosely arranged. Zona intermedia $400-500 \mu \mathrm{m}$ wide. Zona subcompacta inferior 70-100 $\mu \mathrm{m}$ wide. Hymenium ca. $80 \mu \mathrm{m}$ wide, basidia 40 50 long. Spores allantoid, $11-12 \times 4.5-5 \mu \mathrm{m}$.
Auricularia polytricha (Mont.) Sacc.

\section{MANGHWEDE ** Fig. 83}

Fruit bodies at first cup-shaped then earshaped or folded, up to $9 \mathrm{~cm}$ broad, $1-1.5 \mathrm{~mm}$ thick, sessile or slightly stipitate, rubbery to tough when fresh; upper surface strongly convex, densely covered with hairs forming tufts; hymenial surface glossy, usually smooth, dark purple or lilac, becoming blackish when dried.

Habitat: on decaying wood.

Typical of this species is the densely matted hair layer and a rather tough texture.

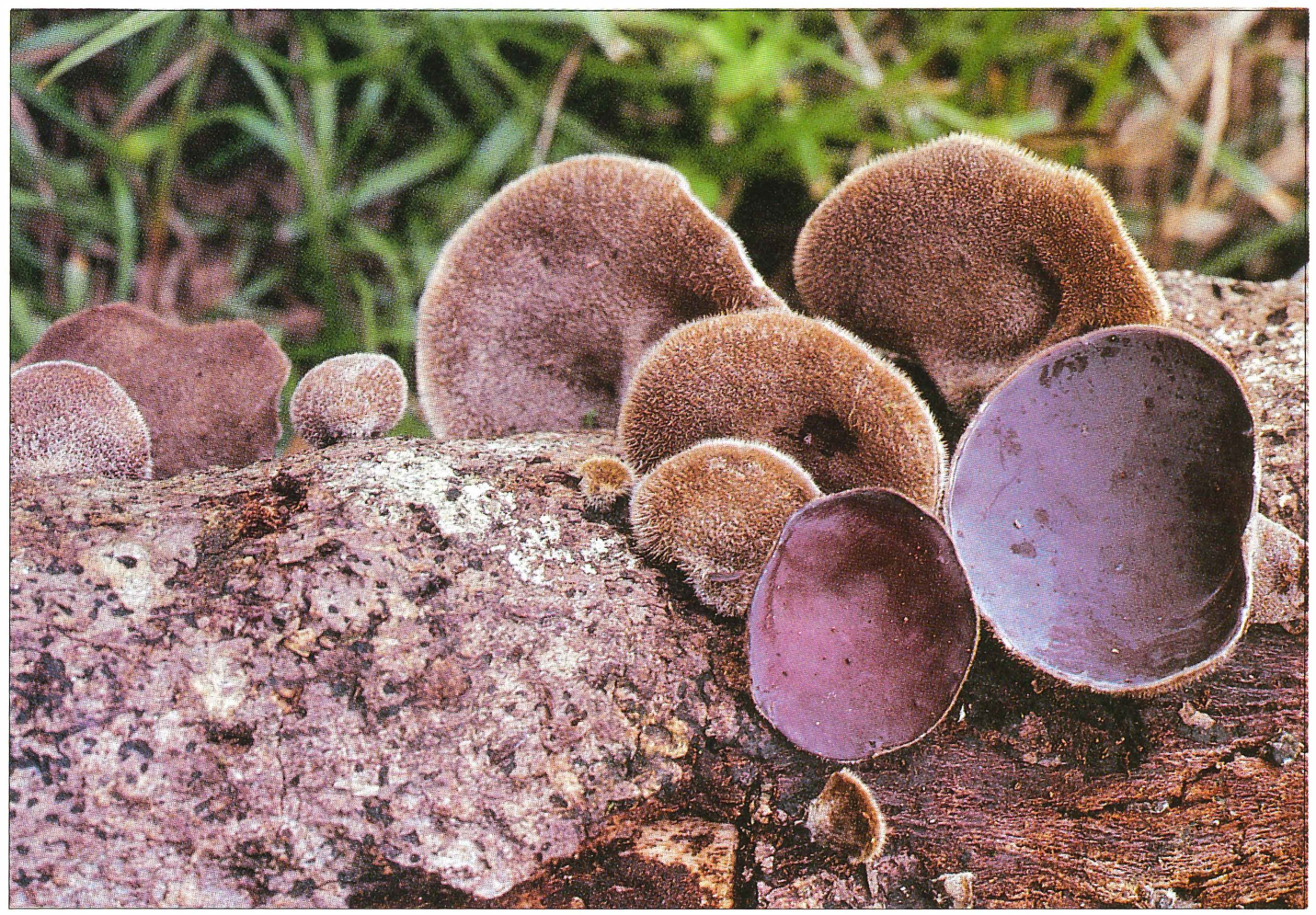

Fig. 83. Auricularia polytricha, MANGHWEDE, is recognized by the densely matted hair layer on the surface of the cuplike fruit body. Two fruit bodies have been turned upside down. This photo was taken in Mazumbai where different species of MANGHWEDE are used for food. The genus Auricularia is a commercial mushroom in many parts of the world, most of all in South-East Asia. 
Zona pilosa with hairs up to $800 \mu \mathrm{m}$ long, 5-7 $\mu \mathrm{m}$ in diameter. Zona compacta 20-30 $\mu \mathrm{m}$ wide. Zona subcompacta superior $80-100 \mu \mathrm{m}$ wide. Zona laxa superior 225-250 $\mu \mathrm{m}$ wide. Medulla ca. $260 \mu \mathrm{m}$ wide with hyphae 3-4 $\mu \mathrm{m}$ in diameter. Zona laxa inferior 200 $225 \mu \mathrm{m}$ wide. Zona subcompacta inferior $100-150 \mu \mathrm{m}$ wide. Hymenium about $80 \mu \mathrm{m}$ wide, basidia 50-55 $\times 4$ $5 \mu \mathrm{m}$. Spores $12-13 \times 4.5-5 \mu \mathrm{m}$, allantoid.

\section{Auricularia fuscosuccinea (Mont.) Farlow}

\section{MANGHWEDE **}

Fruit bodies solitary or growing close to one another; gelatinous and thin when fresh, translucent and brittle when dry; up to $12 \mathrm{~cm}$ wide, $0.5-0.8 \mathrm{~mm}$ thick; upper surface with widely scattered minute hairs giving the surface in some parts a velvety appearance; hymenial layer rosy to reddish brown when fresh, becoming darker when dried, smooth to wrinkled.

Habitat: on decaying wood.

The rosy colour of the hymenium in the fresh state and the thin appearance of the fungus are distinct enough to separate this species from the others.

Zona pilosa with hairs 50-80 $\mu \mathrm{m}$ long, 3-5 $\mu \mathrm{m}$ in diameter, never forming tufts, tips rounded. Zona compacta 20 $25 \mu \mathrm{m}$ wide. Zona subcompacta superior about $20 \mu \mathrm{m}$ wide. Zona laxa superior about $130 \mu \mathrm{m}$ wide. Medulla about $20 \mu \mathrm{m}$ wide, with hyphae $2-4 \mu \mathrm{m}$ in diameter. Zona laxa inferior $60 \mu \mathrm{m}$ wide. Zona subcompacta inferioris 60-70 $\mu \mathrm{m}$ wide. Hymenium $60-80 \mu \mathrm{m}$ wide, basidia 50 $60 \mu \mathrm{m}$ long. Spores $11-12.5 \times 4-5 \mu \mathrm{m}$, allantoid.

\section{Chlorophyllum $\dagger$}

The fruit bodies of this genus are provided with the unique greenish colouration of the gills and spores. In general, only a single variable species has been recognized. It is common and widely distributed in the tropi$\mathrm{cal}$ and subtropical regions. It mostly grows on rich soil, in gardens, plantations and rubbish heaps or in bushlands. There is some controversy about the edibility, but the majority of the people who eat this mushroom get symptoms of poisoning, although not fatal ones.

\section{Chlorophyllum molybdites (Meyer : Fr.) Massee}

\section{VIKAO RANGI-HAFIFU † Fig. 84}

Vernacular names: VIDUDU, VIKAO (Makonde), VIDUDU (Makua).

Edibility: poisonous, poisons causing nausea, vomiting and diarrhoea (see page 35).

Cap $8-13 \mathrm{~cm}$ in diameter, at first subglobose finally flat, with a shallow umbo; white background covered with dense, pale brown scales except of the umbo which stays as a pale brown disk, edge finely striate. Gills free, at first white then pale or yellowish green, close, thin, up to $16 \mathrm{~mm}$ broad, margin smooth. Stipe $7-14 \times 0.6-1.3 \mathrm{~cm}$, equal with bulbous base, easily separable from the cap, surface white to straw, discolouring chrome yellow when handled, smooth and silky. Ring well developed, superior, moveable, white, and thick with a fimbriate rim. Context in cap soft and cottony, up to $10 \mathrm{~mm}$ thick, white turning first yellowish then reddish brown; in stipe fibrous, hollow, slightly reddish on bruising. Smell sweetish. Taste mild, slightly soapy and unpleasant, sometimes bitter aftertaste. Spore print pale green, fading to yellow.

Habitat: cultural and bushland vegetation.

Possibilities of confusion: Chlorophyllum molybdites is an attractive fungus which may tempt a mushroom hunter to pick it unaware. The green tinge on the gills of mature fruit 


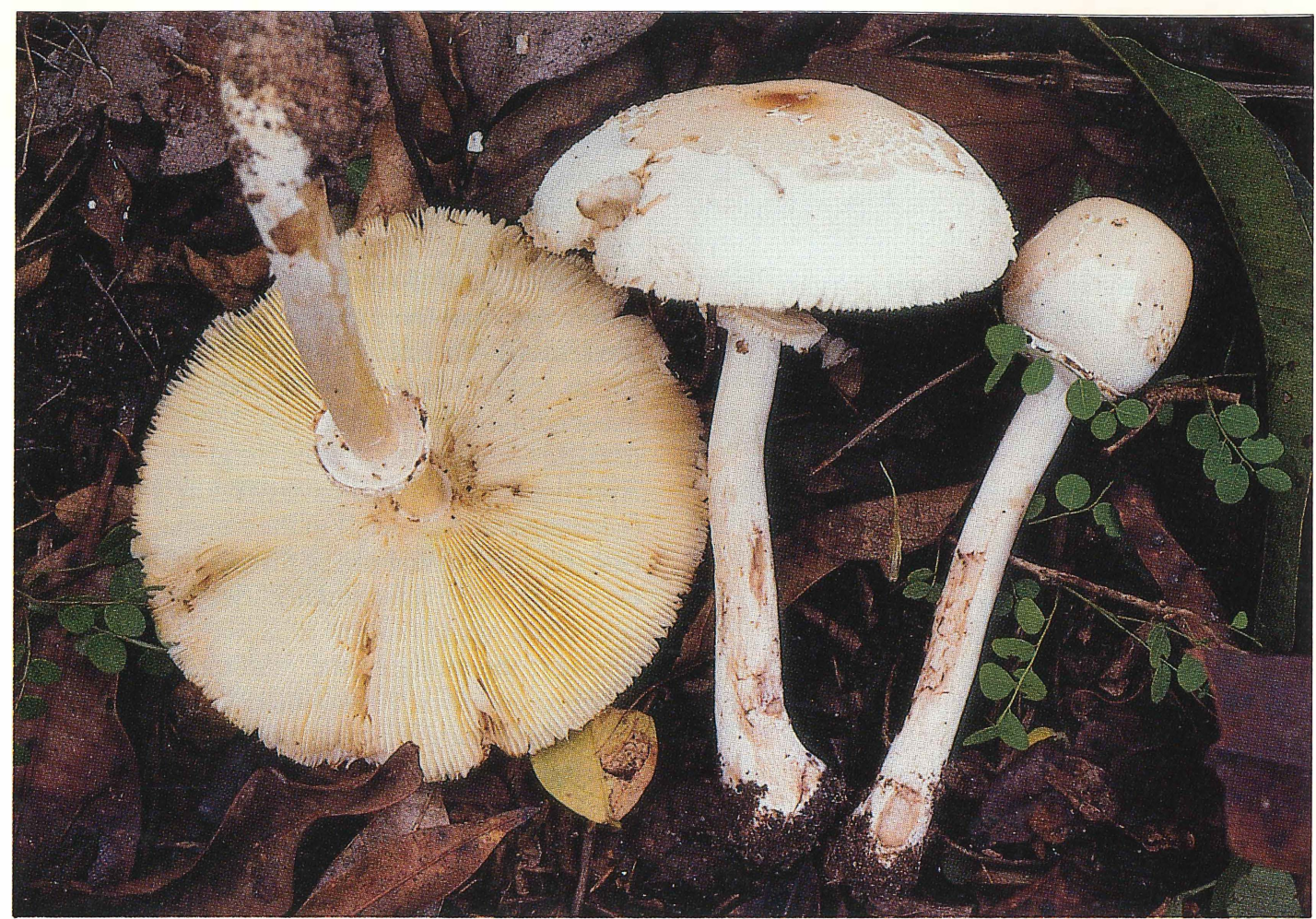

Fig. 84. Chlorophyllum molybdites, VIKAO RANGI-HAFIFU, is a widely distributed species in the tropics and subtropics of the world. It is a pretty mushroom with a movable ring like that in the genus Macrolepiota. The greenish colour of gills distinguishes this poisonous species from Macrolepiota. These fruit bodies grew among grass in Simana village in Lindi district.

bodies is a clear-cut characteristic distinguishing this species from the similar-looking white-gilled genus Macrolepiota which includes several esteemed mushroom species. In its early stage $C$. molybdites has also white gills and since these two genera look macroscopically much alike, special care is needed.

Poisoning: Chlorophyllum molybdites is generally considered poisonous, but some forms are reported edible when thoroughly cooked. Probably people's susceptibility to the toxin differs rather than the toxicity between fruit bodies. The toxins cause gastrointestinal upset of varying severity. In Tanzania people generally considered $C$. molybdites a poisonous mushroom, although we saw some children picking it for food and saw some fruit bodies among edible mushrooms in market places.

First aid: Vomiting is usually enough to remove the poisonous mushrooms from the stomach. After and between vomiting clean water should be drunk to prevent dehydration of the patient.

Spores 9-11 ×6.5-8 $\mu \mathrm{m}$, obovoid to broadly ellipsoid with a truncated germ pore, hyaline or greenish, dextrinoid. Basidia 28-34 × 11-12 $\mu \mathrm{m}$, clavate, thin-walled, with 4 sterigmata. Lamella-edge sterile, crowded with cheilocystidia. Cheilocystidia 24-37 ×9-17 $\mu \mathrm{m}$, pyriform to sphaeropeduculate, hyaline, thin-walled. Pleurocystidia absent. Context composed of hyaline, interwoven hyphae, 4-10 $\mu \mathrm{m}$ in diameter, inflated up to $20 \mu \mathrm{m}$. Surface of umbo a trichodermial palisade of erect, clavate, septate hyphae, 3-11 $\mu \mathrm{m}$ width. 


\section{Glossary}

adnate (gill attachment): broadly joined to the stipe 37 adnexed (gill attachment): narrowly joined to the stipe 37 agaric: a member of the family Agaricaceae which include mushrooms having gills on the underside of the cap; often used as a synonym for a mushroom 41 amyloid (spores): tuming greyish to blackish blue in Melzer's Reagent, which contains iodine ........... 41 apiculus (spore structure): the place of attachment for a basidiospore to the sterigma ....... 41 apothecium, pl. apothecia (Ascomycetes): an open, cup- or saucer-shaped fruit body, the inner surface of which is covered with hymenium ... 23 applanate (cap shape): flattened .................. 37 areolate (cap or stipe surface): being divided by cracks into small, angular patches ................ 36 ascus, pl. asci: a sac-like structure in Ascomycetes in which spores are carried .... 23 aseptate (microscopic structure): having no cross walls ................................................ 23

basidium, pl. basidia (microscopic structure): an inflated cell in basidiomycetes from which basidiospores are produced

bilateral (gill trama): divergent; having downward pointing hyphae turning outward from a central line

bulbous (stipe base): having a swelling at the base 38

campanulate (cap shape): bell-shaped in form, .. 37 cf.: compare

cheilocystidium, pl. cheilocystidia (gill structure): microscopical sterile structure at the edge of a gill..... 41

clamp (connection) (microscopic feature): a small lateral branching curving over the septum between two adjoining cells 47 close (spacing of gills): gills near to one another but with a visible space between them ........ 37 conic (cap shape): cone-shape ..................... 37 convex (cap shape): rounded like an bowl turned upside-down

crenate (gill margin): having the edge scalloped to form rounded teeth 38 crenulate (gill margin): minutely crenate; having minutely rounded teeth 38 crowded (spacing of gills): gills so close together that they touch one another; the space between the gills cannot be seen cuticle (cap or stipe surface): the outer layer of the cap ( = pileipellis) or stipe (= stipitipellis) ...... 41 decurrent (gill attachment): gills continuing down the stipe ............................................ 37 depressed (cap shape): having the middle portion lower than the margin ........................... 37 dextrinoid (chemical reaction): stained brownish to reddish-brown by Melzer's Reagent; (= pseudoamyloid) ............................................ 41 dimitic (hyphal system): fungi in the order Aphyllophorales which have two kinds of hyphae (generative and skeletal) in their trama, .......... 81 disc (cap): the central part of the cap surface, ..... 52 eccentric (stipe attachment): away from the cap centre but not at margin ............................. 38 ecology: the study of the relations between organisms and their environment ................... 28 entire (gill margin): even and unbroken without any interruptions ......................................... 52 family (taxonomic group): comprising groups of related genera. The Latin names of families terminate in -aceae, e.g. Russulaceae

fertile phase: state during which reproductive structures are produced; opposite of vegetative phase ......................................................... 23

fibrillose (surface of cap or stipe): covered with silk-like fibres ................................................ 36 fimbriate (e.g. ring): delicately torn or fringed ... 86 flesh (pileus or stipe): context; trama; the inner sterile tissue, of the cap or stipe ................... 44 floccose (cap or stipe surface): cottony ....... 36 floccus, pl. flocci (cap or stipe surface): cottonlike tufts .................................................... 76 forked (gills): having more or less equal, forklike branches ................................................. 36 free (gill attachment): not attached to the stipe ... 37 fruit body (structure): the overall structure of fungal tissue produced for reproduction; in everyday language $=$ a mushroom …................. 22 fugacious (e.g. veil): falling or fading away early . 36 funnel-shaped (cap shape): with an extremely deep depression ...................................... 36 gelatinized (e.g. cap or stipe surface): having the nature of or resembling jelly in consistency .................. 36 genus pl. genera (taxonomic gategory): a group of related species. Lower rank than family but above the rank of species; the generic name forms the first part of the binomial Latin name, the second being the specific name, e.g. Amanita zambiana 
gill (structure): lamella; a plate-like structure on the underside of the cap on which basidia are born 36 gregarious (growth habit): growing in companies but not touching each other 40 heterotrophic (nutrition): depending on organic matter produced by other organisms ............ 21 hymenium (structure): the spore-bearing layer of the fruit body 41 hymenophoral trama (gill structure): context; in the case of gilled fungi it is called gill trama whereas in boletes it is called tube trama .... 47 hymenophore (gill or tube structure): tissue supporting the hymenium; in mushrooms it is the gills

hypha, pl. hyphae (microscopic structure): hair-like filaments made of rows of fungal cells 23

inamyloid (reaction to a chemical): not turning red or blue in Melzer's Reagent 41

involuted (cap margin): rolled in 37

lactifer (or laticifer) (structure): a hypha that contains latex 72 lamella, pl. lamellae (structure): gill; a plate-like structure on the underside of the cap on which basidia are born 36 lamellula, pl. lamellulae (structure): a short gill between the normal gills that does not extend from cap margin to stipe ............................... 36 lateral (e.g. stipe attacment): at the side .... 38 latex: a milk-like juice that exudes from a broken fruit body, as in genus Lactarius 70 lichen: a thallus consisting of a fungus in symbiotic relationship with an alga, and growing in leaf-like, crust-like, or branching forms on e.g. rocks and trees 23 medulla, pl. medullae (structure): the innermost part of a fruit body, used in the genus Auricularia ..... 86 Melzer's Reagent (chemical reagent): a solution of iodine and iodine of potassium in chloral hydrate, used for testing of amyloidity and dextrinoidity 41 membranous (e.g. ring): resembling membrane; tissue like a thin skin 48 mucronate (cap): pointed, narrowing into a sharp point. 50 mycelium,pl.mycelia(structure): the vegetative stage of the fungi being composed of hyphae 23 mycorrhiza, $\mathrm{pl}$. mycorrhizas or mycorrhizae (structure): fungus root; a symbiotic association of a fungus with the roots of certain plants, in which the hyphae form a mass around the rootlets or penetrate the cells of the root .... 27 order (taxonomical group): comprising groups of related families

paraphysis, pl. paraphyses (microscopic structures): sterile, usually filiform or clavate hyphae growing among spore-bearing structures, especially in Ascomycetes .................................. 24 parasite (nutrition): growing on or in an another living organism from whose body it obtains nourishment .............................................. 26 parboil: to boil for a short time

pendant (ring): a hanging ring ..................... 48 perforatorium (cap structure): umbo; a knob, protrusion, in the center of a cap .................. 46 perithecium, pl. perithecia (Ascomycetes): a subglobose or flask-shaped ascus bearing fruit body ............................................................... 24 pileipellis (cap surface): the outer layer of the cap ........................................................... 41 pileocystidium, pl. pileocystidia (pileus structure): microscopic structure on the surface of the pileus 41

pileus (pl. pilei): cap ................................. 41 plasmodium, pl. plasmodia (slime molds): a growth stage of slime molds which is a multinucleate mass of protoplasm, capable of moving ...................................................... 22 pleurocystidium, pl. pleurocystidia (gill structure): microscopical sterile structure on the side of a gill .......................................................... 41 pore (structure): a small, circular opening... 36 pruinose (cap surface): having a flour-like covering ....................................................... 36 pseudoparenchyma (-tous) (microscopic structure): fungal tissue consisting of more or less inflated interwoven hyphae, having a cellular appearance .............................................. 52 pseudorrhiza (stipe): a root-like underground extension of the stipe ................................... 38 rhizomorph (structure): a tough root-like strand of fungal hyphae at the base of the stipe ..... 62 russuloid (context feature): the brittle, not fibrous context typical of the genus Russula.. 68 saccate (volva): sac- or bag-like .................. 38 saprophyte (nutrition): an organism that lives on dead organic material as do many fungi and bacteria .................................................... 26 scattered (growth habit): fruit bodies that grow moderately far apart; between solitary and gregarious ...................................................... 39

sensu lato $=$ s.lat.: in a broad sense ............ 62 septate (microscopic structure): having cross walls in hyphae ........................................... 23 septum, pl. septa (microscopical structure): a separating wall in a hypha ............................ 23 
serrate (gills): toothed like a saw

sessile (growth habit): without a stipe

sinuate (gill attachment): having a sharp notch at the lower edge where the gills meet the stipe being only narrowly attached 37

slime mold (classification of fungi): an organism usually considered to be a fungus belonging to the class Myxomycetes.... 22 solitary (growth habit): fruit bodies that grow alone or far apart from each other 39 spathulate (cap form): having a broad, rounded end and a narrow base; shaped like a paddle .. 80 species: the basic category of biological classification, composed of individuals that resemble each other and can breed among themselves

sphaerocyst (microscopic structure): inflated globose cells in tissues of fungi, e.g. Russula and Lactarius

squamule (cap or stipe surface): small scale .. 36 sterigma, sterigmata (microsopic structure): a pointed extension from the basidium on which a basidiospore is borne 41

stipitate (stipe): with a stipe 83 stipitipellis (stipe surface): the outer layer of the stipe 41

striate (cap or stipe surface): marked with delicate lines, grooves or ridges 36 stuffed (stipe context): having an interior loosely filled with hyphae 39 sub-: a prefix meaning situated under or imperfect

subhymenium, pl. subhymenia (microscopic structure): a narrow zone of differentiated hyphae immediately beneath the hymenium .... 52 substipitate (stipe): almost or nearly stipitate...... 83 substrate: material on which an orgamism lives .. 30 superior (ring): situated above the middle of the stipe 38 suprahilar spot (spore structure): a small rounded smooth area near the apiculus ........ 68 synonym: one of the two or more names for the same species 80 taxonomy: the science of identifying, naming and classifying organisms

thallus, pl. thalli: a simple plant-like body which lacks roots, stems and leaves

tomentose (cap or stipe surface): densely covered with soft, matted hairs .......................... 48 trama (structure): context; flesh; the inner sterile tissue of the cap or stipe 39 troop (growth habit): a plenty of fruit bodies growing close together but physically apart ...................... 50 tube (structure): a hollow, cylindrical structure on the underside of the cap in which the spores are borne (compare gill) ............................... 36 tuft (growth habit): a bunch or cluster of fruit bodies arising from a common base ............. 40 umbo (cap): a protrusion, a raised knob in the center of a cap ............................................. 46 umbonate (cap): having an umbo ................ 37 vegetative phase: state during which no reproductive structures are produced; growth before reproduction 23 viscid (cap or stipe surface): covered by a sticky substance; adhesive ...................................... 36 zona pilosa, zona compacta, zona subcompacta superior, zona laxa superior, medulla, zona laxa intermedia, zona laxa inferior, zona subcompacta inferior, hymenium: a special terminology based on the characteristic zonation of hyphae in the genus Auricularia; the names of the zones represented here are arranged according their location from the upper surface through the the tissues; all the zones are not present in every species.

\section{Further reading}

The list includes some articles and books dealing with edible mushrooms of Tanzania and the neighbouring countries. For further information see the literature survey by Rammeloo \& Walleyn (1993) and Walleyn \& Rammeloo (1994).
Desai, W.B. \& Peerally, M.A. 1990: Coprinus castaneus Berk. Br.: An indigenous, wild edible mushrooms from Mauritius. - Discovery \& Innovation 2(3):66-69.

Chipompha, N.W.S. 1985: Some mushrooms of Malawi. - Forestry Research Record 
(Malawi) 63:1-54.

Eichelbaum, F. (1906): Beiträge zur Kenntnis der Pilzflora des Ostusambaragebirges. Verh. Naturw. Ver. Hamburg 14:1-92.

Härkönen, M. 1992: Wild mushrooms, a delicacy in Tanzania. - Univ. Helsingiensis 12:29-31.

Härkönen, M., Buyck, B., Saarimäki, T. \& Mwasumbi, L. 1993: Tanzanian mushrooms and their uses 1. Russula. - Karstenia 33:11-50.

Härkönen, M., Saarimäki, T., Mwasumbi, L. 1993: Tanzanian mushrooms and their uses 2. An edible species of Coprinus section Lanatuli. - Karstenia 33:51-59.

Härkönen, M., Saarimäki, T. \& Mwasumbi, L. 1994: Setting up research project on Tanzanian mushrooms and their use. - Proc. 13th AETFAT Congress, Zomba, Malawi, 1991 (in press).

Härkönen, M., Saarimäki, T. \& Mwasumbi, L. 1994: Tanzanian mushrooms and their uses 4. Some reddish edible and poisonous Amanita species. - Karstenia 34:47-60.

Härkönen, M., Saarimäki, T., Mwasumbi, L. \& Niemelä, T. 1993: Collection of the Tanzanian mushrooms heritage as a form of developmental cooperation between the Universities of Helsinki and Dar es Salaam. Aquilo Ser. Bot. 31:99-105.

Heim, R. 1977: Termites et champignons. Les champignons termitophiles d'Afrique noire et d'Asie méridionale. - 190 pp. Boubée, Paris.

Levin, M., Branch, M., Rappoport, S. \& Mitchell, D. 1985: A field guide to the mushrooms of South Africa. - 168 pp. Struik Publ., Cape Town.

Morris, B. 1987: Common mushrooms of Malawi. - 108 pp. Fungiflora, Oslo.

Parent, G. \& Thoen, D. 1977: Food value of edible mushrooms from Upper-Shaba region. - Econ. Bot. 31:436-445.

Pegler, D.N. 1977: A preliminary agaric flora of East Africa. - Kew Bull. Add. Ser. 6:1-615.

Pegler, D.N. \& Piearce, G.D. 1980: The edible mushrooms of Zambia. - Kew Bull. 35:475- 491 .

Piearce, G.D. 1981: An introduction to Zambia's wild mushrooms, and how to use them. - 28 pp. Forest Dept. (Zambia), Ndola.

Piearce, G.N. 1981: Zambian mushrooms, customs and folklore. - British Bull. Mycol. Soc. 19:39-50.

Piearce, G.N. 1987: The genus Termitomyces in Zambia. - Mycologist 1:111-116.

Piearce, G.D. \& Francis 1982: Nutritive potential of the edible mushroom Suillus granulatus (Fries) O. Kuntze, and its utilization prospects in Zambia. - Trop. Sci. 24:157-164.

Piearce, G.N. \& Ross, W.K. 1980: The appeal of the pine bolete Suillus granulatus as a new Zambian mushroom. - Int. Tree Crops J. 1:183-197.

Rammeloo, J. \& Walleyn, R. 1993: The edible fungi of Africa south of the Sahara: a literature survey. - Scripta Bot. Belgica 5:1-62.

Ryvarden, L. \& Johansen, I. 1980: A preliminary polypore flora of East Africa. - $636 \mathrm{pp}$. Fungiflora, Oslo.

Saarimäki, T., Härkönen, M. \& Mwasumbi, L. 1994: Tanzanian mushrooms and their uses 3. Termitomyces singidensis, sp. nov. Karstenia 34:13-20.

Storrs, A.E.G. \& Piearce, G.D. 1982: Don't eat these. Some local African poisonous plants (including mushrooms). - $53 \mathrm{pp}$. Forest Dept. (Zambia), Ndola.

Walleyn, R. \& Rammeloo, J. 1994: The poisonous and useful fungi of Africa south of Sahara: a literature survey. - Scripta Bot. Belgica 10:1-56.

Van der Westhuizen, G.C.A. \& Eicker, A. 1994: Mushrooms of Southern Africa. - 206 pp. Struik Pub., Cape Town.

Williamson, J. 1975: Fungi. - In: The useful plants of Malawi (rev. ed.): 312-336. Univ. Malawi, Zomba.

Zoberi, M.H. 1972: Tropical macrofungi, some common species. - $158 \mathrm{pp}$. MacMillan, London. 
The listed figures or photos were drawn or taken by following persons

Kalevi Härkönen: 2, 3.

Marja Härkönen: 6, 9, 11, 12, 14, 15, 32-39, 43, 47, $50,52,55,58,61,62,64-66,70-75,78$.
Päivi Karhula: 1, 5, 27-31, 40.

Tuomo Niemelä: 57, 59, 81, 82.

Tiina Saanimäki: 4, 7, 8, 10, 13, 16, 32-39, 42, 44$46,48,49,51,53,54,56,59,60,63,67-69$, $77,79,80,83,84$.

Veikko Saarivaara: 17-26.

Vanamo Salo: 41 